Portland State University

PDXScholar

1989

\title{
A Performance Appraisal Model for Postsecondary Education
}

Peggy Connolly

Portland State University

Follow this and additional works at: https://pdxscholar.library.pdx.edu/open_access_etds

Part of the Educational Assessment, Evaluation, and Research Commons, and the Higher Education Administration Commons

Let us know how access to this document benefits you.

\section{Recommended Citation}

Connolly, Peggy, "A Performance Appraisal Model for Postsecondary Education" (1989). Dissertations and Theses. Paper 1246.

https://doi.org/10.15760/etd.1245

This Dissertation is brought to you for free and open access. It has been accepted for inclusion in Dissertations and Theses by an authorized administrator of PDXScholar. Please contact us if we can make this document more accessible: pdxscholar@pdx.edu. 


\title{
A PERFORMANCE APPRAISAL MODEL FOR POSTSECONDARY EDUCATION
}

\author{
by \\ PEGGY CONNOLLY
}

A dissertation submitted in partial fulfillment of the requirements for the degree of

\author{
DOCTOR OF EDUCATION \\ in \\ COMMUNITY COLLEGE EDUCATION
}

Portland State University

Oregon State University

University of Oregon

1989 
TO THE OFFICE OF GRADUATE STUDIES:

The members of the committee approve the dissertation of Peggy Connolly, presented February 23, 1989.
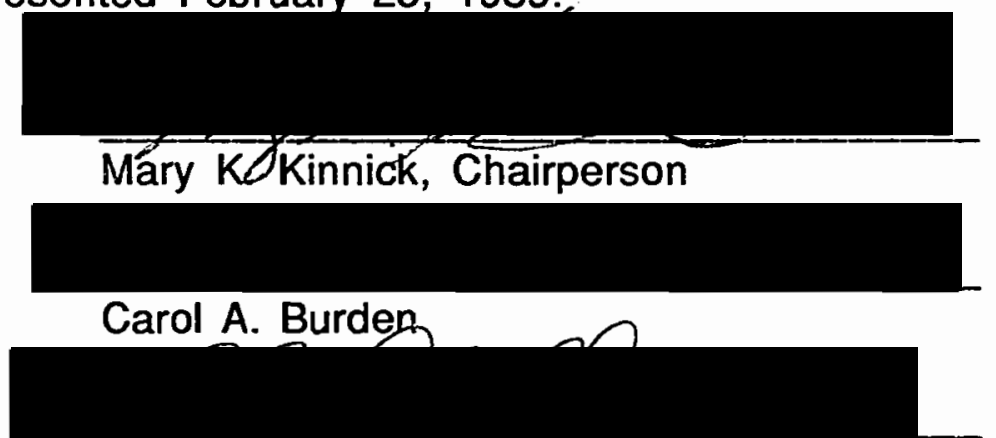

Alan M Cabelly

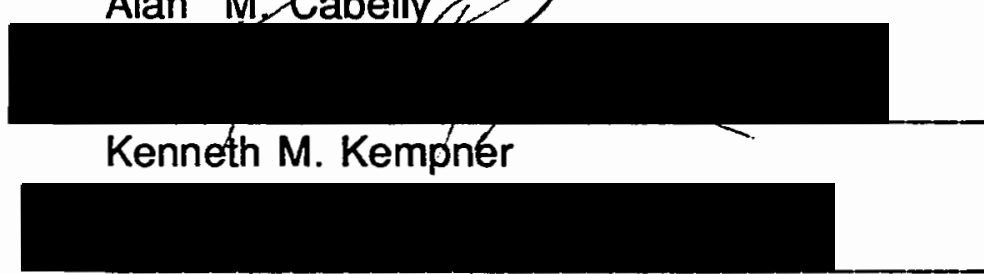

Grant M. Farr

APPROVED:

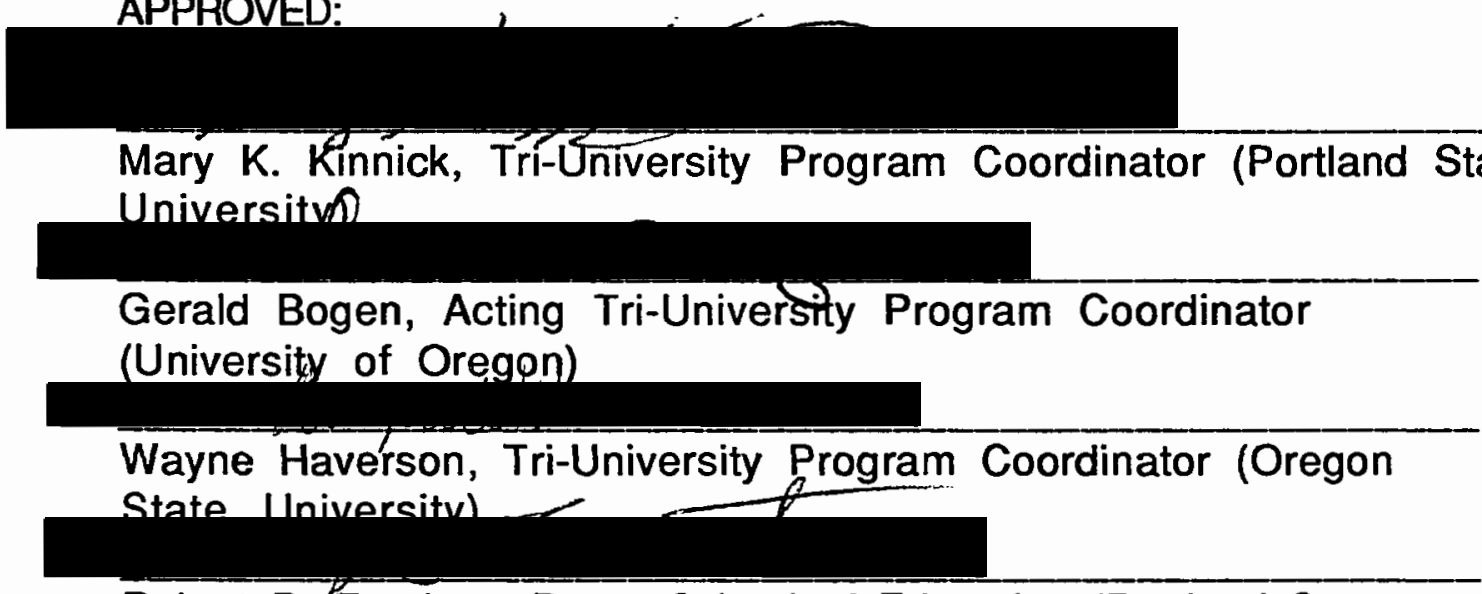

Robert B. Everhart, Dean, School of Education (Portland State University)

Bernard Ross, Vice Provost for Graduate Studies (Portland State University) 
AN ABSTRACT OF THE DISSERTATION OF Peggy Connolly for the

Doctor of Education in Community College Administration presented February 23, 1989.

Title: A Performance Appraisal Model for Postsecondary Education.

APPROVED BY MEMBERS OF THE DISSERTATION COMMITTEE:

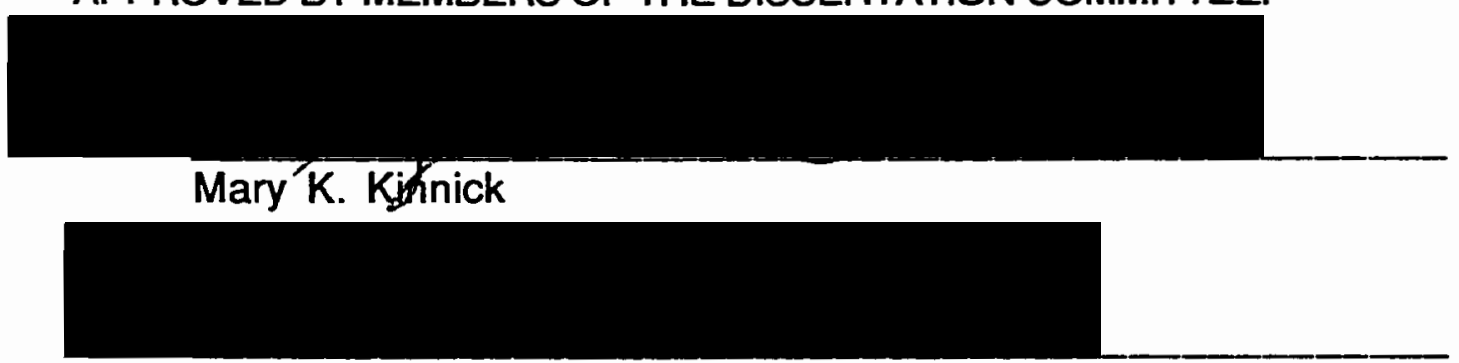

Carol A. Burden

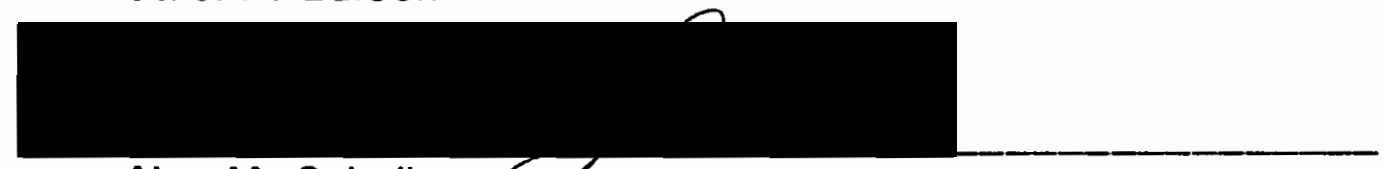

Alan M. Cabelly

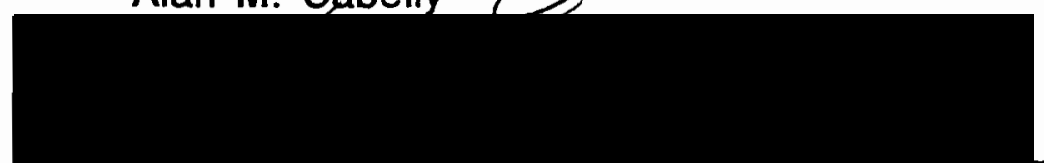

Kenneth M. Kempner/

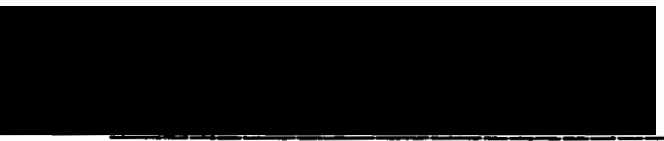

Grant M. Farr

\section{Purpose}

Although performance appraisal is one of the most imporiant factors in the successful operation of an organization, it is often one of the most difficult and threatening tasks. Traditional 
approaches to employee evaluation have often proved to be neither effective nor in compliance with legal standards. This problem affects postsecondary institutions, where the customary subjective appraisal contributes to undesirable employment discrimination.

The purpose of this study is to provide postsecondary administrators with an effective and legally defensible model of performance appraisal. The research was concerned with the following questions:

1. What does statutory law mandate in performance appraisal?

2. What issues, patterns, and decisions concerning performance appraisal have been identified through the judicial process, and what degree of consistency has been shown in court decisions?

3. What standards are suggested by performance appraisal law and practices?

4. What should an appraisal program for postsecondary education that synthesizes performance appraisal practices and emerging legal standards look like?

Official federal statutes and court records governing employment practices were examined; data were collected from these sources. The data were analyzed according to principles of grourited theory development proposed by Glaser and Strauss, and complemented by legal research methodologies recommended by Alton. Appraisal law was summarized, followed by a review of current practices identified in appraisal literature. A model of performance appraisal for postsecondary education synthesizing legal standards and current practices was presented. 
Although statutes governing appraisal apply to all employers, the courts demand less stringent compliance by institutions of postsecondary education. The judiciary acknowledges extensive prejudice in employment decisions in academia, but in the interest of preserving academic freedom, implores postsecondary institutions to regulate their own behavior.

In non-academic employment, periodic appraisals should be based on written, objective standards known to employees, that are valid, reliable, and fair; and administered and scored under standardized conditions by trained evaluators. Records must be confidential.

The courts do not require strict compliance by postsecondary institutions; they urge, but do not mandate, that academic employees be treated without bias.

Guidelines are needed to define a non-discriminatory evaluation process for postsecondary employees. The model presented in this research is a first step toward this goal. 


\section{TABLE OF CONTENTS}

PAGE

CHAPTER

\section{INTRODUCTION}

Statement of the Problem Significance of the Study

Scope and Delimitation

Approach to Research 35

Research Design 42

Procedures $\quad 54$

Limitations $\quad 58$ 
III THEORETICAL SAMPLING AND DATA ANALYSIS 61

Introduction 61

Appraisal Regulations 63

Summary of Regulations 92

Judicial Standards for Non-Academic Appraisal 95

Summary of Non-Academic Decisions 126

Judicial Standards for Postsecondary Education 139

Summary of Postsecondary Appraisal Law 153

Conclusions $\quad 156$

IV PERFORMANCE APPRAISAL PRACTICES 164

Introduction $\quad 164$

Effective Performance Appraisal Programs $\quad 166$

V RESLLTS

191

Elements of a Grounded Legal Theory of

Performance Appraisal

Elements of Effective Performance Appraisal

Practice for Postsecondary Education 200

Summary and Conclusions 205

$\begin{array}{ll}\text { REFERENCES CITED } & 211\end{array}$

LEGAL REFERENCES CITED $\quad 219$

APPENDIX THE UNITED STATES LEGAL SYSTEM 222

Introduction 222

The Branches of Government 224 


\section{LIST OF FIGURES}

FIGURE

1. Graphic Illustration of Case Synthesis

2. Pre-Interview Questions
PAGE

18

177 


\section{PREFACE}

My first experience evaluating employee performance occurred when I supervised an education project. Poor performance of one staff member impeded the effectiveness of the program.

Janet was a delightful person, but a poor secretary. She was warm, cheerful, outgoing, helpful, and had a great sense of humor. However, she could not spell, write a grammatically correct sentence, take dictation, or accurately record minutes of a meeting. The project required a great deal of correspondence. Many of the reports were preserved at the Oregon Department of Education; others were sent to the Department of Education in Washington, D. C. To make sure the reports were done properly, I spent a great deal of time going over Janet's work. Janet's performance had to improve for the project to run efficiently.

After asking others whose advice I respected, I carefully planned how to help Janet improve her performance. 1 asked her to set aside some time to come to my office so we could discuss her job responsibilities. The tone was set by my request: my uneasiness over the performance appraisal was evident. Janet avoided me the rest of the day, and was subdued when this was impossible. At the end of the day, she appeared meekly at the cioor.

Trying to make both of us more comfortable, I fell all over myself telling Janet how great she was, how much she contributed 
to the program, how we all enjoyed working with her. Eventually I got to the inevitable "but there is one thing. . ." and Janet's inevitable, "Oh, I know."

The next line came easily as rehearsal paid off: "How can I help you develop these skills?"

And the clincher: "Well, l've never been able to spell or write too good, but I don't worry about it because (pause) you can."

At this point (being a concerned and involved supervisor), I presented Janet with a dictionary, a thesaurus, and Strunk and White's Elements of Style. I also gave her a copy of the class schedule for the new term in which l'd starred business education classes that might enhance her skills. As an employee of the college, Janet could take any course free. This pleased her, and the session ended on a positive note.

A few days later, Janet excitedly told me how much she just loved both her oil painting and jazzercise classes!

I retreated to proofread her latest report. What happened? Here were all the ingredients of what seemed to be a positive approach to performance appraisal: preparation, concern for the employee's feelings, attention to both strengths and weaknesses, willingness to become involved in the employee's development, and specific suggestions for professional growth. Yet the process had not been effective. There had to be a better way. What was it? 


\section{CHAPTER I}

\section{INTRODUCTION}

\section{STATEMENT OF THE PROBLEM}

Performance appraisal is one of the most important factors in the operation of an organization (Beer, 1981; Latham \& Wexley, 1981). Yet the evaluation of employees is often seen by subordinates as the most threatening aspect of their job (Kaye \& Krantz, 1982), and by supervisors as the most difficult (Lazer, 1980).

Traditionally, performarice appraisals have been fraught with tension, misunderstanding, and bitterness. They typically lack preparation, documentation, employee participation, opportunity for professional development, and follow-up (Survey Provides Piece of Productivity Puzzle, 1980).

Traditional systems tend to judge the individual's personality rather than job performance, focusing on traits rather than work behaviors. Rendero (1980) points out that the greater the emphasis on personality, the stronger negative feelings are apt to be. This is particularly true when the employee perceives the appraisal to be critical or unfair. 
The evaluation is often stressful for the worker. The employee listens while the supervisor assesses strengths and weaknesses, evaluates output and attitude, and delivers impressions of the employee's contributions. The worker may demonstrate a number of negative reactions. These might include inappropriately agreeing with everything the evaluator says, remaining silent although data may be unclear or incorrect, displaying defensive behaviors, trying to mislead the supervisor about performance or conditions, and tuning out negative feedback (Kaye \& Krantz, 1982).

The supervisor may base evaluation on initiative, attitude, dedication, stability, or some other personality characteristic. These traits are hard to measure objectively. Appraisals based on personality lack reliability. They tend to vary widely, depending upon who conducts the evaluation, and the evaluator's emotional and physical state at the time of the appraisal. Fatigue, job satisfaction, stress, health, and other factors may contribute to the way a supervisor perceives an employee on any given day. The appraisal is then more a measure of the manager's condition than the employee's performance (Olson, 1981).

Supervisors may contribute to the unreliability of evaluation in other ways. Some raters are too lenient. They are reluctant to hinder their employees' career opportunities. They may feel they have not adequately observed the employee, and the benefit of the doubt favors the worker. Other managers may hesitate to give a negative rating to an employee with whom they will have to continue working. The supervisor may misrepresent the results of an 
unfavorable evaluation in order to avoid an unpleasant confrontation (Meidan, 1981).

The "halo effect" can erroneously influence ratings. If the supervisor perceives the employee in a positive manner, all aspects of performance and personality are then viewed positively. But if overall reaction to the employee is negative, so is the perception of that individual's work (Universal, 1976).

The assessment may focus on only one aspect of the employee's responsibilities and disregard other assignments and contributions (Lazer, 1980).

Traditional methods of evaluation may cause legal problems. Organizations with subjective performance appraisal programs have fared poorly in court. Subjective evaluations, lack of employee participation, unvalidated rating methods, and lack of rater training have contributed to findings of employment discrimination (Olson, 1981). As a result, in a majority of instances, the employer loses when appraisal programs are challenged and found to be discriminatory.

The term discrimination is used in a specific manner in this document. Certainly the ability to discriminate, to discern differences, is necessary and desirable. However, for purposes of this study, the term discrimination is used in a limited sense as defined by Black's Law Dictionary (fifth ed. 1979).

Discrimination. . . Unfair treatment or denial of normal privileges to persons because of their race, age, nationality, or religion. A failure to treat all persons equally where no reasoriable distinction can be found between those favored and 
those not favored. Federal law prohibits discrimination in employment on the basis of sex, age, race, nationality, or religion. ...(p. 420).

The traditional attitude of the United States courts toward postsecondary education has been that schools are qualified to regulate their own behavior. Institutions of postsecondary education have established processes and procedures that until recently have been accepted as legitimate and reasonable. Over the past two and a half decades, however, the autonomy of colleges and universities has been challenged. The courts are being used with increasing frequency to define relationships and solve problems in education (Likins, 1979).

Among the growing number of education related court cases, the greatest percentage increase has been demonstrated in cases involving employees. Quite a number of these cases deal with personnel questions, where discrimination is a pervasive problem (Journal of Law and Education, 1983).

Avoiding legal entanglement is not the only reason for educational administrators to implement performance appraisal programs. The lack of employee evaluation and the related failure to provide developmental opportunities for staff members are seen by Hammons (1987) as two of the five most critical problems currently facing college administrators. Hammons registers strong criticism, charging that "performance appraisal in ... colleges is a disaster area" (p. 6). Without effective performance evaluaticn, employees are likely to just do their jobs, making little contribution to the development of the organization. Consequently, although the 
organization may continue to function, it will never achieve excellence. This is particularly untenable decause of the role educational institutions play as a consultant to business and government. How can colleges offer guidance to other organizations while neglecting their own employees and institutions?

This study uses the language of the Civil Rights Restoration Act of 1987 to define postsecondary institutions. The Act clarifies earlier anti-discrimination legislation aimed at eliminating bias in education, specifically at "a college, university, or other postsecondary institution" (Congressional and Administrative News, 1988, p. 18). Congress indicates that a "postsecondary institution is a generic term for any institution which offers education beyond the twelfth grade. Examples of postsecondary institutions would include vocational, business, and secretarial schools" (ibid. p. 18).

The purpose of this study is to provide post secondary educational administrators with the information necessary to develop and implement performance appraisal programs. Three major aspects of employee evaluation are presented: (1) an overview of emerging legal requirements, (2) an examination of performance appraisal practices, and (3) a guideline for establishing an appraisal program based on a synthesis of information from emerging legal standards and performance appraisal practices. 


\section{SIGNIFICANCE OF THE STUDY}

\section{Timeliness}

Excellence in education can be achieved only when expectations are clarified and employees are evaluated on their performance. But performance appraisal in postsecondary education is inadequate. If evaluation exists at all in such an organization, it is likely to be poorly conducted and received (Hammons, 1987). With increased demands for accountability and nondiscriminatory empioyment practices, educational administrators need to be aware of acceptable appraisal practices.

Bernardin and Beatty (1984) summarize four reasons that the examination of performance appraisal is particularly timely. The first is a realization that some legal requirements aimed at eliminating discrimination, such as Equal Employment Opportunity, have actually contributed to improved employee performance. For example, Bergman (1982) points out that requiring jobs to be filled by the most qualified person has helped to reduce nepotism and favoritism.

Second, Bernardin and Beatty (1984) indicate that the values of American workers are changing. Employees are no longer satisfied with merely having a job. Workers are demanding greater flexibility in working conditions and promoting changes that enhance personal satisfaction. There is an awareness of empioyment rights and an increased willingness to litigate grievances. Finkin (1980) notes 
that this increased disposition to turn to the courts to settle disputes in employment extents to higher education as well.

Third is the realization that the cost of poor utilization of human resources is staggering, both in dollars and wasted talent.

Finally, concern has been expressed over lagging productivity. Since 1980, American productivity has grown less than $1 \%$ annually (Statistical Abstract, 1987).

\section{Practicality}

The study of performance appraisal is a practical one. It deals with a matter of current concern to administrators. Edwards and Nordin (1980) note that educational administrators have a greater need than ever to understand how the law affects higher education. The daily tasks of administration require specific, practical solutions to legal and personnel problems.

Alfred and Ivan (1978) agree that administrators need to identify solutions to problems posed by societal expectations and legal requirements. As expectations and requirements change, policies must be modified to accommodate new demands. Research assists administrators in the development and modifications of policies, and provides the basis for institutional planning.

The purpose of research in an environment of change is the translation of data into programs that provide solutions to current organizational problems. Useful information must demonstrate:

1. Appropriateness for defining organizational policy.

2. Relevance for organizational planning and development. 
3. Applicability for evaluating the degree to which institutional activities reflect stated practices.

The following research on performance appraisal demonstrates these qualities. The information produced provides guidelines for policy development and a means for translating data into programs. The data analyzed are generated from the problem itself, guaranteeing a high degree of relevance to the actual situation. The knowledge has wide application, being valuable to ousiness, education, and industry. The findings can be applied to organizations of any size. Solutions are proposed in specific, operational terms that facilitate evaluation.

The data lend themselves to analysis by recognized qualitative techniques, such as the strategies suggested by Glaser and Strauss (1967) for generating grounded theories.

Need

Although information is available on employee evaluation, and access to law is obtainable, performance appraisal continues to be a problem for organizations. Supervisors are not provided with the information necessary to evaluate subordinates in a manner that improves performance and complies with legal guidelines (Meidan, 1981).

This dilemma is not surprising, given the nature of law. Regulatory and judicial law are constantly changing. There are inconsistencies in interpretation and application, differences in emphasis between agency and case law. The preponderance of 
legislation and lawsuits can be discouraging to anyone trying to keep up with changing legal expectations in employment practices (Arvey, 1979).

Ignorance is not an acceptable excuse for noncompliance with the law. Administrators must be aware of, and abide, by legal requirements:

Courts have sufficiently delineated what constitutes acceptable and nonacceptable employment practices . . . so that neither employer nor union can claim that they are unaware of what standards are expected of them (United States v. N. L. Industries 479 F.2d 354, 1973).

It is possible, however, not only to understand, but to predict developments in law. The pattern and intent of the law are more important than the individual decisions; when these are understood, prediction is possible (Ledvinka, 1982). Once the purpose of regulation becomes evident, programs that comply with the law can be developed.

\section{Prediction and Beaction}

Theory is a tool that explains and predicts behavior. A good, practical theory of a dynamic social process enables the user to understand and respond appropriately to that particular situation (Glaser \& Strauss, 1967). In other words, a theory enables us to say, "This is what has happened. This is what is likely to happen in the future. If I do this, I may have greater understanding and control of the situation. If I fail to do this, I may be in trouble." 
The development of a grounded theory as proposed by Glaser and Strauss (1967) provides administrators of postsecondary education with a practical approach for understanding and predicting emerging legal expectations involving employee evaluation. The information contained in this study explains the behavior of lawmakers and judges, specifying what has been mandated by regulation and the courts. The evolution of appraisal law is clarified by defining and demonstrating principles that shaped the law's development.

The abundance of statutory and judicial law regarding appraisal does not cover every situation, however. It may be expected that issues will continue to arise that will require further legal intervention. By understanding of the intent, evolution, and principles of appraisal law, practitioners may be able to predict its future development and respond accordingly.

Clearly laws have a great impact on individuals and organizations. But individuals can also have a great impact on laws and their development. Laws may be introduced and refined through the efforts of those who recognize a need for positive societal change, and who have the expertise to suggest appropriate guidelines. Those who understand how law develops are in a position to influence the shape of society. Eaton (1989) specifically encourages involvement of educators in the legislative process when postsecondary institutions and the courts demonstrate unwillingness to provide remedy for employment discrimination. 
Finkin (1980) suggests that college employees must take the responsibility for assuring that fair employment practices are implemented in postsecondary institutions. $\mathrm{He}$ is critical of the judicial restraint which has failed to provide remedy for discrimination in academe:

The development of a sound body of contract law depends on the consistent judicial assimilation of the usage of the national academic profession. As matters currently stand, however, the courts cannot be relied upon to produce such a body of law, either because of the burden placed on counsel in each discrete case to educate both themselves and the court to the 'norms and expectations' of the academic community or because of the ineluctable tendency of some courts to decide based solely on the basis of what they think best for institutions, despite the text and demonstrable intent of the regulatory language before them and the educative efforts of the ablest of counsel (pp. 1188-1189). .. . The courts cannot be relied on to produce a sound, consistent body of law. The disjointure. . . and the uncertainty surrounding the degree to which the courts will defer to the 'norms and expectations' of the national academic community. . . will add fuel to the fire of yet more litigation ( $\mathrm{pp}$. $1199-1200)$.

Finkin (1980) suggests that to preserve academic freedom and shape an environment that encourages excellence and is free from discrimination, members of the academic community must become involved in defining policies and procedures to govern their actions.

The goal of this study is to provide more than an explanation and prediction of appraisal law. This research offers a framework for the development of institutional policies that will increase the effectiveness of employees, thereby promoting excellence in individuals, outcomes, and organizations. 
What is needed is a synthesis of emerging legal expectations and performance appraisal standards to produce guidelines for the development of acceptable appraisal programs.

\section{THE RESEARCH QUESTIONS}

The ultimate goal of this study is to present a practical model for performance appraisal in postsecondary education that is legally defensible. As such, the study is concerned with the following research questions:

1. What does statutory law mandate in performance appraisal?

2. What issues, patterns, and decisions concerning performance appraisal have been identified through the judicial process, and what degree of consistency has been shown in court decisions?

3. What standards are suggested by performance appraisal law and practices?

4. What should an appraisal program for post secondary education that synthesizes performance appraisal practices and emerging legal standards look like?

\section{SCOPE AND DELIMITATIONS}

\section{Performance Appraisal}

Appraisal Literature. Under Title VII of the Civil Rights Act of 1964, the Equal Employment Opportunity Commission was established to deal with employment discrimination. The stringent guidelines established by the commission proved to be too 
cumbersome and bewildering to alleviate adverse impact in employment practices. Adverse impact, "a substantially different rate of selection in hiring, promotion, or other employment decisions which works to the disadvantage of members of a race, sex, or ethnic group" (Uniform Guidelines on Employee Selection Procedures, Sec. 16 B, 1978), continued amid the confusion.

In 1978, the Equal Employment Opportunity Commission, Civil Service, Department of Labor, and the Department of Justice jointly issued Uniform Guidelines on Employee Selection Frocedures. The inflexible Equal Employment Opportunity Commission regulations were replaced with more pragmatic, representative guidelines. The courts have repeatedly stressed the importance of these guidelines in performance appraisal; they have become, in effect, the test of a defensible program (Arvey, 1979).

Some standard employment practices of the seventies are now unacceptable (Ledvinka, 1982). Extensive judicial activity regarding performance appraisal in the seventies defined acceptable practices. The review of performance appraisal literature, therefore, will be limited primarily to works published after 1978 to reflect current legal philosophy. A few earlier resources have been included, such as the Universal Training Systems Company's 1976 manual on performance appraisal. However, the inclusion of earlier works are limited to those that contribute to the development of trends or theories in employment evaluation.

Related Selection Issues. According to the Uniform Guidelines (1978), a number of employment decisions, of which performance 
appraisal is but one, are considered to be selection procedures. This research is concerned primarily with the study of performance appraisal, and so does not address related selection issues such as merit pay and affirmative action.

Certainly employment decisions, such as affirmative action, are related to performance and therefore based on its appraisal. They are not, or should not, become aspects of the content of appraisal. They may more appropriately be considered as a separate, subsequent process following evaluation.

There are times when it is desirable to view performance from the perspective of comparison. From among these candidates, who is most likely to perform best in this capacity in the future? Who among these highly qualified professors most deserves the honor of tenure? However, these decisions must be made following the evaluation of each person's performance on individual merit. Only then, after the completion of a performance appraisal of each individual, should more exacting selections be considered.

The Supreme Court stated this position in Griggs v. Duke Power Company (401 U. S. 424,1971$)$ :

Congress has not commanded that the less qualified be preferred over the better qualified simply because of minority origins. Far from disparaging job qualifications as such, Congress has made such qualifications the controlling factor, so that race, religion, nationality, and sex become irrelevant. What Congress has commanded is that any tests used must measure the person for the job and not the person in the abstract (p. 436). 
A second reason that this study does not address affirmative action and other related issues is that this research is concerned with presenting the requirements of law regarding employment decisions. Justice Stevens, addressing affirmative action in a concurring opinion for Johnson v. Transportation Agency (94 L Ed 2d $615,1987)$ states:

It remains clear that the Act (Title VII) does not require any employer to grant preferential treatment on the basis of race or gender, but since 1978 the Court has unambiguously interpreted the statute to permit the voluntary adoption of special programs to benefit members of the minority groups for whose protection the statute was enacted (p. 638).

This study is concerned with defining requirements of performance appraisal law that are limited to the process of individual evaluations through an analysis of regulation and court proceedings.

\section{Legal Analysis}

United States law emanates from many sources. The nature of law may be constitutional, legislative, administrative, or judicial. Law may originate in any jurisdiction: federal, state, municipal. Law changes over time and from one jurisdiction to another.

Consequently, the same regulation may be interpreted differently at different times and in different locales. The result is a legal system that is full of complexities and contradictions (Llewellyn, 1930). To make this study as widely applicable as possible, and to minimize conflicting jurisdictional mandates, only federal law concerning employment practices is included. 
The First, Fifth, and Fourteenth Amendments of the United States Constitution are frequently cited in charges of discrimination (Arvey, 1979). These amendments are reviewed in this study.

The Civil Rights Act of 1964 marked increased vigilance over personnel procedures. It is the major resource in employment discrimination cases. The Equal Employment Opportunity Act of 1972 expanded the scope of the Civil Rights Act of 1964. The 1972 Amendments specifically require compliance in employment practices by educational institutions (Bernardin \& Beatty, 1984).

This study includes these and other subsequent laws. Court cases dealing with performance appraisal are examined here. The United States Supreme Court is the court of final decision when lower courts conflict. Because the decision of the lower court is not binding, except in the jurisdiction of that court (Llewellyn, 1930), court cases included are limited to those argued before the Supreme Court, cases heard in other jurisdictions but which established rationales upon which the Supreme Court based decisions, and cases which were reviewed by the high court and denied certiorari. Certiorari is a writ in which a high court requests from a lower court the records of a particular case, indicating the appellate court's intention to hear the case (Alton, 1982-83). Cases are limited to those heard after the passage of the Civil Rights Act of 1964, and have been shepardized through 1988 .

Legal Reasoning. Law is made by legislatures, the courts, and government agencies. The courts interpret statutes in the event 
of dispute, or to settle conflicts in the absence of statutes. The analysis of any legal question must include four sources of law: constitutional, statutory, regulatory, and case law (Alton, 1982).

Legal research is an intricate process. The United States judicial system relies heavily on precedent to settle current disputes. Over 30,000 cases are decided each year (Cohen, 1978). No two situations are exactly the same. Comparing and contrasting cases requires diligent research (Alton, 1982).

Alton (1982) suggests two reasons why legal research relies almost exclusively on induction. In fact, deductive reasoning is an inappropriate way to approach legal analysis. This may seem strange because at first glance it appears that interpretation of the law is deductive. The traditional syllogistic argument follows the pattern:

All $A$ is $B$ (major premise).

All $C$ is $A$ (minor premise).

Therefore, all $\mathrm{C}$ is $\mathrm{B}$ (conclusion).

But as Alton (1982-83) points out:

Liberal democrats are disappearing.

Edward Kennedy is a liberal democrat.

Therefore, Edward Kennedy is disappearing (p. 38).

If there were only one rule or precedent governing each incident, deduction would be the logical way to approach legal analysis. However, hundreds of rules or precedents may apply to each incident. To identify what principles apply in a given situation, it is necessary first to examine the facts, and then by induction determine the governing principles. 
A second reason to approach legal analysis by induction is that judges and juries decide cases in this manner. In theory, a judge identifies the rules that pertain to a case. The facts of the case are analyzed within the framework of the rules. A decision is reached based on the degree to which the facts conform to the rules. But judges admit that in practice a decision is often reached, and then an opinion is written that supports the decision. The ruling is based on what the judge senses is appropriate or socially desirable. The same process is often followed by juries. Decisions are based on persona! reactions rather than on the facts and the judge's instructions. Inductively, justification is found for the decisions reached in much case law (Frank, 1932).

Case Law Analysis. The analysis of cases begins with case synthesis. In case synthesis, the researcher identifies the facts and rationale upon which the decision was based. Graphing is a useful way to synthesize the information (Alton, 1982, p. 55).

$\begin{array}{cccccc}\text { Case } & \text { Fact 1 } & \text { Fact 2 } & \text { Fact 3 } & \text { Fact 4 } & \text { Decision } \\ \text { A v. B } & \mathrm{x} & \mathrm{x} & & \mathrm{x} & \text { Plaintiff } \\ \text { C v. D. } & & \mathrm{x} & & \mathrm{x} & \text { Plaintiff } \\ \text { E v. F } & & \mathrm{x} & \mathrm{x} & & \text { Defendant } \\ \text { G v. H } & & \mathrm{x} & & \mathrm{x} & \text { Plaintiff }\end{array}$

Figure 1. Graphic illustration of case synthesis. 
In the analysis of facts it is important to note any gap in information. The degree of similarity or difference in facts should also be recorded.

After the information is synthesized, facts and opinions are studied to identify patterns and form theories.

Another step must be taken before predictions can be made. To ensure that analysis is current, each case must be "shepardized". Shepard's Citations outline the historical development of each case from the time it was first heard, and are updated monthly. This reference guide indicates every subsequent case that has referred to the original case. A citator notes the current status of each case (affirmed, reversed, limited, etc.). Research aids, sich as articles about the case are also recorded (Cohen, 1978).

Although there are other sources that document case development, "the most prolific publisher of citators is Shepard's/McGraw Hill (hence the term shepardizing), but other law books, especially looseleaf services, also include citators" (Fox, 1987).

There may be some question of why so many court decision involving employee evaluation were considered in the seventies, and apparently so few in the decade that followed. Although antidiscrimination legislation was carefully written, as with all laws its implementation raised some questions that were not addressed in the legislation (Edwards \& Nordin, 1980). These issues were referred to the courts for judgement. It seems that the evolution of anti-discrimination law and its legal principles developed from the 
clarification and definition of basic, general issues to the adjudication of less urgent contentions.

Brown v. Board of Education (347 U. S. 483, 1954) pronounced that the concept of "separate but equal" was inherently unfair. This case presented a landmark decision which defined a concept of disparate treatment. Sixteen years later, in Griggs v. Duke Power Company (401 U. S. 424, 1970), the Supreme Court emphasized that that practices which appear to be neutral, but which adversely affect members of a protected class demonstrate disparate imnact. Three years later in McDonnell Douglas v. Green (411 U. S. 792, 1973), the Supreme Court identified a procedure to determine whether proof offered to refute charges of discrimination was a pretext.

Rowe v. General Motors (457 F. 2d 348, 1972) defined issues of objectivity to be used in employee evaluation so that bias might be eliminated. But in 1976, in Rogers v. International Paper Company (613 SW 2d 844, 1976), the Court ruled that objectivity was not always appropriate or feasible. It was acknowledged that some subjectivity was unavoidable in appraisal decisions.

As more issues were decided and the law of appraisal evolved, the courts perhaps became less concerned with refining that area of law, and turned their attention to other topics in which basic issues were still to be determined. This may be why the Supreme Court has rendered fewer decisions directly applicable to appraisal law in the last decade than in the ten years preceding it. 
There are two major weaknesses in legal research. Because the process is inductive, causation can never be proved, only suggested (Alton, 1982). The second weakness stems from the methodology. Issues are categorized, and patterns determined by the categories. If other categories were selected, different patterns might emerge. Grounded theory complements traditional legal research methods. Theoretical sampling and case synthesis embody the same principles. Hypotheses formation is closely related to the analysis of legal facts. Theory generation is the product of the research process in both instances. This approach is particularly appropriate for the following study as the research is concerned with practical problems and processes in an environment of social change.

The Supreme Court has taken a variable stance on the issue of objectivity vs. subjectivity in performance reviews. In a majority of cases, the court has mandated that employee evaluation be based on objective measures. An objective evaluation, that is one that is "based on 'hard data,' such as production records, attendance, etc., has the advantage of being relatively immune from intentional bias" (Kleiman \& Durham, 1981, p.114).

The lower courts, also, have accepted consideration of some subjective criteria in appraising performance. Wells (1982) notes:

Subjective criteria such as . . . initiative, enthusiasm, loyalty, cooperation, ... a are important. However, they are also exceedingly difficult to define and measure, and it is difficult to demonstrate a direct relationship between levels of such characteristics and levels of performance ( $p$. 777). 
Most employment discrimination cases heard by the Supreme Court since 1964 have dealt with blue collar workers. In these cases where desirable employment performance is based on the execution of observable, measurable behaviors or outcomes; subjective evaluation is viewed with doubt.

The lower courts have judged many more cases involving professional or white collar employees, such as educators and lawyers. In these cases, although decisions have varied, many courts have accepted the argument that some subjective assessments, such as leadership or the ability to get along with others are important criteria in evaluating performance (Buckner, 1988). Rogers v. International Paper Company (613 SW 2d 844, 1976) is distinguished from other performance appraisal cases in that for the first time it was ruled that a totally objective performance appraisal may be inappropriate or insufficient.

The issue of objectivity vs. subjectivity is still in dispute. This inconsistency has given rise to issues that pit the desire to preserve academic freedom against acknowledgement that employment discrimination is tolerated in academe. In cases alleging employment discrimination at professional levels in postsecondary education, the courts have again and again rendered holdings that prescribe less stringent standards than apply to other employment situations. Because of the hesitancy of the courts to become involved in what they consider to be matters of academic freedom, professional educators at this level do not enjoy the same protection as other workers. 
This may seem an apparent contradiction between the courts, and the assumption may be made that the lower courts must abide by the ruling of the supreme court. However, Llewellyn (1930) emphasizes that a court may decide only the dispute that is presently under consideration. The facts and issues of the case are limited to the specific circumstances of that particular situation.

Because of the inconsistency regarding the use of nonobjective appraisal n:easures, this study addresses two levels of employee evaluation in postsecondary education. The first identifies legal standards that are applicable to positions where performance can be appropriately measured by objective criteria. The second addresses standards which apply to professional positions where a degree of subjectivity is desirable and necessary, and where the courts have restricted their intervention. However, the problems created by judicial restraint will also be addressed. Judicial Restraint in Postsecondary Education. The United States Supreme Court denied certiorari in a case challenging the system of awarding tenure. The high court accepted the decision of the Seventh Circuit Court of Appeals which conceded that the subjectivity of employment practices inherent in post secondary education "...would ordinarily defeat the purpose of the discrimination laws" (Namenwirth v. Board of Regents of the University of Wisconsin System, 769 F. 2d 1235, p.1243, 1985; certiorari denied, 474 U.S. 1061, 1986). The court acknowledged that standard practices of higher education foster discrimination. 
In case after case alleging bias in post secondary education, the courts decry the pervasive discrimination evident in academe, yet generally refuse to intervene or to enjoin institutions from continuing such practices. Subjective as such practices may be, the courts tend to accept employers' judgements regarding the process of evaluating professional employees (Buckner, 1988). Even in situations of seemingly blatant discrimination, where actions of employers would not be tolerated in a non-education environment, the courts have refused to impose either legal judgement or restraints. Johnson v. the University of Pittsburgh (435 F. Supp. 1328, 1977) illustrates this point.

Doctor Johnson was employed at the University of Pittsburgh for six years as a teacher and researcher, after which she was terminated for two reasons. The first reason given for her termination was that her research did not have immediate relevancy to departmental and university goals. The department chair admitted that this inadequacy had never been communicated to her: "Doctor Heath admitted that he did not mention . . . that her research was not relevant to the mission of the department to the plaintiff or to anyone" (p. 1359). The second reason given for her termination was that she was an inadequate teacher. The court record states that: "The court has approached this question of teaching ability with considerable doubt, in view of the fact that in prior years there does not appear to have been any criticism of her teaching ..." (p. 1366). Even so, the court's decision to dismiss the suit favored the 
university, and imposed no sanctions to prevent subsequent acts of discrimination.

Compare this with the language of the court used in Flowers v. Crouch-Walker Corporation (552 F. 2d 1277, 1977), a noneducation case:

However, the plaintiff need not, and indeed, cannot disprove as a cause of his discharge a source of dissatisfaction of which he is unaware. Accordingly, the employer's express acceptance of his work without express reservation is sufficient to show that the plaintiff was performing satisfactorily. . . (1283).

Although this particular example does not represent all the issues and circumstances of the Johnson case, it does raise disturbing questions about the tolerance of prejudice in education.

How is it tenable that professional employees can be evaluated subjectively on criteria that do not even need to be made known to them? If an instructor's performance has been accepted without criticism for years, does nct its sudden unacceptability suggest either a callous indifference to the students or a vendetta against the instructor? The courts admit that bias is flagrant in employment decisions at professional levels in postsecondary education; or at very least, that the system encourages discrimination. For all practical purposes, having recognized the problem and denouncing it fiercely, the courts have asked the colleges to pretty please stop being so naughty (Johnson, 1977).

Despite over two decades of unprecedented antidiscrimination law, in every discipline, at every level, and in every 
postsecondary educational institution discrimination continues, for both students and faculty (Schuster, 1988).

More disturbing than the failure to eliminate discrimination on campus is the recent increase in prejudicial attacks against both students and faculty because of sex, race, and religion. These attacks include verbal and physical assaults, as well as property damage (Daniels, 1988).

Discrimination is also evident in the classroom. Women and minorities are ignored and interrupted more frequently; their abilities and contributions depreciated. Wher these individuals move beyond the classroom to join the ranks of professional academicians, the same types of denigration continue. They are accorded less esteem for their work, and are less likely to achieve tenure or administrative positions (Mall, 1986).

In non-education cases, such as Parsons v. Kaiser (497 F. Supp. $339,1980)$ the courts have ruled that discriminatory practices must be remedied, even if the cost is excessive and burdensome. However, in cases involving postsecondary education, as in Penk v. Oregon State Board of Higher Education (816 F. 2d. 458, 1987; cert. denied 108 S. Ct. 158, 1987), the court has recognized that historical patterns of discrimination continue, yet do not require remedy because of economic considerations.

There is no substantial dispute that historical disparity existed. However, historical disparity does not give rise to a successful Title VII claim. The efforts to bring its female employees into parity with its male employees had been im- 
peded more by external economic factors than by lack of effort by the board to redress historic imbalances ( $p$. 471).

Compare this with the ruling in Parson v. Kaiser (497 F. Supp. 339, 1980).

Even so, the far-ranging improvements in Kaiser's employment and promotion practices, though relevant to prospective relief,cannot obviate the validity of compensatory relief contentions. Kaiser is responsible to those who can show they have been wronged. Those who have been wronged have a right to be restored to their rightful economic status absent the effects of unlawful discrimination (at 346).

As a district judge, I must, of course, follow the law of the case. . . I am obliged to note that Kaiser was confronted - on the basis of the mandate - with an extremely heavy evidentiary burden. I believe it was too heavy...(at 347).

Buckner (1988) lists three types of institutional discrimination: stereotyping, tracking, and the imposition of career ceilings.

Discriminatory stereotyping assumes that a non-member of a group is inherently inferior to members of that group. In American society, stereotyping means ". . . to be treated and to be seen as a member of a group that is different from and inferior to the group of standard, fully developed persons, the adult white males" (Wasserstrom, 1977, p. 586). Buckner (1988) alleges that in stereotyping, different standards are unconsciously used to judge a non-member, with the benefit of bias favoring group members.

Discriminatory tracking occurs when preconceived ideas about non-members limit access to opportunities or employment 
positions on the assumption that they are inherently less qualified to perform as required.

A third type of institutional discrimination occurs with the imposition of career ceilings on non-members, preventing their promotions into upper level positions on the assumption that their inherent inferiority limits their ability to perform effectively at the highest levels of the organization.

These three types of discrimination are evident in post secondary education. The position of non-intervention taken by the courts is particularly disturbing because as Buckner (1988) points out, most people are unable and unwilling to recognize their own prejudices.

In his dissenting opinion in Namenwirth (769 F. 2d 1235, 1985), Judge Swygert expressed grave reservations about the appropriateness of academicians judging their peers without standards to safeguard the fairness of the process. Because higher education is so fraught with bias, advancement requires approval of those whose ability to judge without prejudice is questionable. When employment decisions are made without guidelines to ensure the fairness of the process, prejudice is promoted.

The system of performance appraisal in postsecondary education invites discrimination, because among other things, subjective evaluations are made primarily by those who have benefitted in the past from institutional discrimination, and therefore may be less likely to recognize their own predisposition to bias. 
OUTLINE OF THE RESEARCH

Although it is customary in a dissertation to present a review of literature pertinent to the field of research in Chapter II, in this study the literature review is placed later.

Fundamental to a performance appraisal program that is both legally defensible and professionally acceptable is an understanding of how law impacts employment decisions, in addition to knowledge of effective methods of employee evaluation. A performance appraisal program that is successful in promoting desired outcomes is worthless if it does not conform to legal standards and consequently embroils the employer in costly and time consuming litigation.

Because an effective appraisal program must be based on legal standards, and the law specifies the minimum acceptable guidelines, legal requirements of employee evaluation are presented before the introduction of a review of performance appraisal practices.

Chapter II, Methodology, examines the Grounded Theory method proposed by Glaser and Strauss (1967). Legal research methods suggested by Alton (1982) are introduced. Grounded Theory and legal research methods complement each other, and provide an effective approach to this type of study.

Glaser and Strauss (1967) suggest that qualitative research may represent the best way to observe and analyze data about processes, conditions, norms, and patterns. It is appropriate for spe- 
cific, practical problems because it relies on relevant data and encourages innovative resolutions. Its purpose is to determine if a certain set of facts leads to predictable phenomena; in other words, the inductive development of theory from data grounded in observation.

Grounded theory as presented by Glaser and Strauss (1967) is particularly useful for analyzing the processes, changes, and options of social groups. After the problem is defined, the process of inquiry involves:

1. Theoretical sampling - the concurrent collection, categorization, and analysis of data.

2. Hypothesis formulation - the identification of general relationships.

3. Theory generation - a development of an explanation that accounts for much of the phenomena.

Grounded theory provides a valuable perspective for organizational research. The analysis of legal precedent as a basis for policy development seems to be an appropriate application of the principles of grounded theory. The weakness of the theory as presented by Glaser and Strauss is the lack of specific method. To be useful for research, the approach needs a more definite methodology. This is provided by traditional legal research methods. A grounded approach to research that identifies the emerging pattern of facts and decisions makes it possible to generate legal theory and predict what outcomes are likely in the future. 
In Chapter III, the legal data are presented and analyzed. In addition to the law previously mentioned, this study includes the Age Discrimination Act of 1967, Rehabilitation Act of 1973, The Civil Service Reform Act, Uniform Guidelines on Employee Selection, Executive Orders Number 11246, 11375, and 11478, and the Civil Rights Restoration Act of 1987. Performance appraisal cases heard by the Supreme Court, or alluded to by this body, are discussed. Cases selected for analysis do not all apply specifically to education. Much of case law concerning performance appraisal has been developed in a business context, and such cases are examined. Court decisions involving postsecondary education are explored, and a comparison of decisions issuing from the two arenas are presented. Although, as previously noted, the court has been hesitant to substitute its judgement for that of academe, the principles upon which business decisions are based may indicate the reasonings the courts might use if more stringent adherence to anti-discrimination laws are demanded of colleges and universities. In some instances the trend may be difficult to determine because the courts have reached inconsistent decisions (Kleiman \& Durham, 1981). Even so, it is possible to identify the major issues with which the courts have concerned themselves, and the stance taken on each.

Cases are summarized for analysis in the form of case briefs. The format used in this study includes: (1) Citation, (2) Decision, (3) Facts, (4) Issues, (5) Rules of Law, (6) Rationale. 
Some references to court cases not presented in brief form or used to develop theory are included. While these cases do not address issues of concern regarding performance appraisal, they may offer a particularly useful definition or illustrate some relevant principle.

Chapter IV examines performance appraisal literature. Following a review and discussion of current recommended practices, key points are summarized.

Chapter V, Results, summarizes the data analysis. A theory of legal standards of performance appraisal is generated from data grounded in the compilation of regulatory information and case law analysis. The presentation of legal appraisal standards demonstrates the differences between court requirements for professionals in postsecondary education, and for workers in other employment contexts. The current recommended standards of performance appraisal practice are presented. The congruence and inconsistencies between legal requirements and current practices are examined. Finally, a model for performance appraisal is introduced that is based on emerging legal standards and current performance appraisal practices. 
CHAPTER II

\section{METHODOLOGY}

\section{INTRODUCTION}

Dr. Watson completed his rounds and returned home through the storm-darkened London streets. Entering the study, he found Sherlock Holmes with his chair drawn close to the fire. Holmes was holding a piece of fine ivory notepaper. Thus began Doyle's (1981) "A Scandal in Bohemia".

'It came by the evening post,' said he. 'Read it aloud.'

The note was undated, and without either signature or address.

'There will call upon you tonight at a quarter to eight $o^{\prime}$ clock' it said, 'a gentleman who desires to consult you on a matter of the very deepest moment. Your recent services to one of the Royal Houses of Europe have shown that you are one who may safely be trusted with matters which are of an importance which can hardly be exaggerated. This account of you we have from all quarters received. Be in your chamber then at that hour, and do not take it amiss if your visitor wears a mask.'

'This is indeed a mystery,' I remarked. 'What do you imagine that it means?'

'I have no data yet. It is a capital mistake to theorize before one has data. Insensibly one begins to twist facts to suit theories, instead of theories to suit facts' (p. 17). 
In his memoirs of the renowned case, "A Study in Scarlet," Watson recounted another incident that revealed the method of Holmes' uncanny inquiries. Watson was becoming increasingly perplexed by Holmes' seeming indifference to a gruesome murder on which he had been consulted. Returning in their carriage from a vislin concert, Holmes prattled on about the virtues of a Stradivarius versus those of an Amati. Finally, Watson could stand it no longer.

'You don't seem to give much thought to the matter in hand,' I said at last, interrupting Holmes' musical disquisition.

'No data yet,' he answered. 'It is a capital mistake to theorize before you have all the evidence. It biases the judgement' (lbid., p.362).

Sherlock Holmes, one of literature's greatest researchers, recognized the importance of developing theory from data. Holmes acquired knowledge about a crime by first examining the facts, and then developing a theory about the case based on evidence. He steadfastly refused to speculate about a crime, as this might bias his judgement and lead to errnneous conclusions. As he explained to Watson in "The Regiate Squires," by starting with a supposition, one may unwittingly misinterpret the evidence to support that theory. " 'I make a point of never having any prejudices and following docilely wherever fact may lead me, . . . " (ibid, p. 275).

Sherlock Holnes, the master of criminal research, solved baffling problems by generating theory from data. When baffling 
problems arise within an organization, the temptation may be to analyze organizational theories and determine how the situation reflects the explanation. However, reliance on the theory may misconstrue the way in which events are perceived: data may be incorrectly generated from theory.

\section{APPROACH TO RESEARCH}

In organizational research, just as in criminal investigation, the generation of theory from data is an effective method of developing useful solutions to specific problems. Glaser and Strauss (1967) call theory that has been qualitatively advanced from data based on observation of actual circumstances "grounded theory" (p.1).

Guba (1978) acknowledges the approach of Glaser and Strauss (1967) in determining criteria for good grounded theories. Good theories work. They adequately explain phenomena and are relevant. They fit: that is, data are not forced or misrepresented in an attempt to create a perfect explanation. Good theories are understandable to both researchers and practitioners, and are readily converted from concepts into workable policies. They provide clear and creative bases for further research.

Naturalistic inquiry, as Guba (1978) calls this method, differs from the traditional deductive approach in a number of ways. Naturalistic inquiries are concerned with discovery, rather than verification of theory, and are grounded in observable phenomena 
rather than predicated from intangible theory. In naturalistic inquiries, critical data are selected and analyzed within their milieu, as opposed to experimental studies where variables are manipulated without regard for the environmental frame of reference. Naturalistic inquiry considers contextual intrusions to be intrinsic; traditional quantitative approaches control conditions to eliminate interference.

Consequently, traditional deductive research methods do not always appropriately address the functional concerns of organizations. Rather than discovering explanations of phenomena by observing what actually occurs, deductive methodologies present a grand theory, then design experiments to prove that the theory is correct. These approaches may be restrictive, relying on the validation of existing theories. Consequently, these theories may be inappropriate for describing existing situation-specific problems. Subsequent studies or experiments based on fallacious premises will not yield useful information, even though the outcomes may have been predicted by the theory.

Although quantitative research may support an existing theory, it is less likely to suggest novel solutions to problems. Fox (1969) suggests that this is because traditional research emphasizes that the only acceptable outcome is a precise, defensible document. The formulation of the research problem is dictated by preestablished assumptions that may not be relevant to the current situation. The result of relying on the traditional de- 
ductive methods of investigation is an abundance of outstandingly correct research that may have little practical application for dealing with an organization's ongoing problems. There are no spectacular successes or failures, no unspectacular failures. There are just "unspectacular 'successes' in the sense of projects which accomplish what they set out to do. . but which do not vividly extend the bounds of knowledge" (lbid. p.33).

Glaser and Strauss (1967) acknowledge that deductive methods are appropriate for some research, but discount sole reliance on the traditional approach that is based on verifying preexisting theory. They charge that the methods and computations used in prior research are rarely reexamined. Theory itself is speculative; never proved, rarely disproved, sometimes improved. Data often are manipulated or ignored in order to fit the theory, solve the puzzle, either consciously or unconsciously. For addressing organizational problems, therefore, Glaser and Strauss (1967) encourage an inductive, qualitative approach rather than a deductive, quantitative one.

Rather than beginning with a theory and using deductive processes to develop data, the authors suggest analyzing data to generate theory. Factual evidence gathered from existing situations provides the most appropriate and relevant means to gain information about empirical situations. This approach encourages creative solutions to predicaments and decreases the likelihood of developing explanations that are based on outdated or irrele- 
vant data. Norms, processes, conditions, patterns, and other qualitative aspects can be accounted for. Applications will be practical. The results are more likely to be useful for predicting and explaining phenomena relevant to the actual situation than would research based on deduction from preexisting theory.

Deductive research, referred to by Kuhn $(1959,1970)$ as "puzzle solving," judges success by how perfectly the piece (the "new" discovery) fits into the puzzle (the theory). The theory determines how the piece looks: its size, shape, and proper place. If the piece does not fit as expected, the researcher, not the theory, loses credibility. The discovery is disregarded as an anomaly; it is not right. The piece, not the puzzle, is questioned. The theory is not assumed to be lacking, but the hypothesis, or the researcher. The researcher may not always have the insight and the courage to suggest that the problem of fit may lie not with the piece, but with the puzzle. Researchers who follow the tradition of puzzle solving may fail to recognize that the weakness often springs from the original theory. They continue to view problems from a traditional context, trying to discover solutions, without realizing that the problems themselves may need to be redefined.

Kuhn (1962) suggests that we need to be aware of two different types of discoveries. One type is a discovery predicted from existing theory, such as a missing element of the periodic table (a piece of the puzzle). The other type is not suggested by existing theory; the discovery of Uranus, for example. 
Prior to 1781, at least seventeen astronomers had recorded sighting the star Uranus. But in that year the scientist Herschel, upon more careful observation, realized that Uranus had moved. It was not a star, but a comet! Excited astronomers and mathematicians tried for months to determine the comet's path, but were unable to reconcile their calculations with known theories. Finally the astronomer Lexell, noting the size, movement, and orbit of Uranus, unearthed its true nature. It was not a comet, but a planet! Rather than twisting the data to accommodate known theories, Lexell developed a new theory grounded in the phenomena he had observed. Other scientists observed the same phenomena as did Lexell. They worked diligently trying to validate existing theories by making the pieces fit the puzzle they had been given. Only Lexell realized that the pieces created a new puzzle.

Kuhn (1962) acknowledges that although the traditional experimental approach of substantiating existing theories by discovering supportive data is acceptable in some situations, there are times when theory generation is more appropriate than theory verification.

In traditional research, the topic for study is often selected because it was identified in earlier studies as an area requiring further investigation. Consequently, the focus is narrow, and the analysis deductive. Sometimes a particular research design is selected because it is one with which the researcher is familiar; however, it may not be the most appropriate. (The Law of the In- 
strument, as it is called, is much like the Law of the Hammer. When a small boy is given a hammer, he realizes that everything needs pounding.) Never mind that no one can use the information. (McGrath, Martin, \& Kulka, 1981).

Carver (1978) suggests that another reason for the selection of quantitative, experimental methods is that complicated statistics lend the impression of authority and scholarship to the work.

"Experiments," say Campbell and Stanley (1966), "often prove to be tedious, equivocal, of undependable replication, and to confirm prescientific wisdom..." (p. 3). And of researchers, they continue:

We must instill in our students an expectation of tedium and disappointment and the duty of thorough persistence. . . We must expand our students' vow of poverty to include not only the willingness to accept poverty of finances, but also a poverty of experimental results" (p. 3).

This is not meant to promote the notion that deductive research is always inappropriate (although admittedly, that last quotation presents an extreme scenario). Rather, its purpose is to propose, as do Kuhn $(1959,1970)$, Campbell and Stanley (1966), Glaser and Strauss (1967), and Fox (1969), that for certain types of research problems (such as identifying dynamic social processes), a theory building approach may be more useful than theory verification. 
Naroll and Cohen (1970) express concern with the limitations of accepted "scientific" approaches to research that is concerned with dynamic social processes. Phenomena occur in cultural context. To disregard underlying causes in order to quantify data distorts reality.

Cultural context dictates that realities will change as cultures do. Continued development of outdated theories moves further away from the discovery of accurate information (Gould, 1981).

Law, for example, must be studied within the context of intervening phenomena. Regulation, common law, and case law develop on the basis of variables specific to certain circumstances which cannot be discounted (Llewellyn, 1930).

To have any practical value, legal research must identify emerging standards and their underlying rationale. Only then can legal justification of organizational policy be defended, and predictions made about future actions of the courts. The number of cases decided in favor of the plaintiff or defendant is not as important as the rationale behind the decision. Legal reasoning does not lend itself weii to quantification. An analysis of legal requirements must be qualitative, and a non-quantitative framework for research is mos: appropriate (Alton, 1982-83).

Theory generation recognizes the importance of creative exploration of alternatives. It encourages flexibility while guar- 
anteeing the precision required for specific situations (McGrath, et al., 1981).

Determining the evolving principles of law governing employee evaluation poses a research problem with a specific, practical application. Traditional research approaches seem inappropriate for analyzing this problem. Grounded theory, as advocated by Glaser and Strauss (1967), provides an appropriate framework for the study and prediction of emerging legal standards.

\section{RESEARCH DESIGN}

\section{Grounded Theory}

The generation of grounded theory, that is, "the discovery of theory from data systematically obtained and analyzed" (Glaser \& Strauss, 1967, p. 1), is a research process in which "most hypotheses and concepts not only come from the data, but are systematically worked out in relation to the data during the course of the research" (p. 6).

Denzin (1970) also promotes the position that when the goal of research is development of theories about dynamic social processes, an interactionist perspective is most appropriate. This perspective asserts that studies involving human symbols (for example, the evolution of legal concepts), necessarily include both the concepts themselves, and the specific situations that produce them. Symbols have meaning, not in and of them- 
selves, but in relationship to subcultures. Concepts change over time; their meanings, although relative, demonstrate a pattern that reflects changing social consensus.

The study of dynamic processes, therefore, requires methodology that is adequately flexible to accommodate ongoing change, yet sufficiently structured to shape interactive theory. Denzin (1970) characterizes interactionist theory as an integrated set of concepts, formulated from the observation of empirical data, which explain particular social phenomena. Because this theory is empirically grounded, it is appropriate for describing both the static and dynamic aspects of social processes. Individual acts and actions are integrated into a theory of shared cultural meaning. For example, separate laws and decisions are integrated into a legal theory which produces guidelines that impact society. Theory is derived from behavior, and in turn, its generation shapes behavior.

Theories are concepts that explain or predict something. Theories serve a number of purposes: they describe and interpret behavior, offer a means to understand and control circumstances, afford guidelines for research, and provide for a logical evolution of topical knowledge.

Glaser and Strauss (1967) distinguish two types of theories. Substantive theory is developed from empirical evidence for use in relevant situations. Formal theory, on the other hand, is developed for use in conceptual research. To illustrate; substan- 
tive theory may be generated from official records of actual court decisions. Formal theory may be developed from sources suggesting what laws say "should" happen. Because this study is concerned with specific, practical applications of legal precedents, it will be limited to the generation of substantive theory.

Process of Theory Generation. The first step in generating a grounded theory, according to Glaser and Strauss (1967), is the development of categories and their properties from data. Properties are specific aspects of the data such as circumstances, causes, consequences, processes, etc. A category is a distinct conceptual component of the theory; it represents ideas about the problem. Categories are comprised of a number of properties, and need to be both analytic and sensitizing. An analytic category is one that is comprehensive enough to unify characteristics of a number of properties. At the same time, the category must be sensitizing; it must be sufficiently specific to reflect facts accurately and yet be relevant to personalized experience.

The actual facts are not as important as the conceptual categories they shape. Data may change without altering the concepts that are abstracted from the evidence. For example, although the specifics of law cases involving the same legal question may vary, the combined cases indicate a single governing principle. Future cases will present different circumstantial facts without changing the prevailing idea of justice. The goal of the research is developing a theory that accounts for much of the 
phenomena. It is consequently unnecessary to describe each case perfectly, but only to extract the relevant facts and delineate its specific nature.

The second step in theory generation is the development of hypotheses through identification of general relationships among the categories and their properties. The objective is to synthesize many diverse categories in order to present alternate hypotheses. It is not important to pile up proof, but to establish as many viable hypotheses as indicated by the evidence. Hypotheses suggest general relationships.

Integration is the third step in theory generation. The relationships among the hypotheses form the core of the emerging theory. At this point, the diverse relationships are integrated into a unified whole. Multiple theories are acceptable, as a single theory may be unable to account for all the indicated relationships.

The final step in the development of a grounded theory is reduction. Underlying uniformities are identified to generate a parsimonious theory with fewer higher level concepts. Numerous categories have suggested several hypotheses, which are reduced to a few concepts which comprise the theory.

When approaching this process, it would be wise to remember the admonitions of Sherlock Holmes. The investigation should be undertaken without preconceived hypotheses or theories. If certain outcomes are anticipated, data may be inadvertently 
misrepresented to accommodate the bias. Evidence that does not seem to fit may be neglected. Glaser and Strauss (1967) suggest that:

An effective strategy is, at first, literally to ignore the literature of theory and fact concerning the area under study, in order to assure that the emergence of categories will not be contaminated by concepts more suited to different areas. Similarities and convergences with the literature can be established after the analytic core of the categories has emerged (p. 37).

Categories begin to emerge during the process of theoretical sampling.

Theoretical Sampling. Theoretical sampling is a process of joint collection, coding, and analysis of information. It is based on a general problem or perspective, and its progress is shaped by the data. Theoretical sampling has a dual purpose. In addition to identifying categories and their properties, this process makes it possible to determine if prediction based on certain contingencies is possible.

Cases are selected for study either because of their ability to contribute many conceptually relevant properties, or because they illuminate the relationships between categories and properties. Both similar and diverse evidence is included in the research: differences need to be both maximized and minimized. The inclusion of negative cases, those which suggest exceptions, maximizes differences, adding depth to the theory and enlarging the explanation while defining its scope. Minimizing differences 
defines conditions, and thus establishes a basis for prediction. Maximization verifies the usefulness of the category. The degree to which properties and categories vary under diverse conditions is noted. Some categories may need to be redefined as new properties are added. Cases may be analyzed individually or simultaneously. Each case will likely provide properties for a number of categories.

Theoretical sampling is not concerned with studying all possible cases for theory verification: its goal is determining conceptual relevance for theory generation. It requires only enough data to produce properties, categories, and hypotheses. A category reaches saturation in the process when additional data do not contribute additional properties. When saturation is reached, there is r.o further need to continue to collect new data. Saturation depends upon the limitations of the data and the sensitivity of the researcher.

Comparisons made among similar cases result in substantive theory that is applicable under like circumstances. Comparisons among dissimilar cases lead to more general, formal theory. Unlike traditional research, the generation of grounded theory will not guarantee identical results when another researcher studies exactly the same data. And also unlike traditional research where data are often separately collected, coded, and anaiyzed, theoretical sampling requires the joint collection, coding, 
and analysis of data. Glaser and Strauss (1967) refer to this as the Constant Comparative Method of Qualitative Analysis.

Constant Comparative Method of Qualitative Analysis. The Constant Comparative Method is a four step process of emergent design that facilitates the identification of hypotheses and relationships among elements of a theory. Because the components on which theory is built emerge from observations about the situation being examined, the theory is generated through a process grounded in reality. The process involves:

1. Comparison of properties within each category

2. Integration of categories into hypotheses

3. Delimitation of the theory

4. Recording of the theory

In the first step, each property is coded into all relevant categories. The property's relationship to the category, not the fact itself, is the important aspect. During this process, new categories may emerge as additional data are introduced. As the property is coded, that is, placed in a category, it is compared with other properties within the same category. As properties are compared within a category, distinct conceptual aspects are suggested. As concepts emerge, ideas are formulated and recorded. The process of joint collection, coding, and analysis continues.

The process of integration begins as the comparison of property to property develops into a comparison of property to 
category. Eventually through constant comparison, relationships emerge and are integrated into theory.

Delimitation of theory occurs as the concepts become more firmly established. The theory is clarified as there are fewer modifications, some possible reductions, and the elimination of non-relevant properties and categories. The scope of application is identified, and the theory becomes parsimonious.

The theory is now ready to be recorded. This may be written in the form of a discussion, or presented as a set of specific propositions. The theory is presentable when it is in a systematic, substantive form that accurately reflects the situation studied, and presents the information in an understandable manner. Because the generation of grounded theory is essentially a process, a record of the individual's method should also be included.

If new categories emerge after the theory is completed, it is not necessary to compare their properties with all previous categories. It is enough to take the new category to saturation, then modify the theory, if appropriate.

The Constant Comparative Method is a developmental procedure. It is therefore useful for the generation of theory about processes and changes in organizations and societies. The method is appropriate for either field research or analysis of documented social phenomena. This feature suggests its appropriateness for legal research. 
Weaknesses of Grounded Theory. The process of developing a grounded theory is not without limitations. Campbell and Stan- . ley (1966) warn that induction can never be proven conclusively. The end results of investigation remain assumptions, no matter how carefully and completely the theory is built. This threat to external validity of the research can be lessened by including many examples in defining the theory. The more that results can be generalized to populations and settings, the stronger the defense of the theory.

A second weakness that the two researchers point out is the threat to validity posed by the interaction of time. The application of theories developed from observing specific situations may prove unsuitable at a later point in history. Guba (1978) agrees, noting that generalizations decay over time. This problem can be overcome by periodically reevaluating outcomes.

A third weakness of theory development is replication (Carver, 1978). Are the outcomes the result of bias and perspective, or will other researchers arrive at the same conclusions? Again by including many instances of repeated data in the study, the likelihood of replication is enhanced.

A point to consider, perhaps not necessarily a weakness, is raised by Guba (1978). When researchers develop theory about processes and sociological phenomena, they must remember that unlike the presumption of experimental methodologies, induction 
assumes no one constant reality. Reality is relative: dependent upon perspective, subculture, history, and myriad other factors.

\section{Legal Research}

Legal research on any topic requires the inclusion of constitutional, statutory, and case law. Although provisions of constitutional and statutory law may seem obvious, this is not always so. Disputes do occur. Case law serves as an authority when controversy arises over the intent or constitutionality of laws. The current status of law can perhaps best be understood through case analysis. Altori (1982-83) specifies a process for the study of cases.

Alton (1982-83) recommends beginning research with the Descriptive Word Index. This source lists common terms that are used to identify the issues in cases. The researcher makes a list of words that describe the issues in question. Each word listed in the index will direct the researcher to topics and key reference numbers in a legal digest. The digest indicates cases in which the issues were presented, as well as identifying the statutes upon which the disputes were based.

Once the cases have been identified, the researcher turns to a court reporter. Court reporters, such as the United States Reports and the Federal Supplement, record the specifics about each case. These are the official record of facts and decisions. 
The researcher outlines the facts of each case in the form of a brief. The case brief format recommended by Alton (198283) includes: (1) citation, (2) facts, (3) decision, (4) issue(s), (5) rule of law, and (6) rationale.

Once the facts are recorded, the researcher synthesizes the circumstances, decisions, and rationale. Cases are compared and analyzed to identify governing principles. Each case is then shepardized to determine its current status as precedent. Finally, the researcher generates theory about the legal principles involved in the cases, and predicts future outcomes.

\section{Comparison of Grounded Theory and Legal Research Methods}

Cenoruence of the Theories. The goal of both grounded theory research and legal research is the generation of theory based upon factual data. They are ideal methods of studying sociological phenomena that are subject to change with time and locale. Although each method of inquiry may involve data that has been analyzed many times, different researchers often develop distinct theories from exactly the same information. Neither approach to research guarantees identical results. Both grounded theory and legal research are enhanced by the development of new perspectives. In theoretical sampling as in case synthesis, facts are extracted and analyzed within a conceptual context. As hypotheses are developed about the relationships of properties and categories, or facts and cases, theory is generated. The substantive 
theory is then applicable to specific situations indicated by the data analysis, and prediction is possible.

Differences Between the Theories. There are a few aspects of legal research that do not conform perfectly to grounded theory as presented. Although Glaser and Strauss (1967) suggest that precise descriptions of properties and samples are not essential in theoretical sampling, Alton (1982-83) strongly emphasizes the importance of accurate presentation of facts in a legal case. Researchers attempting to apply the principles of grounded theory generation to legal research need to be aware of how critical the presentation of precise evidence in case law is.

Another related area that requires modification in generating a grounded legal theory is the emergence of new categories after a theory has been presented. In a legal situation this would occur when a case sets, rather than follows, precedent. Although Glaser and Strauss (1967) do not recommend comparing the new information with all previous categories, in legal circumstances this is essential. All cases need to be reevaluated to determine if the modified ruling changes the precedents established by each case.

A third difference between the two approaches involves saturation. Glaser and Strauss (1967) state that when addition information does not further develop a category, it is not necessary to continue collecting it. In legal research, however, a nuance or small refinement in the law can substantially change the 
interpretation or application of a legal principle. Saturation is only reached in legal cases when every case dealing with a particular issue has been analyzed. Each time a new case is heard which deals with the topic, that case will have to undergo the comparative process. This is neither difficult nor time consuming, as an occasional shepardizing is all that is necessary.

Shepardizing, you may recall, involves following the historical development of a case through the use of a citator. A citator is "a set of books which provides . . . the subsequent judicial history and interpretation of reported decisions, and lists of cases and legislative enactments construing, applying, or affecting statutes" (Black's Law Dictionary, fifth ed., 1979, p. 221).

\section{PROCEDURES}

Constitutional and statutory laws governing performance appraisal will be summarized. Because controversies over acceptable performance appraisal practices are referred to the courts, and court decisions have demonstrated inconsistencies (the negative cases referred to by Glaser and Strauss, 1967), the dissertation will concentrate on generating a grounded theory of legally defensible performance appraisal practices.

Although Alton (1982-83) suggests beginning case selection by consulting the Desscriptive Word Index, this study does not. The index contains over a quarter of a million entries, and

time constraints indicate an alternate approach would be more 
efficient. Glaser and Strauss (1967) discourage researchers from reviewing the topical literature before collecting data so that the developing theory will not be contaminated with presuppositions. In this study, however, the literature of performance appraisal will be consulted prior to data collection for the purpose of identifying regulations and relevant court cases. This seems a more reasoned approach than examining thousands of cases for possible relevance to the topic. Legal and business literature concerning performance appraisal often contains reference lists of relevant court cases. After compiling an initial list of pertinent cases, each case will be examined in a court reporter. The court reporters identify statutory and judicial law governing the cases, and the prior cases so identified will then be examined. Those concerned with similar issues will be included in the data collection and analysis. After cases are selected in this manner, those chosen for inclusion in the study will be shepardized to determine if subsequent rulings provide additional data that should be considered. Selection of cases will include those suggested in these references if they meet the criteria for this study. That is, they must be cases heard by the United States Supreme Court since the passage of the Civil Rights Act of 1964, or which were appealed to the court since then and denied hearing. Also selected will be cases from, lower courts upon which the Supreme Court based rationales regarding performance appraisal. These are 
identified by analyzing discrimination cases recorded in the court reporters.

The concept of emergent design presented by Glaser and Strauss (1967) is patently applicable to the development of legal theories. Like grounded theory, legal theory is developed through constant comparison of properties and categories that emerge from relevant data. Several theories may emerge from the same concepts. This is desirable because the goals of research about processes include generating multiple explanations that account for much of the data, and encouraging an open minded creativity toward further research. Emergent design recognizes and accommodates change as an essential aspect of societies, and provides a process to deal with transition. As law is by nature dynamic, and legal theory is generated from grounded information, the concept of emergent design offered by grounded theory provides a theoretical framework for legal analysis and discussion.

The process of theoretical sampling will be handled in the legal investigation by identifying properties (evidence and facts of the cases) and categories (issues). As each case is analyzed, properties and the categories they suggest will be will be noted on butcher paper hung on the walls. Each category that develops will be listed on a separate sheet of paper. Because a particular issue may be addressed in more than one case, it is to be expected that one case may contribute to more than one category. Each case will also be recorded in brief form. Saturation will be 
assumed when all qualifying cases have been presented, and will be monitored through shepardizing.

Facts and issues will be compared. Dissenting opinions will be given particular attention as these will maximize the theory by adding depth to it. These opinions are critical to examine because of their predictive potential. When a case is overturned, the decision is often based on the rationale presented in a dissenting opinion. To be a useful theory for practical application, this must be considered.

Hypotheses suggested by the data will be noted, refined, modified, and developed into substantive theory. Rationale for the theory will be presented. This will be presented in the form of a summary of legal standards according to statutory and case law.

Although anti-discrimination statutes were intended to be applied to employment in general, the courts have chosen to require less stringent adherence to the laws when they involve institutions of higher learning. Because court decisions involving postsecondary educators have differed substantially from those rendered in other employment contexts, education cases will be presented and analyzed separately.

The summary of Chapter III will present a developmental perspective of appraisal law. Because appraisal procedures must comply with legal standards, an understanding of the law governing evaluation is essential before specific practices can be discussed. Therefore, a review of performance appraisal litera- 
ture will be presented only after discussion of appraisal law. Although in traditional dissertation format this chapter would precede the one on methodology, it seems more appropriate in this study to present the literature review later, in Chapter V.

Chapter V, Results, will present the generation of grounded legal theory based on statutes and court decisions. Again, because of the differences in legal interpretation that have been applied to academe and to other employment settings, two separate theories will be generated. The theories will be recorded in final form as a set of propositions reflecting concepts and presenting specific recommendations suggested by emerging legal standards for performance appraisal.

\section{LIMITATIONS}

Because some data may be finite, saturation may be reached in some categories without suggesting conclusive concepts. Other types of data may be almost infinite, and unlike puzzle solving, the researcher may never be certain that the process is complete, although saturation appears to have been accomplished.

A second limitation arises because the selection of certain issues or aspects will determine the shape of the data. Observation is imprecise and biased. What is selected depends on perspective. If other facts were chosen, the outcomes might differ.

Glaser and Strauss suggest that a weakness of qualitative research is its traditional lack of systematic method. Their ap- 
proach to grounded theory offers a structure that provides a systematic method of inquiry. Similar methods of legal research augment and strengthen this methedology.

The accuracy of the theory generated will be restricted by the limitations and subjectivity of the legal system.

Limitations are placed on the research by the choice of naturalistic inquiry in the process of developing a grounded theory. Specific weaknesses of this approach include the question of validity in generalizing theory beyond the parameters of the source data, the potential for diminished relevance of the theory over time, replication, and the issue of multiple perspectives of reality.

Data regarding evaluation of grounded theories are scarce. Glaser and Strauss suggest that this limitation may be overcome with time as the theories generated prove their effectiveness in predicting and explaining phenomena, and offering solutions to problems.

The study will be limited by the researcher's creative and inductive abilities. Because the methodology is qualitative, as is legal research, right answers will be suggested, not proved. The correctness of the conclusions will be demonstrated over time in organizations and in the courts. Answers may also change with time as appraisal theory and law evolve.

Finally, I am not a lawyer, and do not wish to leave anyone with the impression that this is the case. I have studied law to 
understand how the legal system and legal research operate, and suggest that this is the minimum exposure any administrator should have to the law. Law, in this situation, is much like medical practice. Without extensive training it would be foolish to attempt to remove your own tonsils. Even with extensive training, the assistance of another would be highly recommended if a problem were to arise. But with some understanding of the principles of good health, you may be able to prevent disease. By the same token, if you require legal assistance, consult an attorney. But with fundamental knowledge of the law, you may be able to keep abreast of emerging legal standards and avoid litigious confrontations. 
CHAPTER III

\section{THEORETICAL SAMPLING AND DATA ANALYSIS}

\section{INTRODUCTION}

Performance appraisal standards have been shaped by constitutional, legislative, and administrative law. Since 1964, a number of significant laws regarding employee evaluation have been passed. The law has been further developed by the courts.

The First, Fifth, and Fourteenth Amendments to the United States Constitution, although established well before 1964, guarantee rights that form the basis of legal challenges in a majority of employment discrimination cases.

Since 1964, ten new laws have contributed significantly to the development of appraisal practices. Legislative law concerning performance appraisal includes the Civil Rights Act of 1964, the Age Discrimination Act of 1967, the Equal Employment Opportunity Act of 1972, the Rehabilitation Act of 1973, the Civil Service Reform Act of 1978, and the Civil Rights Restoration Act of 1987.

Administrative law that affects employment practices includes Executive Orders Number 11246, 11374, and 11477, as well 
as the Uniform Guidelines of Employee Selection Procedures of 1978.

As laws become incorporated into daily life, conflicts and questions arise. When disputes occur concernibg the interpretation of statutory or regulatory law, the courts are called upon to arbitrate these differences. Since the enactment of the Civil Rights Act of 1964, a number of important federal court cases have interpreted and further defined appraisal law. Although constitutional and statutory law regarding performance appraisal requires compliance of all employers, the courts have demanded less stringent adherence to these laws when they involve institutions of postsecondary education. It is therefore important to analyze judicial decisions concerning appraisal law in both academic and non-academic contexts.

Presented is a discussion of appraisal law and briefs of significant cases dealing with performance evaluation. Without exception, all of the included law regulates much more than performance appraisal. Only those aspects of the law that directly affect employee evaluation will be discussed. Following the presentation of legal data is an analysis based on principles of grounded theory development. A summary of the information concludes this chapter. 


\section{APPRAISAL REGULATION}

\section{Constitutional Law}

The First Amendment of the United States Constitution guarantees the right to free speech. In some cases alleging discrimination, the employee charges that actions were taken by an employer in retaliation for the exercise of the right to free speech.

The Fifth and Fourteenth Amendments frequently are invoked when a performance appraisal program is charged with discrimination. Both amendments prohibit the deprivation of life, liberty, or property without due process. In these cases, the charge may be that the individual was deprived of liberty; that is, the termination of employment results in fewer options, and liberty has been infringed. Or, the employee presents the argument that a job is one's property and when it is taken away, there must be a hearing and the opportunity to challenge the decision. The Fourteenth Amendment also guarantees equal protection under the law.

\section{Statutory Law}

The Civil Rights Act of 1964. Prior to the passage of this act, twenty-eight states had anti-discrimination laws. They were ineffective because of lack of administration and supervision, and failure to grant relief to wronged parties (Ledvinka, 1982). The passage of the Civil Rights Act precipitated sweeping reform. 
Although equal rights are constitutionally guaranteed, flagrant and frequent violations of the law were rife prior to 1964 . The right to full participation in citizenship, employment, education, and public activities was frequently denied because of race, sex, or other discriminatory reason. To remedy this continued denial of rights, the Civil Rights Act of 1964 established explicit mandates prohibiting prejudicial treatment in these areas.

This Act requires the Attorney General to prosecute equal rights violators, and empowers the office of Attorney General to authorize redress and compensation for victims.

This law also established the Equal Employment Opportunity Commission to provide extensive supervision in areas of concern and to investigate allegations of noncompliance.

Eleven titles comprise the Civil Rights Act of 1964. A number of civil rights issues are addressed by this law, such as voting rights and desegregation of public facilities. However, this study only investigates those sections of the law that are applicable to employment discrimination. Two titles directly impact employment practices: Title VI, Nondiscrimination in Federally Assisted Programs, and Title VII, Equal Employment Opportunity.

Title VI forbids discrimination because of race, color, or national origin in programs or activities that receive any federal funds, where the purpose of the funding is to provide employment. Failure to comply may result in termination of financial assistance. Funding may be terminated only after a due process of 
recorded violation, opportunity for a hearing, followed by continued noncompliance. The termination of funds applies only to the parts of the program in violation.

The purpose of Title VII is to eliminate employment discrimination based on race, color, religion, sex, or national origin, by removing unnecessary barriers to employment that adversely affect these protected classes. Title VII mandates equal opportunity in employment by outlawing practices that result in disparate treatment or disparate impact. "Disparate treatment occurs where members of a race, sex, or ethnic group have been denied the same employment, promotion, membership, or other employment opportunities as have been available to other employees or applicants" (Uniform Guidelines on Employee Selection Procedures, 1978). "'Disparate impact'...involve(s) employment practices that are facially neutral in their treatment of different groups but in fact fall more harshly on one group than another and cannot be justified by business necessity." (International Brotherhood of Teamsters v. the United States, et al. 431 U. S. 324, 1976). Overt, prima facie discrimination is forbidden; prima facie meaning "on the face of it, or at first sight, as the way something appears to be from seeing and judging it from the first disclosure" (Cascio and Bernardin, 1981, p. XVI). Buckner (1988) notes that if the court accepts the assertion of prima facie discrimination, it presumes intent. Also outlawed is any "neutral" practice that has the 
effect of discrimination (disparate impact). The Title contains sixteen sections labeled 701 to 716 .

The law forbids discrimination in hiring, dismissal, referral, compensation, privileges, and conditions of employment. It prohibits classification of workers in any way that interferes with equal employment opportunities. The mandate applies to labor organizations and employers of at least twenty-five workers per working day for a minimum of twenty calendar weeks. This only governs operations within the United States. Exempted from compliance are states and their political subdivisions, Indian tribes, tax-exempt private clubs, and religious organizations where the employee's work involves the religious education of the organization. The United States is also exempted, although federal civilian employees are protected by the Act. Section $703 e$ of the Act states that discrimination based on religion, sex, or national origin is permissible in certain circumstances. A bona fide occupational qualification exists for example, in the case of an institute of religious education. There are no specifics given, however, that indicate under what conditions discrimination based on sex or national origin is permissible.

The law does not always prohibit an employer from applying different criteria in compensation and conditions of employment. According to Section $703 \mathrm{~h}$, differences that are the result of a bona fide merit or seniority system, or are justified by locational dissimilarities are permitted. 
In a clause that has substantial impact on employment procedures, Section $703 \mathrm{~h}$ also permits discrimination based on the outcomes of professionally developed abilities tests. Such differentiation is allowable provided that the test, its development, administration, and resulting decisions are not designed or used prejudicially because of race, color, religion, sex or national origin.

Section 706 of the Civil Rights Act of 1964 specifies the procedure to be followed in the case of alleged discrimination. If a state or its political subdivision prohibits such discrimination, the plaintiff must first bring charges in that court within ninety days of the alleged violation. If no such state or local law exists, or if sixty days have passed since the initiation of such proceedings, the matter may be referred to the Equal Employment Opportunity Commission. Upon receipt of a written charge, the Commission is required to proceed privately. The Commission is to provide the employer with a written copy of the charge, and to investigate the allegation. The employer has thirty days in which to comply with the law. After thirty days of noncompliance, the Commission notifies the plaintiff, and may instigate action in United States District Court against the employer. If the district court finds the employer guilty, remedy and compensation may be required. Proceedings may also be instigated by the Attorney General, or by a chief judge of a district court. 
Employers are required by Section $709 \mathrm{c}$ to maintain records which indicate compliance with the law. Conspicuous notices regarding equal employment opportunity must be posted as designated by the Equal Employment Opportunity Commission.

The Civil Rights Act of 1964 established the minimum acceptable standards of nondiscriminatory employment practices. States may require more stringent guidelines; and must not tolerate less.

Age Discrimination Act of 1967. This Act prohibits employment discrimination because of age, originally affecting workers from age forty through sixty-four. The Act protects workers by requiring that ability, not age, be the determining factor in employment decisions. A secondary purpose of the legislation is to provide a vehicle for rectifying employment problems that arise because of age.

The Age Discrimination Act of 1967 extends the protection of the Civil Rights Act of 1964 to include instances of age discrimination. Employers, labor organizations, and employment agencies are specifically bound by the law.

Compensation, classification, terms and conditions of employment may not be differentiated because of age, within the categories protected by this law. A stated preference or specification for employment may not be based on age.

The United States Government, any of its wholly owned corporations, a state or its subdivision are excluded from compliance. 
The Act was amended in 1978, and the age ceiling was removed for federal employees. Protection in the private sector was extended to age seventy. The Act was amended again in 1986, this time removing the ceiling for the private sector. There still remain some positions in both private and government employ for which a mandatory retirement age can be set. Airline pilots, firefighters, and foreign service officers, for example, may have an imposed retirement age (Eglit, 1988).

Equal Emoloyment Opportunity Act of 1972. The purpose of this act is to broaden the scope of the Civil Rights Act of 1964 in a number of ways.

The 1964 legislation required compliance by employers of twenty-five or more workers. The 1972 act requires compliance by employers of fifteen or more workers.

Protection of the law is expanded to include not only workers and union members, but applicants as well.

Although governments, their agencies and political subdivisions were initially exempted from compliance with the Civil Rights Act of 1964, they must now abide by its regulations. However, the Equal Employment Opportunity Act of 1972 specifically exempts elected public officials and personal staff members selected by such officials. Also exempted are appointees and advisors who oversee the legal and constitutional aspects of the office, unless those persons are state employees covered by civil service laws. 
In the 1964 law, the term "religion" was given no elaboration. The law merely decreed that an individual could not be discriminated against because of religion. The 1972 legislation clarifies the term, stating that religion encompasses belief, observance, and practice. An employer must accommodate the religious practices of an employee unless such accommodation can be shown to interfere unreasonably with business function.

The 1972 law also expands the protection given to educational employees. Congress recognized that the exemptions enjoyed by educational institutions under earlier civil rights legislation did little to eliminate rampant discrimination in higher education. This act specifically extends protection to employees of colleges and universities.

The passage of the Equal Employment Opportunity Act of 1972 established a specific timeline during which the Equal Employment Opportunity Commission is required to act in an employment discrimination case. When a written charge, taken under oath, has been filed by the commission, the employer must be notified within ten days and the investigation begun. The notification must state the date, place, and circumstances of the activities in question. The Commission is instructed to determine the outcome within one hundred and twenty days of its becoming a party to the process. If the investigation discloses no violation, the charge is dropped and the plaintiff so notified. 
The time during which an employee may bring charges following the alleged violation was increased from ninety to one hundred days.

The Civil Rights Act of 1964 empowered the Attorney General to enforce its provisions. The Equal Employment Opportunity Act of 1972 transfers these responsibilities from the Attorney General to the Equal Employment Opportunity Commission.

The Act established the Equal Employment Opportunity Coordinating Council. Council members include the Secretary of Labor, the Attorney General, and the chairs of the Equal Employment Opportunity Commission, the Civil Service Commission, the Civil Rights Commission, or their representatives. The Council is charged with facilitating the full implementation of equal employment opportunity legislation. The Council's task is to coordinate the efforts of various governmental agencies, and to eliminate conflicts and inconsistencies among them.

Rehabilitation Act of 1973 Among the goals of the Rehabilitation Act of 1973 is the removal of barriers to employment for handicapped individuals.

The law requires periodic evaluation of each agency of the executive branch that is under the authority of the Civil Service Commission. The Commission is to review hiring, assignment, and promotion practices involving handicapped persons, and to make appropriate recommendations for necessary changes. All agencies of the executive branch are required to implement an affirmative 
action program. The program is to be reviewed annually by the Commission.

Any employer who receives a government contract in excess of $\$ 2500.00$ must have an affirmative action program for handicapped individuals.

Handicapped persons may not be discriminated against, solely because of handicapping condition, in any activity that receives federal funds.

Civil Service Reform Act of 1978. The purpose of the Civil Service Reform Act of 1978 is to promote efficiency and equality in the federal work force. Employees and applicants are to be given equal opportunity to compete for positions regardless of race, color, religion, sex, national origin, political affiliation, marital status, age or handicapping condition.

The basic principle of the law is that employment decisions are to be based solely on ability, knowledge, and skills. Job retention is to be based on performance. Employees unable or unwilling to perform adequately are to be terminated if poor performance is not remedied.

The law governs executive agencies (independent commissions, for example, such as the National Labor Relations Board or the Securities and Exchange Commission), the administrative office of the federal courts, and the government printing office. Excluded from compliance are intelligence and defense agencies, -government corporations (such as the Federal National Mortgage 
Association which operates as a private business), and the General Accounting Office.

Chapter 43 of the Act defines guidelines for performance appraisal. Section 4302 of the law states nine requirements:

1. Performance appraisal must be scheduled periodically (a1).

2. Emsloyees are to take part in the development of performance criteria (a2).

3. Employment decisions are to be based on the evaluation (a3).

4. Performance appraisals must be based on objective standards (b1).

5. Employees must be informed of performance criteria (b2).

6. Evaluations must be based on the performance of such standards during the appraisal period (b3).

7. Appropriate performance is to be recognized and duly compensated (b4).

8. Employees who do not perform adequately are to be given the opportunity and help needed to improve (b5).

9. Following assistance given to improve the performance of an employee, if performance does not improve adequately, the individual is to be reduced in grade or terminated (b6).

Section $4303(b)$ defines the procedure to be followed when action is taken against an employee because of unimproved per- 
formance. The employee is to be given written notice at least thirty days before action is to be taken. The notice must cite each specific occasion when performance was unacceptable according to previously determined criteria. The employee has the right to an attorney, and must be given reasonable time to respond to the charges.

If the employee's performance does improve, and is acceptable for one year, the account of the performance inadequacy is to be removed from all agency records.

Civil Rights Restoration Act of 1987. President John F. Kennedy, in his endorsement of the proposed Civil Rights Act, asserted that since all taxpayers contribute to the federal government, federal funds must in no way support, encourage, or subsidize direct or indirect discrimination.

The passage of laws subsequent to the Civil Rights Act of 1964, in particular Title IX of the Education Amendments of 1972, the Rehabilitation Act of 1973, and the Age Discrimination Act of 1975, purposely employed the same specific language used in Title VI of the Civil Rights Act of 1964 to broaden the scope of protection. Consequently when the United States Supreme Court ruled in Grove City College v. Bell (104 S. C. 1211, 1984) to interpret "programs and activities" in its narrowest possible sense, the limited scope of protection was applied to all such legislation.

Although the Grove City decision was rendered for an educational question, the ruling set a precedent for employment cases 
as well. Not only was the identical language of other laws affected, but in another ruling the same day, the court applied the same narrow interpretation of "program or activity" to an employment discrimination case, Consolidated Rail Corporation v. Darrone (104 S. C. 1248, 1984).

In Grove City, the court ruled that the college received federal assistance through its financial aid department. But although the Civil Rights Act of 1964 prohibits discrimination in federally subsidized "programs or activities," and the judges considered the financial aid depariment to be the only program receiving subsidy, the court ruled that the college did not have to eliminate discrimination in other areas to continue receiving federal assistance.

In response to the Grove City and Consolidated Rail rulings, congress passed the Civil Rights Restoration Act of 1987 for the express purpose of overturning these rulings. The new law stresses the original intent of congress to eliminate discrimination completely. It emphasizes that any institution or agency that receives federal funds or provides a public service must eliminate discriminatory practices from every part of the organization (Congressional and Administrative News, 1988).

According to provisions of the law, state and local governments, public schools systems and postsecondary educational institutions, and private businesses must comply with the legislation in all parts of the organization if any part of the organization 
receives federal assistance. In addition, if a state or local governing agency receives federal funds, and in turn distributes aid to another agency, the secondary recipient must comply to the same extent. (Civil Rights Restoration Act of 1987, effective March 22, 1988).

This legislation continues to allow an exemption granted by the Education Amendments of 1972 for religious educational organizations. Such organizations are allowed to discriminate on the basis of sex when religious beliefs dictate.

When private corporations receive federal assistance only the geographically separate facility that receives the funds need comply. However, if the the corporation as a whole receives federal monies (as in the instance of the Chrysler bailout) the entire organization must comply.

The law exempts individuals who are ultimate recipients of federal funds, such as welfare recipients and farmers who receive subsidies.

\section{Administrative Law}

Executive Order Number 11246 (September 28, 1965). The purpose of Executive Order Number 11246 is to assure equal employment opportunity for federal civilian employees regardless of race, creed, color, or national origin. This may include the implementation of Affirmative Action Programs. The Civil service Commission is to oversee the program by providing assistance in 
compliance, arbitrating alleged violations, and issuing necessary guidelines.

The order directs government agencies to require businesses with whom they contract to refrain from discriminatory treatment of their employees. The contractors must inform labor unions and other businesses that provide them with workers or provisions of this requirement. Labor unions, contractors, and subcontractors may be required to file compliance reports with the government agency.

Contractors are exempted from compliance when the work takes place outside the United States, or when the Secretary of Labor determines that compliance would not be in the national interest.

Noncompliance by the contractor may result in termination of existing government contracts and exclusion from future government contracts. In addition, criminal charges may be filed against the contractor if false information is provided in compliance reports.

Supervision of Executive Order Number 11246 falls under jurisdiction of the Secretary of Labor, who may refer violations to the Equal Employment Opportunity Commission, the Justice Department or other federal agencies.

Executive Order Number 11375 (October 17, 1967). Executive Order Number 11375 amended Executive Order Number 11246 
to include sex as a protected classification. The term "creed" was changed to "religion" to broaden its scope.

Executive Order Number 11478 (August 12, 1969). This executive order supersedes Executive Orders Number 11246 and Number 11375 by expanding the responsibilities of administrators in combating employment discrimination. This law demands that recruitment efforts be extended to all potential candidates. Employees must be given the maximum opportunity and training to develop and utilize their abilities. Managers must be trained not only to comply with the order, but to involve community and educational organizations in its implementation. Regular evaluations are to be conducted to assess compliance.

This act requires all executive branch departments and agency directors to implement some Herculean ideals. For example, each department and agency director is required to "assure participation at the local level with other employers, schools, and public or private groups ..." (Sec. 2). Unlike other anti-discrimination laws that establish minimum acceptable standards, this act prescribes ambitious tasks to promote employment decisions which not only maximize opportunity, but make directors responsible for the participation of others who are not under their authority!

\section{Uniform Guidelines on Emplovee Selection Procedures}

(1978). No consistent standards existed to guide and govern employers in selection and appraisal procedures, although this need 
had been recognized since the enactment of the Civil Rights Act of 1964. Finally, a cooperative effort by the Civil Service Commission, the Equal Employment Opportunity Commission, and the Departments of Labor and Justice produced the Uniform Guidelines on Employee Selection Procedures of 1978. The guidelines were developed by clarifying legislation, incorporating relevant court decisions and professional psychometric standards, and reevaluating mandates in the light of practical experience. The law provides a single set of standards for employers and employment related organizations to aid compliance with federal equal employment opportunity regulations, specifically those regulations concerned with selection procedures or other forms of testing.

Selection procedures include:

Any measure, combination of measures, or procedure used as a basis for any employment decision. Selection procedures include the full range of assessment techniques from traditional paper and pencil tests, training programs, or probationary periods, and physical, educational and work experience requirements, through informal or casual interviews and unscored application forms (Sec. $16 \mathrm{Q})$.

Employment practices that involve testing "include but are not limited to hiring, promotion, demotion, membership, . . . referral, retention, and licensing and certification,...selection for training or transfer" (Sec. 2B).

Exempted from the regulations are bona fide seniority systems and recruitment programs that are part of an affirmative 
action campaign. The law also excludes from protection employees covered by the Age Discrimination in Employment Act of 1967, and the Rehabilitation Act of 1973. The law goes so far as to suggest that if the effects of prior discrimination exist, the applicant should be subject to less demanding requirements, unless business necessity requires more stringent guidelines.

This doctrine of business necessity, which has risen as an exception to the amenability of discriminatory practices, 'connotes an irresistible demand.' The system in question must not only foster safety and efficiency, but must be essential to that goal (United States v. St. Louis

- San Francisco Railway Co. 464 F. 2d 301, 308 1972).

The Uniform Guidelines are particularly concerned with validity, "the extent to which the procedure actually accomplishes what it seeks to accomplish or measures what it seeks to measure" (Fox, p. 367, 1969).

This law requires employment practices to be validated when adverse impact is indicated. According to these guidelines, adverse impact may be assessed by the four-fifths rule. It is desired that women and minorities be represented on the job in the same proportion that they constitute the qualified labor pool. If representation falls below $80 \%$ of the desired ratio, adverse impact is indicated.

There are exceptions to the four-fifths rule. An aggressive recruitment program, for instance, may create a qualified labor pool that is atypical. A smaller representation may be acceptable in a force of few workers. (However, in the case of a small work 
force, it is acceptable to use a sample collected over a longer period of time, or to use studies conducted elsewhere under similar conditions.) In such instances, the four fifths rule may not be appropriately applied to indicate adverse impact.

When adverse impact is indicated, validity studies are required to justify continued use of the evaluation procedure. Alternative methods of selection, and their acceptability or lack of suitability, must be presented as part of the study. This demonstrates the user's consideration of alternatives that may have resulted in less adverse impact, and substantiates the decision that the chosen procedure is the most appropriate. If more than one relatively equivalent selection method is available, the employer must use the instrument resulting in the least adverse impact. If an employment practice results in less favorable outcomes for members of a protected class, the practice is allowable only if it is essential for business necessity, and has been validated according to the guidelines established in this act. Validation must be based on job analysis, "a detailed statement of work behaviors and other information relevant to the job" (Uniform Guidelines on Employee Selection Procedures, Sec. $16 \mathrm{~K}$ ). Some employment criteria, such as punctuality and absenteeism, may be used as a standard without validation studies, if the employer can demonstrate the importance of the criteria in successful job performance. 
The guidelines specify acceptable technical standards for conducting validity studies, whether content, criterion, or construct oriented.

According to standards established by this act, testing demonstrates content validity when the test is a representative measure of the content of the job (Sec. 16D). A typing test given to applicants for a secretarial position reflects content validity, given that typing is an important component of job responsibility.

Valid criterion related tests are those which predict or are positively correlated with acceptable job performance (Sec. 16F). The ability to jump backwards from the top of a ladder is a criterion related test that is a predictive measure of future successful performance as a skydiver.

Content validity, then, measures an aspect identical in the test situation and the job. Criterion related validity measures a distinct yet related aspect in which test and job performance are positively correlated.

The third type of validity, construct validity, is a measure of a psychological attribute (construct) whose manifestation has a significant positive correlation with desirable job performance (Sec. 16 E). A lie detector test given to employees is a method that may be used to indicate the attribute of honesty.

Content-related validity studies must assess a sample of representative, observable behaviors or outcomes that can be operationally defined. It would be inappropriate, for example, to use 
a content-related measure of validity to assess unobservable mental processes (leadership, common sense), or to evaluate competencies that are expected to develop on the job. The content and context of the test environment should conform as much as possible to the work environment to strengthen reliability of the procedure.

Content studies that involve ranking as a tool in employment decision making are permissible only when higher test scores are positively correlated with more desirable job performance.

For each criterion-related test an employer chooses to use, four aspects need to be considered. First, the components measured by the professionally developed test must be substantially similar to job components, as demonstrated in each case by job analysis. It is not sufficient for a test instrument to show a high degree of correlation with only a limited number of job performance aspects. The test must reflect most significant job behaviors. Second, the test sample must be typical of the user's labor pool candidates. The criterion sample should include members of protected classes, if they are represented in the qualified labor pool. Third, the degree of adverse impact must be indicated. Fourth, the availability of alternative methods demonstrating equal or greater validity must be investigated.

Empirical data demonstrating criterion-related validity with a positive correlation between test performance and job performance at th.e 0.05 level of significance are acceptable. The 
Guidelines acknowledge this level of probability as a professionally established standard.

When the overall selection procedure demonstrates adverse impact, the component parts must be analyzed for discriminatory effect. Where there is no overall discriminatory effect, there is no need for individual analysis, with two exceptions. If the selection procedure acts as a factor in an incumbent employment program based on prior discrimination, then individual components must be validated. Also, if the courts or administrative agencies determine that a specific requirement (such as height) is not job related in identical or similar circumstances, validity studies must be conducted to indicate that this requirement is appropriate in the specific situation.

Selection procedures and methods, including directions given to supervisors, should be administered and scored under standardized conditions, whenever possible, to eliminate bias. It is recommended, though not required, that testing procedures be professionally supervised. If any part of the test requires subjective evaluation, rating techniques and evaluation instructions must be carefully developed to eliminate as much as possible the opportunity for bias. If informal selection procedures are used and result in adverse impact, they must be quantified and validated.

It is not always necessary for the employer to personally validate procedures. If a professionally acceptable published test is used for selection, the employer is not required to conduct ad- 
ditional validity studies, but may rely on the expertise of test publishers. Experiise does not mean the reputation of the publisher or the test, promotional literature, testimonial or anecdotal statements. Empirical records are the acceptable evidence of validity.

Users are encouraged to meet three criteria when relying on professionally developed tests. First, the professionally developed test must substantiate validity claims. Second, the test must be representative of most significant job behaviors or outcomes. A high correlation on a limited scope of job behaviors is not likely to be acceptable under scrutiny. Third, the professionally developed test should contain fairness studies that indicate the test's impact on each race, sex, and ethnic group represented in the employer's labor pool.

Section 14B8a of the guidelines define unfairness as a situation:

... when members of one race, sex, or ethnic group characteristically obtain lower scores on a selection procedure than members of another group, and the differences in scores are not reflected in differences in a measure of job performance.

(In Section $16 \mathrm{P}$, religion and color are included as part of the definition of ethnic group, although not included specifically in the body of the law.) Fairness, then, may be assumed when differences in test scores reflect differences in job performance. 
Lawmakers consider the process of developing a concept of iairness in empioyment testing to be in its early stages. They recognize that the development of applicable standards requires testing a large number of subjects representative of applicants and employees. Consequently, compliance with the obligation to conduct fairness studies is not required of small employers. (No clue how small "small" is.)

The extent of obligation in fairness compliance is vague. If the selection procedure demonstrates adverse impact, the user "generally should" determine if "possible" unfairness is suggested (14B8b).

Consideration for user-conducted fairness tests include validity, appropriate application of the test, sample representativeness, and sample size. If there are not enough employees in a particular job to conduct appropriate studies, several similar jobs may be grouped together for the study. The law specifically states that employers are not required to hire or promote employees to achieve an adequate sample size. Employers should follow guidelines recommended by the American Psychological Association when conducting studies. Specifically, test users must be knowledgeable and competent in the administration and use of tests, and testing must be conducted under standardized conditions and procedures.

If unfairness is indicated, the user may replace the instrument with another; or continue to use the test, but revise the in- 
strument to achieve acceptable correlation between test performance and job performance.

Although it is permissible to use professionally developed tests that do not include fairness studies, users are encouraged to strongly consider the availability of this information when purchasing a test. The choice between appropriate instruments of similar validity must consider the degree of adverse impact of each.

If fairness testing is not feasible, the employer may continue to use the test if it meets validity requirements of this act. However, past discriminatory actions that are the reason for the infeasibility of fairness testing are not a justifiable reason for exemption. For example, a small sample size is not an acceptable excuse for the failure to conduct studies examining the impact of the test on women, if women had previously been denied employment.

The user can rely on evidence provided by other studies of similarly representative groups in identical or comparable work situations, if it is not feasible to conduct internal studies.

The regulations acknowledge that no definitive guidelines exist to determine the currency of validity for a particular instrument of employment testing. However, employers are encouraged to consider the effects of changing job and labor market conditions on validity. 
A selection procedure that is not fully validated may be used if there is "substantial evidence of validity" (sec. 5J1), and if a study is in progress to produce required documentation "within a reasonable period of time" (sec. 5J2). The guidelines do not specify what constitutes substantial evidence of validity, or a reasonable period of time.

In some circumstances unvalidated procedures may be used. An unvalidated test that eliminates adverse impact, for example, is acceptable. If such testing is used, it must be highly correlated with job performance.

Lawmakers recognize that it is not feasible to conduct technically acceptable criterion-related validity studies in some circumstances. These may include situations where the number of employees involved is too small, the range in scores too limited to constitute a sample representative of the labor population, or if by its nature the job is not amenable to standardized evaluation of criteria that is unbiased, reliable, and relevant. Once it becomes technically feasible for the employer to conduct internal studies, the test must be validated.

Employers are cautioned that construct-related validity studies are a relatively new and complex procedure in employment evaluation. They require extensive effort, including reliance on content-related and criterion-related data, to establish acceptable empirical evicience. The user must demonstrate that the selection procedure is related to the construct, and the construct is 
related to significant job requirements, as determined by criterion-related tests. If the user has not developed criterion-related data on which to base the studies, validity studies from another source can be used only under certain circumstances. If the criteria studies are to be transferred, the user must demonstrate that the work behaviors or products in each situation are the same. If neither is the same, the governing agency may assume that the transfer of criterion-related validity is inappropriate.

Requirements for record keeping are scattered throughout the regulation. However, by extracting and compiling the information it can be seen that whatever type of test the employer chooses, the Uniform Guidelines require that the following information be kept on record, available for scrutiny by regulatory officials:

1. A complete job analysis.

2. Dates and locations, including mailing addresses, of studies. In the case of criterion-related studies, data on the development of criteria must be included.

3. Users; including job titles and codes as defined in the Dictionary of Occlipational Titles, and the contact person.

4. Problem and setting, specifying conditions of testing and work environments.

5. Existing selection methods and scoring requirements.

6. Complete description of the selection method, whether developed professionally or by the user. If construct or criterion- 
related methods are used, data concerning the impact of the procedure on protected classes should be included.

7. Alternative methods considered, and the justification.

8. Rationale for selecting a particular instrument, its method of use, appropriateness, purpose, impact, demonstrated validity, and acceptability of scoring standards.

9. For construct and criterion-related studies, information must be kept about each person in the sample. This includes scores on selection and criterion tests, age, sex, race, ethnic group, and relevant job experience. Results of each rater's score for each sample member is to be available, although names, social security numbers, or other identifying data are not to be used.

10. Descriptions of the relationship between job and test performance whether content, construct, or criterion-related measure. In criterion-related studies, data must be included about the research sample; size, race, sex, ethnic origin, and their relationship to the qualified labor pool.

11. Construct studies must specifically define the construct as supported by psychological literature, and indicate desirable performance standards.

Section $4 B$ requires employers to keep records that indicate the adverse impact of selection procedures for each job, and how the results of their selection procedures differ for the following classifications: sex, Blacks, American Indians, Asians, Hispanics, Caucasians, and total. 
If adverse impact is indicated, records must show one of the following:

1. The procedure is justifiable because of acceptable content-related validity.

2. The procedure is justifiable because of acceptable criterion-related validity.

3. The procedure is justifiable because of acceptable construct validity.

4. The procedure, although not validated by the user, is justifiable based on the acceptability validity studies in similar situations.

5. Evidence demonstrates that it is unnecessary or infeasible to test the procedure for validity, and that this decision is not inconsistent with federal law.

If the user employs less than one hundred workers, studies do not have to include such detail. Section 15 (1) states that it is sufficient to record:

1. The test used.

2. The number of hirings, advancements, and terminations for people of each category by sex, race, and national origin. Information on race and national origin need be included only if that category represents more than two per cent, and less than ninetyeight per cent of the labor force in the area.

3. The number of applicants of each category. 
4. The results of annual studies demonstrating the currency of information about the test's adverse impact.

5. The analysis of individual components of the test, if the overall procedure demonstrates adverse impact.

Once adverse impact has been eliminated, it is necessary for the user to collect and reexamine data for two years.

If the number of employees is insufficient to determine adverse impact, it is acceptable to collect data over a period of time until enough information has been generated to determine if a problem exists.

These records may be used only for the purpose for which they were designed, and the privacy of all subjects is to be guarded. Statistical information should be presented in the form of tables or graphs. If records have not been kept in accordance with the regulations, the regulatory agency may infer adverse impact.

Following the validity procedures outlined in this act does not relieve employers of the responsibility to comply with affirmative action regulations. This law specifically requires compliance with previous legislation aimed at remedying the effects of past discrimination.

\section{SUMMARY OF REGULATION}

Because the purpose of this study is to provide information to develop legally defensible appraisal programs, the legislative 
summary will not reiterate the specifics of the laws with all their exceptions. Rather, the summation will emphasize the practices mandated by legislation to eliminate employment discrimination. This summary answers the first question posed by the research: What does statutory law mandate in performance appraisal?

The Civil Rights Act of 1964 established the minimum acceptable standards of non-discriminatory employment practices. Subsequent laws refined, expanded, and clarified the law.

Discrimination based on race, color, religion, sex, national origin, age, or handicapping condition is forbidden. In addition, the federal work force may not discriminate on the basis of political affiliation or marital status. These regulations safeguard the rights of workers, union members, and applicants.

These guidelines are to be followed by any organization receiving federal funds; state and local governments, public school systems, post secondary educational institutions, and private businesses. Every part of the organization must comply with these guidelines if any part of the organization receives funds. Any secondary recipients that receive funding from any primary recipient organization are aiso required to comply with the law.

Employment practices must be free from bias whether manifested as disparate treatment or disparate impact. Forbidden are the use of employment practices that blatantly discriminate, as well as those which appear to be neutral but result in adverse im- 
pact. If representation of protected classes in the employer's work force falls below eighty per cent, adverse impact is indicated. Selection procedures then must be validated to show acceptable relationship between selection procedures and the job requirements. Continued use of discriminatory practices or procedures are justified only by business necessity.

Employment practices include hiring, termination, referral, promotion, classification, compensation, privileges, terms and conditions of employment, as well as performance appraisal.

Performance appraisal is in fact a test, and as such is subject to the guidelines for selection procedures. Appraisals should entail periodic evaluation of employee performance on predetermined, objective criteria. Employees' input should be sought in establishing performance standards. Workers are to be informed of performance criteria, and evaluated by performance on these standards. Evaluation procedures, including instructions to evaluators and testing conditions, should be standardized. If informal or subjective criteria are used, they should be standardized and validated. If performance is found to be inadequate, the employee is to be given training and time to improve.

If professionally developed selection procedures are used, they must demonstrate validity, reliability, and fairness.

Employers are required to keep records indicated their compliance with antidiscrimination regulations. These records are to 
be used only for this purpose. The privacy of all subjects is to be guarded.

When a selection procedure is used, as in performance appraisal, large employers must keep on record the following information about the test: purpose, user, date, setting, complete job analysis on which selection of the test is based, scoring requirements, methods, alternative procedures and rationale for choice, and the relationship of the test to the job.

Employers of fewer than one hundred workers need only record: the test used; the number of employment decisions based on the test by race, sex, and national origin; the number of applicants of each category; and annual statements noting the adverse impact of the selection procedure.

All employment practices should be subject to periodic review.

Conspicuous notices indicating the employer's compliance with equal employment opportunity guidelines are to be posted.

Although legislation provides specific guidelines for employment practices, questions and issues arise that are not covered by its scope. When this occurs, the courts are called upon to clarify and arbitrate, and judicial law emerges over time.

\section{JUDICIAL STANDARDS FOR NON-ACADEMIC APPRAISAL}

The abundance of explicit administrative and legislative regulation does not address all issues that arise concerning em- 
ployment practices. Nor does the profusion of requirements prevent disputes over the interpretation and intent of anti-discrimination laws. Legal questions that remain unresolved are referred to the court system. The United States Supreme Court elects to adjudicate cases which it deems to be of significant national importance and that are properly within the limited jurisdiction of the high court (Edwards \& Nordin, 1980).

The following court cases have played a significant role in the development of performance appraisal law and have had a major impact on defining legal expectations. Six cases were heard by the United States Supreme Court, and nine were argued in the federal appellate courts.

Although circuit court decisions are not usually binding in other locales, the United States Supreme Court has relied on the rationale presented in these cases as a basis or substantiation for their decisions. Consequently, the decisions rendered by the lower courts may become extremely significant. If granted certiorari and heard by the Supreme Court, a case is no longer considered an appellate decision. However, in many cases, the Supreme Court may use the reasoning of the lower court without actually hearing the case. McDonnell Douglas v. Green (411 U. S. 792, 1973) demonstrates the extent to which lower court rationale may influence the reasoning of the Supreme Court. (A detailed analysis of this case follows.) 
When an issue of particular importance is decided by the high court, it is most desirable to speak unanimously to give the decision its proper authority (Lacayo, 1987). The Supreme Court recognized that it was necessary to clarify court procedures in cases alleging employment discrimination, due to the tremendous increase in this type of litigation following the passage of the Civil Rights Act of 1964 and subsequent anti-discrimination legislation. Justice Powell, writing for the unanimous court, praised the efforts of the Court of Appeals and indicated the reason that the Supreme Court selected this particular case:

... the Court of Appeals attempted to set forth standards to govern the consideration of respondent's claim. . . . In order to clarify the standards governing the disposition of an action challenging employment discrimination, we granted certiorari. . . (McDonnell Douglas v. Green, 411 U. S. 792, 1973, p. 798).

In the case briefs that follow, all the information has been taken from records of court proceedings documented in the official court reporters.

The court briefs and judicial analyses address only the issues before the court that deal with performance appraisal. There are other issues adjudicated in these proceedings (such as percentage interest acceptable for awards of back pay, determination of attorney fees, regulations regarding timely filing of forms) that are not directly concerned with performance appraisal, and therefore not included in this research. 
Cases are included in which the issues at first glance may not appear to be directly related to performance appraisal. Griggs v. Duke Power Company (401 U. S. 424, 1970), for example, was a case involving the use of tests for making hiring decisions. In a subsequent case, Brito v. Zia Company (478 F. 2d 1200, 1973), performance appraisal was ruled a test. As such, appraisal must abide by mandates regarding employment tests that have been established by regulation and court decisions.

The cases are presented in chronological order to indicate how law develops. In some instances, the rule of law governing a court decision was based on a regulation that has been updated. For example, the Civil Rights Act of 1964 established guidelines governing the use of tests. These were clarified by a subsequent regulation, the Equal Employment Opportunity Commission Guidelines, which were then replaced by the Uniform Guidelines on Employee Selection Procedures of 1978. To avoid (more?) confusion, the research does not introduce the standards established by all three regulations; only the currently governing rules of law are presented. However, when a court case was decided in part based upon an earlier version of the regulation, this is noted.

Some of the following decisions remanded or vacated lower court proceedings, then ordered the case back to the lower court for further hearings. This occurs because although the court has made a determination on the issue of law, it suggests that more facts may be needed to render a just solution, but that the fact 
finding is the proper jurisdiction of the lower court. Because the particular facts subsequently unearthed by the lower courts do not contribute to the clarification of appraisal law, they are not included in the court briefs, and the outcomes of such cases are not included in this study. This study is concerned with the principles of appraisal law and not, for example, the proper dollar amount that should be awarded a particular victim.

Dissenting opinions, whenever rendered, are included.

Griggs et al. v. Duke Power Company 401 U. S. 424 (1971)

Facts. Prior to the effective date of the Civil Rights Act of 1964 (July 2, 1965), Duke Power Company openly discriminated against blacks. Of five divisions, blacks were employed only in the labor department, where the highest possible wage was lower than the lowest wage in any other division. On July 2, 1965, the company replaced this policy with one requiring a high school diploma, or a minimum score on two standard intelligence tests. The stated purpose of the new requirement was to improve the overall quality of the work force. These requirements were not job related, however, and had a disparate impact on black workers.

The promoticn and seniority systems were also challenged. The incumbent programs operated within each division. A black worker who wanted to transfer to a division with better compensation and conditions would forfeit all seniority when vying for promotions, and promotions were based on departmental seniority. 
The effect of the policy was to maintain the favored position enjoyed by whites, while continuing the effects of past discrimination against blacks. Griggs filed suit, alleging that required employment testing was not job related and resulted in adverse impact. Duke was also charged with maintaining policies that, while not in themselves discriminatory, continued the effects of prior discrimination in violation of the Civil Rights Act of 1964.

Decision. The Supreme Court ruled in favor of Griggs.

Issues. Are employment practices that result in disparate impact allowable if the resultant discrimination is unintentional?

May employers demand successful performance on non-related job measures as a condition of employment, if the purpose is to improve the general quality of the work force?

Rule of Law. Title VIl of the Civil Rights Act of 1964; Equal Employment Opportunity Commission Guidelines.

Rationale. The purpose of anti-discriminatory legislation is the removal of unnecessary barriers to employment that adversely affect protected classes. Both disparate treatment and disparate impact are forbidden. Lack of intent to discriminate does not permit practices that favor one group over another. Motivation is not the concern of the law; the consequence for the employee is.

Congress has not commanded that the less qualified be preferred over the better qualified simply because of minority origins. Far from disparaging job qualifications as such, Congress has 
made such qualifications the controlling factor, so that race, religion, nationality, and sex become irrelevant (p. 436).

If testing is a condition of employment, even if the purpose is to upgrade the work force, the test must be validated to show its relationship with important aspects of the job, if it disqualifies disproportionately large numbers of members of protected classes.

Tests that appear to be neutral, even if they are used with no intent to discriminate, are not permitted if they result in adverse impact, or if they serve to continue the effects of past discrimination. Justice Burger, in delivering the opinion of the court, stated: " . . . any test used must measure the person for the job and not the person in the abstract" (p. 436).

Tidwell V. American Oil Company 332 F. Supp. 424 (1971)

Eacts. American Oil had a history of discriminatory practices. Although the company was located in a racially and ethnically diverse population, only seven of 773 employees were minorities, and none were black.

Tidwell was hired by American Oil Company in 1961. Her evaluations had been excellent. In 1966, Tidwell was asked to falsify the test scores of a black applicant. When Tidwell refused, she was given the option of resigning, or being fired. 
After seeking counsel, Tidwell chose to be fired, then brought suit. Tidwell alleged that her employment had been terminated because of her refusal to engage in racial discrimination.

Decision. The District Court ruled in favor of Tidwell.

Issues. When specific and accurate evidence is lacking, are other means permissible to substantiate a charge of discriminatory employment practices?

Does the employer bear the responsibility for losses suffered by an employee when a supervisor, acting in an authorized capacity, discriminates against the employee?

Rule of Law. Title VIl of the Civil Rights Act of 1964.

Rationale. When direct evidence is not available in a case of employment discrimination, inferences may be drawn from the work environment. Attitudes, events, and arguments presented in the case may serve as evidence.The organization bears responsibility for the actions of supervisors when they act in official capacity. When these acts are discriminatory, the organization bears the liability for losses suffered.

Rowe et al. V. General Motors Corporation 457 F. 2d 348 (1972)

Eacts. Until 1962, General Motors hired blacks only for a few custodial jobs. In 1962, all jobs were opened to anyone. There were two ways a worker could advance from hourly to salaried position. The employee's foreman could recommend advancement, or the employee could request advancement and then seek the fore- 
man's approval. Either way, the foreman's recommendation was required. Foremen received no written instruction on performance appraisal. Evaluations were subjective, based on personal judgement. Job openings and requirements were not posted.

General Motors had instigated an aggressive program to combat discriminatory hiring practices. Information on avoiding discriminatory practices was distributed throughout the organization. The corporation began a program for hiring the hard core unemployed of all races. A program involving ten black colleges provided equipment, training, and summer jobs. Blacks were actively recruited. However, although the company promoted affirmative hiring practices, advancement opportunities for minorities within the organization were limited.

Plaintiff Rowe sought promotion, and was denied. He brought suit, alleging racial discrimination in employment practices.

Decision. The Court of Appeals ruled in favor of Rowe.

Issue. Are informal performance appraisals discriminatory, and therefore not permissible?

Bule of Law. Title VII of the Civil Rights Act of 1964 .

Rationale. All employment practices that favor one individual or group over another, and are not essential to the safety and efficiency of business, are prohibited.

Performance appraisals must be standardized and objective to guard against bias. 
Information about advancement opportunities must be made available to all employees on an equal basis.

Although General Motors testified that discrimination resulting from its employment practices was unintentional, this does not absolve the company of liability. The court interprets the term "intentional" to mean not accidental. Intent does not mean motivation. Because the practice was a common procedure, and not an isolated incident, it was not an accident. Although discrimination may not have been intended, by definition the practice was intentional.

McDonnell Douglas Corporation V. Green 411 U. S. 792 (1973)

Facts. Mechanic Green, a black activist, was laid off in a work force reduction. Protesting that his discharge was racially motivated, Green engaged in illegal and disruptive actions against the corporation. Three weeks after the illegal activities, McDonnell Douglas advertised for mechanics. Green was not rehired. He was told that the decision was based on his disruptive activities.

Green filed suit, alleging that the company violated the Civil Rights Act of 1964. Section 704(a) of the Act forbids discriminatory treatment of employees who protest or try to remedy employment discrimination. Green also alleged that the company violated Section $703(a)(1)$ of the Act, which forbids discrimination in employment. 
The case was tried in District Court. On appeal, the Court of Appeals upheld the lower court verdict favoring McDonnell Douglas on the first count, but reversed on the second charge, allowing Green to appeal in federal court on the second allegation of employment discrimination.The United States Supreme Court agreed to hear the case, recognizing the value of the procedure established by the Court of Appeals for cases alleging employment discrimination.

Decision. The lower court ruled for McDonnell Douglas. The United States Supreme Court vacated the decision. Although Green established a prima facie case of discrimination, and McDonnell Douglas rebutted by showing its actions were based on non-discriminatory reasons, Green was not allowed to give evidence that stated the reasons were pretext. The case was remanded.

Issue. What are the proper court procedures and criteria in alleged violations of Title VII of the Civil Rights Act of 1964?

Rule of Law. Title VII of the Civil Rights Act of 1964.

Rationale. The Supreme Court established the following as procedure for civil rights violations:

The complainant in a Title VII trial carries the initial burden of establishing a prima facie case of racial discrimination. This may be done by showing (i) that the complainant belongs to a racial minority; (ii) that complainent applied and was qualified for a job for which the employer was seeking applicants; (iii) that, despite qualifications, the applicant was rejected, and (iv) that, after his rejection, the position remained open and the employer continued to seek applicants from persons of the 
complainent's qualifications. . . The burden then shifts to the employer, who must show some legitimate, nondiscriminatory reason for the applicant's rejection (p. 802). ... respondent must. . . be afforded a fair opportunity to show that the organization's stated reason for rejection. was in fact pretext (p. 804).

\section{Brito et al. v. Zia Company 478 F. 2d 1200 (1973)}

Eacts. Zia is a government contractor. When a reduction in force became necessary, Zia used a performance appraisal test to determine terminations. The test was subjective, based on the judgement of the evaluators. Two of the three evaluators did not regularly observe èmployees; one evaluator admitted that he appraised employees who did not work for him. Criteria for evaluation included quality and volume of work, job knowledge, dependability, and cooperation. Evaluation conditions were not standardized, and the test was not correlated with job behaviors. Only one evaluator kept records. Spanish surnamed workers scored lower on the evaluation, and were discharged in disproportionate numbers.

Brito was hired in December, 1967, and was terminated seven months later in a reduction of force. He filed a charge of discrimination based on national origin and race with the Equal Employment Opportunity Commission. Under the settlement, Zia rehired Brito, and agreed to eliminate discriminatory employment practices. A week after his return to work, Brito was discharged because of low test scores. 
Brito filed suit, alleging that the employer's test was subjective and was not correlated with work behaviors, thus violating the Civil Rights Act of 1964 which prohibits informal testing procedures that result in adverse impact.

Decision. The court ruled in favor of Brito.

Issue. Do informal appraisal procedures that disqualify a disproportionate number of minority workers, even if based on the best judgement of evaluators, constitute a discriminatory employment practice?

Rule of Law. Title VII of the Civil Rights Act of 1964; Equal Employment Opportunity Commission Guidelines. (The EEOC Guidelines clarified the testing regulations established by the Civil Rights Act of 1964, but were themselves replaced by the Uniform Guidelines on Employee Selection Procedures of 1978.) Rationale. Informal testing procedures allow the opportunity for bias, promoting discrimination. Performance appraisal is in fact a test, and must comply with Equal Employment Opportunity Guidelines for testing. Appraisals must be objective, validated for correlation with significant job activities, administered and scored by trained evaluators under standardized conditions, and records must be kept.

United States $v . N$. L. Industries, Inc. 479 F. $2 d 354$ (1973)

Facts. N. L. Industries had a history of discriminatory practices in hiring, promotion, and seniority. Prior to 1962, the labor 
department was made up exclusively of blacks. In 1963, workers in this department were allowed to transfer from labor to other departments. Workers in other departments had always had this right. Seniority for vacation time, job bidding, and insurance was based on length of time employed at the plant. However, seniority for layoff and recall was based on the amount of time worked in the department. If an employee chose to bid into another department, the worker would lose all seniority in case of a work force reduction. As a result, he would be the first to be laid off, and the last recalled. The risk for blacks was too great, and effectively prevented them from bidding out of labor and into other departments.

Promotion to foreman was based on the subjective evaluation of the current foreman. In 1967 the company compiled a list of thirty-seven blacks considered suitable for the position of foreman. By the time of the trial six years later, none had been promoted. Twenty-six whites had been advanced during that time, some with less education and experience than the black applicants.

Blacks were not hired in laboratory and clerical positions. Upon application, a number of blacks had been evaluated by a test developed on the spot. In one case, an applicant was handed a scrap of paper on which some math problems had been jotted and was required to perform the operations without a comptometer. Another applicant was required to take five minutes of dictation 
first from a technical manual at the speed of about eighty words per minute.

The United States Attorney General brought action against the company, alleging that its selection procedures were subjective and lacking written guidelines; as such they were discriminatory and violated the Civil Rights Act of 1964.

Decision. The Court of Appeals ruled in favor of the United States.

Issues. What testing criteria are to be followed to avoid discriminatory practices?

Is an employer liable for discriminatory acts if unaware that such acts violate the law?

Rule of Law. Title VII of the Civil Rights Act of 1964; Equal Employment Opportunity Commission Guidelines (since replaced by the Uniform Guidelines on Employee Selection Procedures of 1978).

Rationale. To avoid discriminatory practices, tests must be based on written, objective measures. Employees must be made aware of these criteria. Conditions of testing must be standardized. Evaluations must be conducted by trained personnel, and accurate records kept.

Ignorance is not an acceptable excuse for discriminatory employment practices. The Law is sufficiently clear in its expectations of employers, and the courts have specified what constitutes acceptable and unacceptable practices. 
Albemarle Paper Company v. Moodv et al. 422 U. S. 405 (1975)

Eacts. Alberiarle had a history of racial discrimination.

Prior to 1964 , job lines were segregated. Blacks were relegated to lower paying, less skilled positions, and whites were employed in higher paying higher skilled jobs. In 1968, job lines were merged, supposedly to eliminate discrimination, as promotion was based on seniority within the job lines. However, in reality, the merger only tacked the black job line onto the tail end of the white job line. Whites still received favorable treatment because they held senior jobs.

A second area of discrimination in the company involved testing. In order to work on the skilled lines, the employee was required to have a high school diploma, or pass two tests, the Wonderlic, and the Beta. Incumbent white workers who were unable to met the criteria were not penalized. By the employer's admission, the tests did not improve the general quality of the work force as was intended. In addition, the testing criteria had a disproportionate impact on blacks. The tests failed to meet Equal Employment Opportunity Commission standards in four ways: (1) the test showed no significant job relatedness in five of eight areas, (2) test scores were compared with subjective ratings of untrained supervisors whose evaluations were not based on objective standard criteria, (3) the test sample was not representative of the work force or of job duties, and (4) the workers by 
whom the test was normed were different than those for whom the test was intended; scores achieved by experienced workers were used as standards to evaluate new employees.

Moody et. al. filed a class action suit, alleging discrimination in terms and conditions of employment; specifically in testing, compensation, and seniority.

Decision. The Supreme Court vacated a decision that favored Albemarie, and remanded for action consistent with the opinion.

Issue. What standards must an employer meet to show that tests which have a disparate impact are sufficiently correlated with work behaviors to be acceptable under Title VII of the Civil Rights Act of 1964?

Rule of Law. Title VII of the Civil Rights Act of 1964; Equal Employment Opportunity Commission Guidelines.

Rationale. Tests must be validated by professional standards suggested in Equal Employment Opportunity Commission Guidelines to show job-relatedness. Tests must be objective, administered by trained evaluators under standardized conditions.

Burger Dissenting. Justice Burger emphasized that the guidelines were only intended to be guidelines. They do not require slavish adherence, as this would be both unreasonable and unduly cumbersome. 
Wade et al. V. Mississippi Cooperative Extension Service 528 F. 2D 508 (1976)

Facts. Mississippi Cooperative Extension Service is a government funded agency that sponsors educational and informational programs. Until 1965 the service was totally segregated. A black division, totally staffed by blacks, provided services to blacks. A white division for white clients operated the same way. In 1965 the divisions merged, and began to share facilities. Black county agents were given new titles of associate county agents, while white agents retained the title of county agent. While white extension agents kept their old title, black agents became associate extension home economists. Prior to the merger, all county agents were promoted to the position of county leader. The result of these title changes was, in effect, a demotion for black employees. The only black with supervisory responsibilities under the merger was the former director of the black division.

Between 1965 and 1970, evaluation and promotion were based on five criteria: education, seniority, job knowledge, performance, and understanding of job responsibilities. The relative weight of the criteria was left to the discretion of the evaluator. Vacancies were not posted.

In late 1969, Wade, a black associate county agent, applied for advancement, but was denied promotion. The vacancy was filled by a white man with less education and eleven years less experience. The reason given for Wade's rejection was that the 
county would not accept a black agent.Wade filed suit, alleging employment discrimination because of race.

Decision. The court ruled in favor of Wade, with aspects of the case being vacated, reversed, and remanded.

Issue. What criteria in employee evaluation are demanded to eliminate discriminatory employment practices?

Rule of Law. Title VII of the Civil Rights Act of 1964.

Rationale. Subjective evaluations invite bias and consequent discrimination. Performance appraisal must be based on written standards which are objective, and validated to show correlation with significant job activities. The relative weight attached to each standard must be predetermined.

Washington, Mavor of Washington. D. C. V. Davis et al. 426 U. S. 229 (1976)

Facts. The Washington, D. C. Police Department had an aggressive program of minority recruitment. Since 1969, forty-four percent of the force has been black, a figure in proportion to the qualified labor pool.

The department required a written examination designed to measure applicant's ability in written and oral communication. The department contended that oral and written communication skills were essential to job performance, and the test was therefore an appropriate measurement tool. Also, as the training 
program dealt with skills and problems intrinsic to the job, the practice was valid.

Unsuccessful black applicants charged that the department's recruitment practices were discriminatory. Davis et. al. brought suit, alleging that testing and training were not job related, and that they disqualified a disproportionate number of blacks.

Decision. The Supreme Court ruled in favor of Washington. Issue. Are racially neutral requirements for employment that have a disparate impact on minorities permissible, if the job requirements are sufficiently job related?

Rule of Law. Title VII of the Civil Rights Act of 1964; Equal Employment Opportunity Commission Guidelines.

Rationale. When requirements for employment are racially neutral and do not discriminate against qualified blacks, the fact that a greater percentage of blacks fail, does not constitute illegal practice. If all programs non-discriminatory in design, but which in fact benefit or burden one group unequally were unacceptable, there would be serious doubts about the legitimacy of taxes, welfare, and other government programs. Congress did not intend to prevent government agencies from seeking highly qualified work forces by proscribing standards that require more than minimal competence. Oral and written communication skills are essential to adequate performance of police duties, and it is appropriate to evaluate these skills in applicants. Because training 
familiarizes recruits with skills and problems involved in the job, adequate job relatedness is present. The standards here are not as rigid as those established in Griggs and Albemarle, but they are more reasonable for this particular situation.

Brennan Dissenting. This decision does not present a more reasonable standard of validation. It severely weakens regulations that protect minorities from employment discrimination. The judgement was faulty in that it did not conform to precedent. Testing and training were not based on job analysis. There was no validation demonstrating significant correlation between testing/training and job performance. Evaluation criteria were not fully described. This ruling is flawed both in substance and procedure.

Mount Healthy School District Board of Education v. Doyle $429 \mathrm{U}$. S. 274 (1977)

Facts. Doyle, a non-tenured teacher, was refused renewal of his contract. Although not required to state the reasons for dismissal in the case of non-tenure, the school board specified its reasons. Doyle had sworn at students, made obscene gestures to them, and had publicly criticized the school. Doyle brought suit, alleging that his rights to free speech and due process had been violated.

Decision. The appellate court ruled in favor of Doyle, but the United States Supreme Court vacated the decision. The case was 
remanded to determine if Doyle's constitutional rights had been violated.

Issue. If the exercise of a constitutional right plays a substantial part in an employment decision, is the action taken by the employer necessarily unconstitutional?

Rule of Law. Amendments I and XIV, United States Constitution.

Rationale. There is a balance between the exercise of a constitutional right, such as the right to free speech, and the need of a state to efficiently govern and provide services. The balance protects against the denial of those rights, while discouraging undesirable consequences or actions because of the exercise of those rights. An individual should not be able to benefit from undesirable behavior by invoking constitutional protection. Even if the major reason for punitive action was for the exercise of a protected right, if the same decision would have been reached regardless, the employer's actions may be permissible.

Elowers v. Crouch-Walker Corporation 552 F. 2d 1277 (1977)

Eacts. Flowers, a black bricklayer, had worked for CrouchWalker for four years, when he was transferred to a new construction site. Prior to his transfer, the company recognized Flowers for his excellent work.

Flowers had never worked under the new supervisor. A few minutes after he began, the supervisor criticized Flower's work, 
ordering him to redo the wall. That same morning the supervisor examined Flower's tools and found fault with his jointer. Flowers borrowed a jointer for the remainder of the day, and purchased a new one that evening. While at the site, Flowers was assigned to supervise the only apprentice working on the project. Three days later, the supervisor terminated Flowers, citing a shortage of work. There were two new white bricklayers at the site the following day. When Flowers asked the president of the company why he had been dismissed, the president investigated the matter and told Flowers that the owners of the project had been unhappy with his work. Flowers sued the company, alleging that racial discrimination was the cause of his arbitrary termination from a job that he had performed satisfactorily, and which was subsequently filled by a new white employee.

Decision. The court ruled in favor of Flowers.

Issues. Who bears responsibility for the discriminatory actions of supervisors when they are acting in their authorized capacity?

Can action be taken against an employee when work is judged to be unsatisfactory if the employee is not made aware of the problem?

Rule of Law. Title VII of the Civil Rights Act of 1964.

Rationale. The organization is responsible for the civil rights violations caused by supervisors in their official capacity. 
If an employer does not tell a worker of unsatisfactory work, action cannot be taken because of unacceptable performance. Before action can be taken for unacceptable performance, the worker must be made aware of the problem and given adequate time for improvement. If action is taken without discussing the situation with the employee and allowing time for improvement, it may be assumed that some factor of bias is involved.

Furnce Construction Corporation v. Waters et al. 438 U. S. 567 (1978)

Facts. Following industry practice, Furnco does not maintain a permanent crew of bricklayers. A supervisor is hired for each job, and in turn hires a qualified crew. The crew is generally made up of bricklayers who have worked with the supervisor on other jobs, or experienced bricklayers recommended by the crew. There is no on-the-job training, and applications are not accepted at the site. For safety reasons, only excellent bricklayers are hired. Poor quality work would be dangerous, and would result in shutdowns and layoffs. The company's reputation would suffer irreparably.

Furnco has an aggressive affirmation action program. Their goal is a sixteen percent black work force, which is a significantly greater percentage than blacks in the qualified labor pool. At the time of the trial, 13.3 percent of the work force was black. Prior to the alleged incident, to demonstrate Furnco's commitment 
to non-discriminatory labor practices, the general manager had hired three blacks who had previously filed discrimination suits.

Waters and two other black bricklayers applied at the site, but were denied positions. They filed suit, alleging racial discrimination.

Decision. The Supreme Court ruled in favor of Furnco.

Issues. Is an employer required to utilize practices which maximize opportunities for minorities? When a prima facie case of discrimination is shown, are statistics alone enough to rebut the charge?

Bule of Law. Title VII of the Civil Rights Act of 1964.

Rationale. Employment decisions based on non-discriminatory practices do not have to maximize opportunities for minorities. Each person is to be treated equally regardless of race, color, religion, sex, or national origin.

Statistics indicating a racially balanced work force may be used to rebut a prima facie case of discrimination. They do not stand alone as proof, but rather suggest intent and employment patterns. At the very least, they are not irrelevant, and may be considered by the court in an employer's defense.

Marshall and Brennan Dissenting. Justices Marshall and Brennan questioned the majority opinion that found Furnco's hiring practices acceptable. The foreman used methods not specified in court records to hire blacks. However, the dissenting justices did not accept the findings of the majority that the use of word of 
mouth recommendations or rehiring previous employees were not discriminatory hiring methods, particularly because no blacks were on the lists of recommendations or previous hires. The two justices did not agree with the court opinion that sufficient business necessity was evident to allow continued use of Furnco's hiring methods, and pleaded for remand.

Greenspan et al.v. Automobile Club of Michigan 495 F. Supp. 1021 (1980)

Facts. Most employees of the Automobile Club of Michigan were women. Women were relegated to lower paying jobs and greatly underrepresented in higher paying managerial positions. In some situations men and women performed basically the same work, but had different titles. The men received greater compensation. Advancement for women was difficult. Management openings were not announced or posted. When women did find out about an opening, they were unable to apply without the approval and recommendation of their manager. This recommendation, like other performance evaluations, was subjective and not standardized.

In 1973, the company began to institute policies to comply with EEOC guidelines. Job descriptions were developed, many women were given management titles and supervisory responsibility, and management jobs were posted and open to women. However, job descriptions were based on manager's ideas about the 
job, and not on job analysis. There was little or no input from employees who performed the work, and no on-site visitation to validate results. Job descriptions were not stated in objective terms, and conditions for evaluations were not standardized. Most of the women given management titles and supervisory responsibility remained in clerical positions. Management jobs that were posted often required experience in positions that had only been available to men.

Greenspan was asked to assume greater responsibility with no reduction in other duties and with no additional compensation. When she declined, the position was given to a man at almost double the salary and with fewer responsibilities. When Greenspan left the company because of alleged continued sex discrimination, her male replacement was given a salary 65 percent greater than hers. Greenspan and five other women brought suit against the company, alleging gender discrimination in conditions and terms of employment.

Decision. The court ruled in favor of Greenspan.

Issue. Are employment practices such as job posting, job descriptions and requirements, compensation and promotion, that act to the disadvantage of women, permissible when not warranted by business necessity?

Rule of Law. Title VII of the Civil Rights Act of 1964.

Rationale. Employment evaluations that are subjective, unvalidated, and not standardized offer the opportunity for discrimi- 
nation, and are not allowed. Procedures for evaluation and promotion must be objective, validated, and standardized.

Equal Employment Opportunity Commission v. Sandia Corporation 639 F. $2 d 600$ (1980)

Facts. Sandia is an engineering and research corporation. All of Sandia's contracts are with the government, and consequently all of its funding is from federal sources. Its reliance on government contracts results in dramatic fluctuations in its labor force.

Sandia perceived its older workers as less able to keep up with advances in technology, and therefore as less productive. The organization recruited young $\mathrm{Ph}$. D.s, while at the same time it.encouraged termination of older employees. Various means were used to lower the age of the work force, including the suggestion or threat of retirement.

Termination in the face of work load reduction was based on performance appraisal. The appraisal process was subjective and never validated. The result was a disproportionate termination of workers between the ages of fifty two to sixty fouir.

Based on statistics and evidence (memos, records) the EEOC brought suit alleging age discrimination in determining termination on the basis of unvalidated performance appraisals.

Decision. The Court of Appeals ruled in favor of the EEOC.

Issues. Is a prima facie case of discrimination offset by the burden on the company to drastically reduce its labor force? 
Are victims entitled to relief?

Rule of Law. The Age Discrimination in Employment Act of 1967.

Rationale. Statistical and other evidence indicates that Sandia engaged in a pattern and practice of age discrimination as a matter of corporate policy. Although the organization was required to undergo a painful reduction in force, the criteria used for termination were subjective and had not been validated. As such, the company could not defend its actions on the basis of business necessity.

Victims are entitled to compensation that would put them in the same position they would have been in were it not for the discrimination they had suffered.

Parson v. Kaiser Aluminum And Chemical Corp. 497 F. Supp. 339 (1980)

Facts. Prior to 1965, Kaiser hired only white foremen. There were no written standards or objective criteria for employee evaluations. Advancement opportunities were not posted. In 1968, Kaiser began a concerted effort to end employment discrimination. Job openings were posted, evaluations were made more objective, and efforts were made to recruit and train blacks. Despite efforts, however, the overwhelming majority of upper level, higher paying jobs were held by whites. 
Vacancies for skilled positions were filled following an oral interview. The interview was a question and discussion situation that allowed workers to demonstrate the extent of their knowledge, rather than confine answers to specific questions. Although the skilled positions required previous experience, this demand was sometimes waived after an oral interview. The purported idea for the waiver was that this would allow positions to be more easily filled by blacks.

Parson had first applied for a foreman job in 1966, but his request was denied. Despite Parson's continued efforts, his request was repeatedly denied, although several white workers with less seniority had been advanced to foreman. Parson's work record was not exceptional. Records indicate that his technical skill was excellent, but his performance was below average. In addition, P.arson was a vocal, and at times, confrontational, black activist in the company.

Kaiser experienced severe racial tensions. Their antidiscriminatory efforts resulted in work slowdowns, sabotage, and confrontation. The company was hesitant to put Parson in a supervisory position, fearing that this particular appointment might result in injury or property damage.Parson sued, alleging that Kaiser discriminated in employment by using different standards for evaluation that favored whites over minority employees.

Decision. The District Court ruled in favor of Parson. The Court of Appeals affirmed the decision, and the Supreme Court de- 
nied certiorari. The court recognized Kaiser's desperate situation, noting that although the burden was excessively heavy, it must still be borne. The court pleaded for a "temperate approach" ( $p$. 347) in appeals.

Issues. Are employment practices designed to facilitate the advancement of minorities, but which involve differential treatment, allowable?

Can a discriminatory act be justified because it is the best management decision?

Rule of Law. Title VII of the Civil Rights Act of 1964.

Rationale. Any employment practice that selectively favors one individual or group over another, even if the intent of the practice is to remedy past wrongs, is not permissible. Any practice that allows for the selective benefit of employees, in effect, allows the opportunity for discrimination against those who the actions were designed to protect.Good management decisions are not necessarily essential to business necessity. Kaiser's position in failing to promote was understandable, yet unacceptable. Fear of reprisal does not justify discrimination, even in the face of efforts to remedy past discrimination.

Stastny et al. v. Southern Bell Telephone And Telegraph Company 628 F. 2d 267 (1980)

Facts. In January, 1973, the Equal Employment Opportunity Commission, the Lepartment of Justice, and the Department of La- 
bor accused Southern Bell Telephone and Telegraph Company of sexual and racial discrimination. The company was ordered to begin affirmative action for women and minorities. In 1975 Stastny and other women brought individual and class action suits, alleging discrimination in compensation, promotion, and conditions of employment, resulting in class wide discrimination based on gender. Among other charges was the allegation that performance appraisal operated against women because the appraisals were subjective, and administered by male supervisors.

Decision. Individual allegations of Stastny and other plaintiffs were upheld; class action charges were dismissed.

Issue. Are subjective performance appraisals that result in disparate impact permissible?

Bule of Law. Title VII of the Civil Rights Act of 1964.

Rationale. Appraisals that allow subjective evaluations afford the opportunity for bias and are therefore prohibited.

\section{SUMMARY OF NON-ACADEMIC DECISIONS}

What issues, patterns, and decisions concerning performance appraisal have been identified through the judicial process, and what degree of consistency has been shown in court decisions? The following review answers the second research question.

A review of pertinent case law reveals four motifs concerning performance appraisal that have emerged through the judicial system. The court has clarified the philosophical framework 
of anti-discrimination law, specified court procedure to be followed in a legal challenge to employment practices, established standards for employment testing, and defined operational guidelines for employee evaluation. In some circumstances properties may be applicable to more than one category. For example, the specification that employers must provide written objectives stating job requirements and qualifications falls under the concept of "operational guidelines." This property (written guidelines) is contained in three categories within this concept. Written guidelines are an aspect of performance appraisal that reflect objectivity, standardization, and employee involvement.

\section{Philosophical Framework.}

The court addresses two basic types of employment discrimination: disparate treatment, and disparate impact. Because the measure of disparate impact is the effect of an employment practice or procedure on a group, allegations of disparate impact are generally leveled in class action suits.

Guidelines for determining the appropriateness of a class action suit were outlined in Stastny v. Southern Bell Telephone and Telegraph Co. (628 F. 2d 267, 1980). A class action suit alleges that patterns or practices of the employer discriminate against an entire protected class of workers. To bring suit, there must be a sufficiently homogeneous class affected by the employer's actions. The discrimination issues must be common to 
class members. There must be sufficient proof to proceed with the case.

Charges of disparate treatment are usually brought in individual cases of discrimination (Stastny v. Southern Bell Telephone and Telegraph, 628 F. 2d 267, 1980).

Disparate Treatment. Disparate treatment means that one group or individual is treated less favorably because of race, sex, color, religion, or national origin. It is the most obvious type of discrimination. It exists in an organization when an employment pattern or practice is used with the intent to discriminate against individuals of a protected class by treating them different (Greenspan, 1980). Intent means that the policy or procedure was established as part of the organization's customary operation, or that it was the result of personal prejudice. The courts determine disparate treatment by what actually occurs, not by accepting unverifiable statements of purpose. That an employer says discrimination was not intended, that it was not realized that particular practices were discriminatory, does not absolve the organization from responsibility, and does not permit or justify discrimination (Rowe, 1972).

The only justification for disparate treatment is legitimate business necessity (Griggs, 1971).

This doctrine of business necessity, which has risen as an exception to the amenability of discriminatory practices, 'connotes an irresistible demand.' The system in question must not only foster safety and efficiency, but 
must be essential to that goal (United States v. St. Louis San Francisco Railway Co. 464 F. 2d 301, 308 1972).

Different procedure and practices for members of protected classes are not allowable if they provide an opportunity for unlawful discrimination. This holds true, even when the special treatment is designed to overcome the results of previous discrimination. If the practice, however well intended, may cause further discrimination, it is not acceptable (Tidwell, 1971). Employers are not required to maximize opportunities for minorities. Each person is to receive the same treatment regardless of race, color, religion, sex, or national origin (Furnco, 1978).

A balanced work force, that is, one without evidence of adverse impact, does not absolve the employer in individual cases of disparate treatmen! (Furnco, 1978). In such cases, reliance on statistics to support allegations of discrimination may be less compelling because an individual represents a small sample size (Johnson, 1977).

If an individual is discriminated against because of the exercise of a constitutionally protected right, this alone does not mean the action taken against the employee is unwarranted. For example, the right to free speech does not allow a teacher to use abusive and profane language in the classroom. Even if the exercise of a constitutionally protected right is the main reason for disparate treatment, if the employee's conduct alone is reason enough for punitive measures, the action against the worker may be permissible. Otherwise, an emplovee could engage in unaccept- 
able behavior, hiding behind the constitution, and the employer would be unable to take action (Mount Healthy, 1973).

Disparate Impact. Disparate impact refers to practices that are applied uniformly to all, but which in fact are more burdensome to members of a protected class.

Disparate impact is more difficult to prove than disparate treatment. Statistics may be used to establish a case of discrimination (McDonnell Douglas Corporation v. Green, 1973; Wade v. Mississippi Cooperative Extension Service, 1976; Parson v. Kaiser Aluminum and Chemical Corporation, 1980).

Statistics alone do not tell the whole story. Other acceptable evidence to support a claim of disparate impact may inciude inferences about the work environment and conditions, activities of the organization, demonstrated attitudes towards protected classes, and any history of discrimination (Tidwell v. American Oil Company, 1971).

Equal opportunity for employment must be provided for all, regardless of the percentage of a protected class represented in the work force. Lack of adverse impact is not necessarily the same as lack of discrimination. A balanced work force, that is one without evidence of adverse impact, does not absolve the employer in individual cases of disparate treatment (Furnco Construction Company v. Waters, 1978 ).

As with disparate treatment, the consequences and results of employment decisions are what concern the court, not the in- 
tent. Procedures which have a disparate impact as the result of maintaining past discriminatory practices are not permitted. Residual discrimination must be remedied (Griggs v. Duke Power Company, 1970). Even if an organization does not discriminate at the time of the trial, it will be judged on its actions at the time the charge was brought (Tidwell v. American Oil Company, 1971; Rowe v. General Motors Corporation, 1972).

The degree of discrimination is not a factor. Discriminating just a little is not acceptable. By the same token employment programs (such as a successful Affirmative Action plan) in one area of the organization do not offset discrimination in another part of the organization (Rowe v. General Motors Corporation, 1972).

Legitimate business necessity is a justifiable reason to tolerate practices which result in disparate impact. These practices must be essential to safety and efficiency. The cost to an organization of compliance with anti-discrimination legislation, however high, is not an acceptable business justification for discrimination (United States v. N. L. Industries, Inc. 1973). Nor is the fact that a particular employment practice is the best management decision an acceptable reason to discriminate (Parson $v$. Kaiser Aluminum and Chemical Corporation, 1980).

Ignorance of the law is not an excuse. Employers and unions are liable for their actions, even when they are not aware that their practices are discriminatory. When an employer authorizes an individual to act for the organization, the employer bears the 
responsibilities and consequences for authorized acts. If these acts involve civil rights violations, the employer is liable (Tidwell, 1971; Flowers, 1977). Employment rights cannot be bargained away (United States v. N. L. Industries 1973).

If an employee refuses to comply with a supervisor's request to engage in a discriminatory act, the employee may not suffer negative consequences as a result (Tidwell, 1971).

\section{Court Procedure}

In McDonnell Douglas Corporation v. Green (1973) the United States Supreme Court established the procedure to follow in a legal challenge to employment discrimination. This has become the accepted method for all cases.

First, the plaintiff establishes a prima facie case of discrimination. That is, the plaintiff is a member of a protected ciass. The plaintiff was qualified for the position, applied, and was rejected. After the plaintiff was rejected, the position remained open and the employer continued to seek applicants, or the position was filled by someone less qualified.

Next, the defendant presents evidence to show that the reason for the practice is non-discriminatory.

Finally, the plaintiff demonstrates that the reasons given were untrue or a pretext for discrimination.

The procedure established in the McDonnell Douglas case was further defined in Furnco Construction Company v. Waters (1978). 
If a prima facie case of discrimination is presented, the employer may use statistics of a balanced work force to rebut the charge. Statistics may not be sufficient in themselves to carry the case, but they should be considered by the court as an indication of employment practices and patterns.

\section{Iesting Standards}

The Griggs decision (1970) first began a heavy reliance on statistics to substantiate or refute allegations of discrimination in employment evaluation.

Employment tests must be a representative measure of job performance. Tests should be validated to show the relationship between the instrument and the job (Griggs, 1970; Brito, 1973; United States v. N. L. Industries, 1973). Validation is mandated, however, only when adverse impact or a prima facie case of discrimination is indicated (Griggs, 1970: Albemarle, 1975).

Validation based on subjective ratings is not acceptable (Albemarle, 1975).

Albemarle (1975) stipulates emphatically that validation adhere to standards established by the Uniform Guidelines on Employee Selection Procedure. This writ is somewhat weakened by a strong dissent of the opinion. Justice Burger cautioned that the guidelines were just that - guidelines, not rigid mandates. He argues that absolute compliance is unreasonable. However, subse- 
quent decisions have strengthened the majority opinion by continued reliance on this landmark case as precedent.

Tests must be validated and based on a representative sample of work and workers (Brito, 1973; Albemarle, 1973; United States v. N. L. Industries, 1973). Examiners must have adequate testing expertise or training (United States v. N. L. Industries, 1973).

The question of using tests to promote a highly qualified work force has rendered conflicting opinions.

You may recall that in Griggs v. Duke Power Company (1970) the company required either a high school diploma or a minimum score on two intelligence tests. The company used the requirements as a means to improve the overall quality of the work force. Because the results of the tests had an adverse impact, and the requirements were not job related, the practice was found unacceptable by the courts.

Again in Albemarle Paper Company v. Moody (1975) the court reaffirmed that tests must be validated to show job-relatedness if they result in adverse impact.

However, in Washington v. Davis (1976) the court was divided. Although employment tests administered to applicants for the Washington, D. C. Police Department demonstrated adverse impact, the court ruled that the practice was acceptable.

The police department argued that these tests were necessary to ensure a police force of high caliber. The court considered 
the police department a government agency, and noted that Congress did not intend such organizations to accept the minimum possible ability level in its work force.

There was some question regarding the degree to which these requirements were job related; the court was divided on this issue. The court admitted that the standards were less restrictive than those decreed by Griggs (1970) and Albemarle (1975), but stated that they were appropriate for this situation. (Recall Llewellyn's statement: "This rule only holds of redheaded Walpoles in pale magenta Buick cars" [1930, p. 73]). Although the court did not overturn the prior decisions, by redefining the scope of the interpretation, precedent was downplayed.

Justice Brennan dissented. The ruling, in his opinion, contradicted the two landmark cases in employment discrimination, and this disiegard for precedent severely weakens efforts to end employment discrimination. He did not accept the argument that testing in this case was a valid criterion as it was not based on job analysis.

As it is now, the court's stance is that a practice is not necessarily unconstitutional because it results in adverse impact. A neutral standard that disqualifies a greater number of minorities may be acceptable depending upon specifics of the situation. The justices point out that it is naive to expect procedures that are designed to benefit all equally in fact to do so. The holding in Washington V. Davis (1976) specified that government agencies 
may use tests to upgrade the quality of the work force, and did not require job analysis to determine the validity of the procedure.

Is it permissible to require employment tests for the purpose of developing a highly qualified work force if they result in adverse impact and show a questionable relationship between the evaluation instrument and desirable work behaviors or outcomes? The jury may still be out, but it seems prudent for an organization to assure that all testing is properly validated and based on job analysis.

Qperational Guidelines:

Objectivity. Evaluation standards must be specific and objective (Rowe, 1972; Brito, 1973; Wade, 1976; United States v. N. L. Industries, 1976; Greenspan, 1980; Parson, 1980; Equal Employment Opportunity Commission v. Sandia, 1980); they must be job related (Albemarle, 1975).

Employees must be notified of job qualifications and requirements (Rowe, 1972; United States v. N.L.Industries, 1976).

Subjectivity allows conscious or unconscious discrimination, and so is not permissible. (Wade, 1976). Even when an evaluator makes a decision based on the best possible judgement, if it is subjective, it is not allowable (Brito, 1973).

Evaluation instruments must meet professional standards. It is not enough to adapt or adopt a procedure that seems appropri- 
ate. Proper validation of objective criteria is necessary (Greenspan, 1980).

Job descriptions and qualifications must be stated in specific, objective terms (United States v. N. L. Industries, 1973).

Standardization. All employment evaluation procedures must be formalized (Brito, 1973).

Evaluators must have written instructions specifying qualifications and standards, and employees must be made aware of these criteria (Rowe, 1972; United States v. N. L. Industries, 1973; Wade, 1976). Test administration is to be standardized (Brito, 1973; Albemarle, 1975).

Scoring must also be standardized (Brito, 1973; Albemarle, 1975). If a number of factors are considered in making a decision, the relative weight of each must be fixed (Wade, 1976).

Emplovee Participation in Evaluation. Employees must be aware of evaluation criteria and procedures (Flowers, 1977; Greenspan, 1980).

If work is accepted without any indication that it does not meet standards, then substandard performance cannot be used as grounds for punitive actions. Silence on the part of the employer assumes acceptance. The employee does not need to prove that job performance was acceptable. The worker need only show that if the work did not meet standards, this was not communicated, and no means of remedy, or sufficient time to improve were provided (Flowers, 1977). 
Performance appraisals and the job descriptions they were based on should be signed by the employee (Greenspan, 1980).

Training and Promotion. Information regarding training and promotion opportunities and the application procedure is to be made available to all employees (Rowe, 1972).

Job openings are to be posted and information made available so that all potential candidates have an equal opportunity for hiring and promotion (Greenspan, 1980; Stastny, 1980).

Records. All employment decisions must be documented (United States v. N.L.Industries, 1973).

If work is unsatisfactory, records must indicate how it compares to other employees' performance, or to established standards (Flowers, 1977).

Records must be secure to protect the individuals' privacy. Records are to be used only for the purpose for which they were intended (Brito, 1973).

The judicial process has identified standards for basic performance appraisal that may be approached within the framework of four motifs: philosophical framework, court procedures, testing standards, and operational guidelines. Are these same standards and motifs applied consistently in cases involving postsecondary education? 


\section{JUDICIAL STANDARDS FOR POST SECONDARY EDUCATION}

In deciding issues of alleged employment discrimination against professional employees in post secondary education, the courts have rendered decisions that diametrically oppose the rationales applied to other employment situations. Most cases involving post secondary education do not advance to the supreme court, but are settled in the lower courts. This may be because of denial of certiorari, as in the case of Powell v. Syracuse University (580 F. $2 d$ 1150, 1978; cert. den. 439 U.S. 984, 1979), or the dismissal of the case in the lower court, as in Johnson v. University of Pittsburgh (435 F. Supp. 1328, 1977).

The Supreme Court holds the position that discrimination in academe should be remedied within the scholarly community without intervention from the outside. This view receives general support in the lower courts, although there has been dissent at all levels. State and district courts have ruled on a far greater number of education cases than the highest court, as is to be expected because of the nature of the judicial system. However, their continued reliance on the concept that colleges are the most appropriate judges of their own behavior is evident. Strong concern has been expressed repeatedly over the continued prevalence of discrimination and lack of remedy in post secondary education. This ambivalence is expressed in legal opinions at all levels of the court system. 
It is within [ the college administrative structure] and within the academic community that problems such as these should be resolved. The courts, state and federal, should be a last resort (Healy v. James, 408 U. S. 169, p. 195, 1972).

Of all fields which the federal courts should hesitate to invade and take over, education and faculty appointments at a university level are probably the least suited for federal court supervision (Faro v. New York University, 502 F. 2d 1229 , p. 1231,1974$)$.

The federal courts cannot of course allow the faculty or university to use facially proper criteria for promotion and tenure to be used as window dressing to disguise what is actually a case of invidious. . . discrimination. To do so would completely wipe out the provisions of the act of Congress in this field which Congress has expressly mandated to be applicable to appointments in educational institutions (Johnson v. University of Pittsburgh, $435 \mathrm{~F}$. Supp. 1328, p 1355, 1977).

On the one hand we have the important problem to whether. . discrimination is operating. . . in the halls of academia. If so, Congress has mandated that it must be eradicated. Colleges and universities must understand this and guide themselves accordingly.

On the other hand we also have the important question as to whether the federal courts are to take over the matter of promotion and tenure for college professors when experts in the field agree that such should not occur. In determining qualifications in such circumstances the court is beyond its field of expertise. . ( (ibid, p. 1371). 
We fear, however, that the common-sense position we took in Faro,namely that courts must be ever mindful of relative institutional competencies, has been pressed beyond all reasonable limits (Powell v. Syracuse, 580 F. 2d 1150, p. 1153, 1978).

It is clear beyond cavil, then, that the Congress has evidenced particular concern for the problem of employment bias in an academic setting. Indeed it might be said that far from taking an anti-interventionist position with respect to the academy, the Congress has instructed us to be particularly sensitive to evidence of academic bias. . . .

It is our task, then, to steer a careful course between excessive intervention in the affairs of the university and the unwarranted tolerance of unlawful behavior. Faro does not, and was never intended to indicate that academic freedom embraces the freedom to discriminate (ibid, p. 1154).

To illustrate the attitude and rationale the courts use in addressing issues of employment discrimination in post secondary education, five cases will be presented in brief form. Two of these cases were decidec by the United States Supreme Court, and three by the lower courts. The issues with which the courts concerned themselves will be noted, and the disparity in standards applied to education and business will be summarized.

Note that in Board of Regents of State College v. Roth (408 U. S. 564,1972$)$, the decision and rationale do not differ appreciably from those in non-education cases. This case is included, however, because it illuminates the perspective of the courts on intervention in post secondary education.

At times, a judge may render a decision in a case that favors one party, yet deliver an opinion that supports the position of the 
other. For example, in Powell v. Syracuse University (580 F. $2 d$ 1150, 1978; cert. den. 439 U.S. 984, 1979), the court ruled in favor of the university on the evidence presented. Even so, Judge Smith leveled a harsh criticism at postsecondary education for its failure to eliminate blatant employment discrimination, and its complicity in promoting bias under the guise of academic freedom.

Board of Regents of State Colleges y. Roth 408 U. S. 564 (1972)

Eacts. At the end of his one year contract with Wisconsin State University, Roth was not granted a renewal. Although he had excellent ratings as a teacher, he had been critical of the university's administration. Roth brought suit, claiming his right to free speech guaranteed by the first amendment had been violated, and that his right to due process under the fourteenth amendment had been denied.

Decision. The Supreme Court ruled partly in favor of the Board of Regents, declaring that nonrenewal of a non-tenured teacher's contract does not deprive the individual of a property right. The court rernanded the case to determine if Roth had in fact been denied renewal because of his exercise of the right of free speech.

Issues Can a non-tenured teacher be denied contract renewal if the action is based on the exercise of the right of free speech? 
Does nonrenewal of a non-tenured teacher's contract entitle the individual to the constitutional right of due process?

Rule of Law. Amendments I and XIV, United States Constitution.

Rationale. Academic freedom is essential to a university. To discharge teachers for the expression of controversial philosophical or political views is untenable. Nonrenewal of a contract as retaliation for the exercise of the right to free speech is unconstitutional. In this case where no reasons for dismissal were given, there is the possibility that the denial was a violation or a protected right. There is a fine line, however, between academic freedom and the orderly administration of a school. In this case the university is not required to give reasons for dismissal, nor does it have to provide a process of review.

Due process is guaranteed only when the individual is deprived of life, liberty, or property. Nonrenewal of a teaching contract that specifies a period of employment does not guarantee an unlimited claim to that property. Property rights are violated only when there is tenure, or when employment is terminated within the period covered by the contract. Nonrenewal does not deprive the individual of liberty unless the action causes damage to reputation, honor, name, or integrity.

Douglass Dissenting. If a teacher can be denied continued employment without the institution being required to demonstrate a legitimate reason for the decision, it can never be ascertained 
that the cause for dismissal was not in retaliation for expression of the constitutionally protected right to free speech. Free speech is the most important academic freedom. When a teacher is terminated, cause should be required.

Marshall Dissenting. Governmental agencies, including schools are not permitted to arbitrarily deny continued employment to their workers. Consequently, a teaching position may be considered a property right, not to be denied without due process.

Perry v. Sindermann 408 U. S. 593 (1972)

Facts. Sindermann had been employed by the state college system of Texas for ten years: the last four had been at Odessa College under a series of one year contracts. Following his fourth year, Sindermann had become involved in a controversy with the administration, at one point testifying to the legislature. Although Sindermann was not allowed a hearing or provided with reasons for his dismissal, the regents of the college issued press releases accusing him of insubordination.

The Coordinating Board of the Texas College and University System established guidelines offering tenure to teachers who had been in the system for a minimum of seven years. The faculty handbook of Odessa stated that, although the college had no formal tenure system, teachers were considered tenured as long as their teaching was considered satisfactory, and they were cooperative and happy. 
Sindermann submitted that under state and college guidelines he had a contract, although implied. When his contract was not renewed, Sindermann alleged that he had been denied property to which he had a legitimate claim. He accused the school of penalizing the exercise of his right to free speech as well, and brought suit alleging violation of rights protected by the first and fourteenth amendments.

Decision. The Supreme Court ruled in favor of Sindermann. Issue. Does an implied condition of tenure constitute a property right protected by the United States Constitution?

Bule of Law. Amendments I and XVI, United States Constitution.

Rationale. Dismissal from a non-tenured position does not necessitate due process, unless the teacher is denied liberty or property. However, in the absence of a formal tenure system when de facto tenure does exist, the guarantee of continued employment may be considered a property right. These circumstances require that the faculty member be provided with reasons for dismissal, and given the opportunity for a hearing to contest those reasons.

Marshall Concurring. Although he concurred that Sindermann was entitled to continued employment, Justice Marshall did not base his reasoning on the denial of a property right because of de facto tenure. Marshall advocates the position that employment by any government institution, including institutions of post secondary education, entitle the individual to continued employment 
unless a legitimate, nonarbitrary reason can be demonstrated as the basis for dismissal.

Equal Employment Qpportunity Commission/White v. Tufts $421 \mathrm{~F}$. Supp. 152 (1975)

Facts. White and Joost were female assistant professors in the Fine Arts Department at Tufts. White was initially hired in 1965 and served on the faculty through the 1972-73 academic year. Joost began teaching at the school in 1969 and was also terminated at the same time. Each alleged that she had been discriminated against in compensation and working conditions because of sex bias.

Joost was hired under a one year contract, and rehired under a three year contract. Her contract was not renewed after her fourth year. Reasons stated were inadequate scholarship, slow progress toward her doctoral degree, and involvement in departmental conflicts.

Joost filed suit, alleging sex discrimination.

White applied for tenure during the 1971-72 academic year. Doctor Galantic, the chair of the Fine Arts Department, was a member of the ter.ure committee. White contacted the Dean of the School of Arts and Sciences and the chair of the tenure committee, requesting that Doctor Galantic be replaced. Both the dean and the chair were aware that Galantic's attitude toward women was disparaging. Several accusations of sex bias had been lodged 
against Galantic by both students and faculty. Galantic had made public his opposition to White's request for tenure, going so far as to solicit letters against her advancement. White's request for Galantic's replacement was denied, and subsequently her request for tenure was denied.

White filed suit, alleging that to be evaluated by someone whose publicly acknowledged sex bias included actions undertaken specifically to discredit her and prevent her advancement constituted sex discrimination.

Decision. The District Court granted relief to White, but denied relief to Joost.

Issue. When denial of tenure is influenced by a committee member whose bias against the applicant's sex is documented, is refusal unlawful?

Rule of Law. Equal Employment Opportunity Act of 1972.

Rationale. The court should not and will not substitute its judgement in matters of tenure for professional for professional educators who are eminently more qualified to make these decisions. Although the courts have generally required employee appraisal to be based on objective criteria, subjective evaluation in education cases is not only permissible, it is essential. When the criteria for evaluation are reasonably related to the needs of the department and the school, and when procedures are applied fairly, there is no cause for intervention. However, if tenure is denied for nonlegitimate or a-bitrary reasons, the courts have the obligation 
to become involved. When evidence indicates that a female applicant was qualified for tenure and in all likelihood would have been granted tenure but for the known bias held by a committee member against woman, the institution is guilty of discrimination.

Johnson $V$. University of Pittsburah 435 F. Supp. 1328 (1977)

Eacts. Doctor Johnson, an assistant biochemistry professor, was unanimously denied promotion and tenure after six years on the faculty of the University of Pittsburgh. Although Johnson's performance had been accepted for six years, she was terminated and replaced by a man. The university's policy was to terminate teachers if they had not been granted tenure within six years. Doctor Johnson's failure to gain tenure resulted in the loss of her job and of grant funds she received for research.

During Doctor Johnson's appointment, there was little departmental direction and morale was low. A third chairman, Doctor Heath, took over. Doctor Heath immediately began a reevaluation of the department's purpose in relationship to the mission of the university. Goals and priorities for research were established. The department's primary purpose was identified as teaching biochemistry to medical students. Because of financial constraints over which he had no control, Doctor Heath was able to meet goals only through a change in non-tenured faculty.

The university presented evidence to show that its termination of Doctor Johnson was based on nondiscriminatory reasons. 
Although teaching was the primary goal of the department, Johnson was given poor ratings by both students and peers. Medical students were so upset by Doctor Johnson's incomprehensible lectures that they swore, shouted, and stormed out of the classroom. Doctor Heath and department faculty attended four of Johnson's lectures, and admitted that they were unable to understand them.

Research was considered another important area in the decision to grant tenure. It was determined that Doctor Johnson's research was not appropriate for the department. Doctor Heath did not convey this information to Doctor Johnson, however, stating that there would have been insufficient time and no purpose in changing her research.

Statistics on the university employment record demonstrated that while forty-five percent of the men in tenure track positions gained tenure, only six percent of the women did. Johnson alleged that her dismissal was the result of sex discrimination.

Decision. The court dismissed the suit entirely.

Issues. Is the court or the university the proper forum to determine tenure?Are subjective evaluations of faculty permissible in as much as subjectivity permits bias?

Rule of Law. Equal Employment Opportunity Act of 1972.

Rationale. Judge Knox characterized postsecondary education as "one of the bastions of male chauvinism" (p. 1351). Congress 
expressed its concern with discrimination in education by the 1972 amendments to Title VII of the Civil Rights Act of 1964 (Equal Employment Opportunity Act). In reality, it is hard to discern the difference between diligence and intrusion. Tenure is an honor, not a right, even when the individual is eminently qualified. It is awarded for superior teaching and research, in accordance with the goals of the university and its departments. Denial of tenure does not question the excellence of the faculty member. It merely indicates that the institution's need at that time would be best met in another way. The nature of teaching and research is such that the academic community, even if it makes poor decisions, is the only appropriate panel to determine the suitability of tenure. The purpose of tenure is to protect academic freedom. Judge Knox states that the courts must intervene, however, when tenure policies are used as a guise to discriminate. If practices are arbitrary or applied unfairly, congress requires the courts to step in. This may be difficult to judge as the court has no intention of applying the same standards in higher education as they do in other types of discrimination cases. To rely on statistics, for example, as proof of discrimination, could lead to the undesirable consequence of encouraging the employment of unqualified personnel. Unlike subjective performance appraisal by a supervisor in a business environment, subjective evaluation in post secondary education is not only permissible; it is essential. Decisions about promotion and tenure cannot be based solely on 
subjective criteria. Faculty may be evaluated in terms of university and departmental purposes, as well as by qualitative judgements concerning teaching ability and appropriateness of research. The court does not demand, however, that a researcher be made aware of the appropriateness of individual research to the university.

Powell v. Syracuse University 580 F. 2d 1150 (1978), certiorari denied 493 U. S. 984 (1979)

Facts. Powell was hired by Syracuse University to teach one class in basic design for the 1972-73 school year. In the spring the Committee on Appointments, Promotion, and Tenure voted not to promote Powell to a full-time position, but to allow her to teach one class in architectural rendering. In December, 1973, the committee again met to consider Powell's continued employment. Based on samples of her students' work, and her own background and experience (Powell was working on her master's thesis, but did not have the degree at that time), the committee decided not to rehire Powell. Later, a white male with a master's degree was hired to teach design. A white female with a doctoral degree was hired to teach architectural history. Powell, a black female, filed suit alleging discrimination based on sex, race, and color.

Decision. The Court of Appeals ruled in favor of Syracuse University. The United States Supreme Court denied certiorari. 
Issue. Are the same standards required to eliminate discriminatory employment practices in business settings appropriate for post secondary education?

Rule of Law. The equal Employment Opportunity Act of 1972. Rationale. Although Powell established a prima facie case of employment discrimination, the university demonstrated that the decision to terminate her employment was based on non-discriminatory reasons. The courts have allowed post secondary institutions to determine how their own needs can best be met in personnel decisions.

Circuit Court Judge Smith did not let the decision favoring the university prevent him from delivering an opinion critical of blatant discriminatory employment practices in post secondary education. He stated that congress did not intend the concept of academic freedom to protect institutions from bearing the responsibility to act without prejudice in their employment practices. He further stated that the courts have gone too far in their failure to require academic institutions to comply with federal anti-discrimination regulation. Educational institutions should not be free from prosecution when they fail to apply fair and impartial standards in employment decisions. The intent of congress has been undermined by the failure of the courts to intervene in academe.

Moore Concurring. Circuit Court Judge Moore supported the decision, but not the reasoning, as it did not account for the dif- 
ferent precedents that have been established for business and education. In cases dealing with tenure, the courts have stated that academic peers are the most suited for determining promotion. Unlike business, employment decisions in post secondary education must necessarily include subjective criteria.

\section{SUMMARY OF APPRAISAL LAW}

Clearly the standards established by the courts in instances of alleged employment discrimination in postsecondary education differ from standards applied to non-academic settings. However, the employment laws applying to postsecondary education can be categorized as they are for business.

\section{Philosophical Stance}

Discrimination is prevalent in higher education. Even so, the courts have ruled that intervention is not warranted unless prejudicial treatment is a guise to conceal retaliation for the exercise of a constitutionally protected right. The United States Supreme Court does not address issues of disparate treatment and disparate impact that dominate cases in non-academic situations. The concern of the higher court does not seem to be whether the plaintiff has been a victim of discrimination, but whether the alleged victim was denied constitutional rights. Questions Of discrimination seem to be relegated to the scrutiny of the lower courts. 


\section{Court Procedure}

The court procedure in cases of employment discrimination in post secondary education follows the format of McDonnell Douglas Corporation v. Green (1973). The plaintiff presents a prima facie case of discrimination, after which the defendant articulates a non-discriminatory reason for the practice, and the plaintiff then presents evidence to show that the reason was pretext. This may be more difficult in education than in business cases, as the courts have generally determined that here statistical evidence of discrimination is insufficient to establish prima facie evidence(Johnson, 1977).

In non-education cases, discrimination is illegal, even if there is no intent to act with bias. The fact that a discriminatory act is part of the iegular process accepted by the organization indicates it is not accidental, but intentional, and the organization therefore is subject to prosecution (Rowe, 1972). But in contrast to business settings, the process and practices of appraisal in post secondary education are discriminatory by design. It is generally accepted that subjectivity, which allows discrimination, is essential in education. This does not mean to imply that it is impossible to substantiate a claim of prima facie discrimination, but to point out that it may be difficult. If the allegation of prima facie discrimination is accepted by the court, the defendant offers reasons why the actions were non-discriminatory. Again, a favor- 
able ruling for the plaintiff may be difficult. That the courts do not wish to substitute their judgement for that of educational institutions (Equal Employment Opportunity Commission/White, 1975; Johnson, 1977; Powell, 1978) suggests that the reasons presented by the university may be viewed less critically than would be true in cases in a business setting. This attitude increases the burden on the plaintiff to show that the reasons stated were pretext.

\section{Iesting Standards}

Where validity is of crucial concern in allegations of bias in business settings, the courts have not required the same emphasis in education cases. In Equal Employment Opportunity Commission/White (1975) the court held that qualifications and requirements should be reasonably related to the job, and that evaluations be conducted fairly. It does appear that as subjectivity is customary, fairness and validity may be difficult goals to accomplish. This is particularly true if the courts uphold the opinion of Johnson (1977) that employees do not necessarily need to be informed of the appropriateness of their work.

\section{Qperational Guidelines}

Subjectivity in evaluating professional employees in post secondary education is not only permissible, it is essential (White, 1975; Johnson, 1977; Powell, 1978). Appraisals in post 
secondary institutions may be based on what the school and review committees determine is most appropriate to meet its goals at that time. It is not required that researchers be aware of the appropriateness of their research for meeting these goals (Johnson, 1977). This is unlike business settings where work that is accepted without criticism is considered adequate, and actions may not be taken against an employee in this situation because of failure to meet acceptable standards (Flowers, 1977). In education, unless a professional employee is tenured, no reasons need be given for dismissal (Roth, 1972; Sindermann, 1972).

\section{CONCLUSION}

These rulings raise some questions. A primary obligation of a school and a teacher is to the students: how then can there be any justification for allowing an inept instructor to teach for six years? If employees do not have to be made aware of standards by which they will be judged, is there any guarantee that such standards do in fact exist? In situations where six percent of the women on tenure track positions are awarded tenure as compared to forty-five percert of the men, does this indicate a lack of discernment in employment practices, or prejudice about the capabilities and roles of women? Why is not post secondary education more concerned with making faculty aware of institutional and departmental goals? Do administrators and department heads lack the skills to guide institutions and their employees? Should 
instructors be faulted for the failure of the school or department to articulate needs and goals and identify ways to meet these?

Although the courts are critical of employment discrimination in post secondary education, and strongiy encourage academic institutions to eliminate bias, they emphasize their reluctance to substitute their judgement for that of professional educators. Sympathy, however, provides no redress for the victim, nor does it require remedy for institutional discrimination. Anti-discrimination legislation that Congress intended to apply to postsecondary institutions is not enforced by the institutions themselves or the courts. Clearly guideline are needed to establish policies that will eliminate discrimination in postsecondary education.

The fox is guarding the chicken house. The farmer is yelling, "Now you cut that out!" The fox is still guarding the chicken house. What can we do?

There is a court case that demonstrates a divergence from the typical appeal heard by the Supreme Court. It is unusual in that it is not concerned with objective appraisals in a blue collar or technical environment. The case does not address itself to post secondary education. So why include the case in this study? At issue in Hishon v. King and Spaulding (467 U. S. 69, 1984) is a question of discrimination in a professional situation: a law practice, to be specific. Appraisal for evaluation and audvancement in this environment is necessarily subjective. The decision emphasized that the application in this case is very narrow; in fact, 
the concurring opinion specifically excluded its application to questions of tenure in higher education. This limitation does not preclude the case from suggesting a viewpoint for approaching the problems of discrimination in post secondary education, however. Hishon (1984) offers a transitional perspective that bridges some of the gaps left by the legal tradition developing in appraisal law.

Hishon v. King \& Spaulding 467 U. S. 69 (1984)

Eacts. Hishon, a female attorney, was hired by the law firm of King and Spaulding. When she was recruited, the firm had assured her that the offer of partnership was customary after five or six years of satisfactory performance, and that she would be considered on a fair and equal basis. After her fifth year with the firm, Hishon was not offered partnership, although her performance had been satisfactory. After six years with the organization, Hishon still was not extended an offer of partnership, and her employment was terminated. At the time of her termination, none of the fifty partners was a woman. Hishon brought suit, alleging that she was discriminated against on the basis of sex in terms and conditions of employment, as the offer of partnership was part of the recruitment enticements of the firm, and a primary reason she has chosen to become an associate of King and Spaulding.

The defendant argued that the selection of partners was an exercise of the rights of free expression and association, pro- 
tected by the First Amendment. The defendant further asserted that the position of a partner was that of an employer, not an employee; therefore, the Civil Rights Act of 1964 which protects employees did not apply.

Decision. The Supreme Court ruled in favor of Hishon, remanding for further proceedings.

Issues. Does the denial of partnership constitute an exercise of the rights of free expression and association?

Rule of Law. Title VII of the Civil Rights Act of 1964.

Rationale. When the privilege of advancement is offered as an enticement to become associated with an organization, this constitutes a condition or term of employment, and falls under the protection of the Civil Rights Act of 1964. As such, the consideration for advancement must be based on non-discriminatory criteria. This is not an issue of free expression or free association. Constitutional protections were never intended to include the right to participate in invidious acts of private discrimination. More specifically, the contributions lawyers make to society in terms of ideas and beliefs is in no way impeded by the requirement to base considerations for partnership on merit.

Justice Powell Concurring:

In admissions decisions made by law firms, it is now widely recognized - as it should be - that in fact neither race nor sex is relevant. The qualities of mind, capacity to reason logically, ability to work under pressure, leadership, and the like are unrelated to race or sex. . . Law firms - and of course, society - are the better for these changes ( $p .70)$. 
With respect to laws that prevent discrimination, much depends upon the standards by which the courts examine private decisions that are an exercise of the right of association. For example, the Courts of Appeal generally have acknowledged that respect fo: academic freedom requires some deference to the judgement of schools and universities as to the qualifications of professors, particularly those considered for tenured positions. . . . The present case before us. . . does not present such an issue (footnote 4 p. 70 ).

Note that in this case the Supreme Court did not impose judgement about the contents of the evaluation. Its concern was with the fairness of the process. This perspective suggests a new approach to the problems of discrimination in performance appraisal when peers are the proper forum for judging an individual's professional merit, and those judgements are necessarily subjective. If the courts determine that academia has gone too far in its disregard for laws specifically established to protect educational employees, perhaps this type of rationale will be applied to justify limiting the tradition of academic freedom.

The case addressed employee evaluation where appraisal was subjective and judged by peers, similar to the process of evaluation in education. The court made no attempt to judge the plaintiff's qualifications, but concerned itself with addressing the conditions of advancement.

This case presents a context much like postsecondary education, where professionals are judged subjectively by their peers. Perhaps the lesson that academe can learn from this case is that if the process of evaluation is standardized and fairly ap- 
plied, the content of appraisal can still be based on subjective criteria. Peers may be the best judge of qualifications, and this might be most appropriate if all are judges under the same circumstances. Reread the last line of the rationale in Hishon (467 U. S. 69 (1984), substituting 'educators' for 'lawyers', and 'promotion' for 'partnership': ". . . the contributions educators make to society in terms of ideas and belief is in no way impeded by the requirement to base consideration for promotion on merit". Justice Powell expressed the fact that the decision in this case does not apply directly to postsecondary education. But remember that each case must be judged only on the issues before the court, within the context of the specific facts of that case. The judgement applies only to that particular situation. "This rule only holds of redheaded Walpoles in pale magenta Buick cars" (Llewellyn, 1930, p. 72). There are issues similar to both situations, however, that do not preclude its consideration as a valuable approach to the problem of discrimination in postsecondary education.

Finkin (1980) pointed out one of the great difficulties facing the courts when addressing questions of discriminatory employment practices in academe. Lawyers and judges are not well aware of the norms and policies in education, yet recognize that subjectivity is essential in employment decisions in this environment. While indicating a strong desire to preserve academic freedom, judges have again and again issued dicta decrying bias in educa- 
tion and urging postsecondary institutions to eliminate discrimination. As in other areas of law, concepts of justice develop slowly. Justice Powell's caution is desirable and understandable. Establishing precedent in an area of developing law must necessarily proceed witn caution.

Waintroob (1979) indicates that in performance appraisal at the professional level, the courts have been more concerned with procedural fairness, and less inclined to judge the merits of performance measures. He suggests that this may be so because judges are more familiar with professional standards in employment, and recognize that subjectivity in this situation may be a more reasonable approach than total reliance on objective measures. This willingness to accept subjective evaluation reflects the attitude that professional jobs require skills, education, training, or experience that the general population is not likely to possess.

When a performance appraisal program in a professional context is challenged, the plaintiff usually prevails when the process reflects preconceived, prejudicial attitudes. Employers, on the other hand, are likely to win favorable decisions when the process demonstrates fairness. At the professional level, the courts have been more concerned with procedural fairness, and less inclined to judge the merits of performance measures. Waintroob (1979) suggests that this may be so because judges are more familiar with professional standards in employment, and recognize 
that subjectivity in this situation may be a more reasonable approach than total reliance on objective measures. This willingness to accept subjective evaluation reflects the attitude that professional jobs require skills, education, training, or experience that the generai population is not likely to possess.

Even if (or especially if) the courts continue to refrain from involvement in academe, postsecondary educators and administrators must take upon themselves the task of identifying fair employment processes.

Current performance appraisal practices offer methods that may provide useful guidelines for the development of appraisal programs. The following chapter will discuss components of effective performance appraisal programs. The final chapter will present a model performance appraisal program for postsecondary education that is based on an assimilation of legal theory and current practices. 


\section{CHAPTER IV}

\section{PERFORMANCE APPRAISAL PRACTICES}

\section{INTRODUCTION}

The goal of this research is to provide guidelines for postsecondary education administrators for implementing effective, legally defensible programs. This chapter builds on the legal foundation presented in the preceding chapter and reviews current performance appraisal practices, emphasizing components of an effective program.

Increased morale and productivity and decreased litigation are the results of a good appraisal program. But ninety percent of organizations use employee evaluation methods that are not acceptable in terms of effectiveness or legal compliance (Latham, Cummings, and Mitchell, 1981). The researchers note, however, that a credible performance appraisal program promotes increased productivity and optimizes human resources. In addition, employers who base personnel decisions on the outcomes of acceptable performance appraisal programs are most successful in avoiding or prevailing in legal challenges to these decisions (Martin, Bartol, and Levine, 1986-87). 
Personnel decisions that are based on performance appraisals may include promotion, discharge, layoff, compensation, merit pay (Martin, Bartol, \& Levine, 1986-87), transfer, strategic planning for human resources (Gruenfeld, 1981), professional development, and team building (Kaye \& Krantz, 1983).

Although performance appraisal is one of the important employment practices, it remains one of the most difficult and complex processes for an organization. There are many approaches to evaluating employees, each with advantages and disadvantages (Bernardin and Beatty, 1984). However, unlike aspects such as government regulation and the cost of goods and services over which organizations may have little control, employee performance can be greatly influenced by managers (Gruenfeld, 1981).

Even so, few managers feel comfortable with appraisal. Because supervisors are required to evaluate the efforts of subordinates with whom they will continue working, the process may be stressful for both. In addition to the problem of future employee relations, the task may seem overwhelming because there is so much information to review, and that information is critical to the future of both the employee and the organization (Miller \& Steinbrecher, 1979; Nix, 1980).

Difficult as the process of employee evaluation is, the development of performance appraisal theory provides organizations with the tools necessary to implement a sound employee appraisal program. 


\section{EFFECTIVE PERFORMANCE APPRAISAL PROGRAMS}

It is not surprising that many organizations have difficulty implementing employee evaluation programs. Performance appraisal is a complex process. Even the gurus do not agree.

Although accord exists on the principle that the type of appraisal depends upon the intent of its use, and although there is further agreement that each system has its strengths and shortcomings, there is a difference of opinion about the effectiveness of different approaches (Gruenfeld, 1981; Bernardin \& Beatty, 1984).

For example, in the last several years, MBO or managementby-objectives, has received a great deal of attention. MBO is an organizational approach to goal setting in which objectives and standards are mutually determined by employee and manager. Evaluation measures performance outputs rather than behaviors. Bernardin and Beatty (1984) suggest that in some circumstances, MBO provides a very effective method of performance appraisal. But Kane and Freeman $(1986,1987)$ call for an end to all performance appraisals based on MBO principles. The researchers cite detrimental factors inherent in many MBO systems that undermine the effectiveness of appraisal. These include the tendency to set and maintain low goals that can be met easily, the autocratic approach to MBO taken by many organizations that discourages motivation by imposing goals, emphasis on short term goals, indepen- 
dently established standards that are not comparable between work units and which result in unreliable measures, inflexibility of annually established goals, and evaluation of units rather than individuals.

\section{Appraisal Proaram Components}

There is some consensus, however, on what constitutes an effective performance appraisal program. Baker and Holmberg (1982), Kaye and Krantz (1982), Lazer (1980), Martin (1986), Miller and Steinbrecher (1979), Rendero (1980), Sashkin (1981), Thompson (1981), and Truskie (1982) agree that effective programs are behaviorally based and focus on specific job behaviors. The researchers have made similar observations regarding the components of such systems. Although not all of these researchers said all of the following, general opinion seems to include the following components in an effective appraisal program. A good system demonstrates the following characteristics:

1. Ongoing Process. The appraisal program is an ongoing process, not an occasional function.

2. Job Analysis. Evaluation measures how well the employee has carried out responsibilities based on specific, predetermined performance standards that have been determined through analysis of important work behaviors.

3. Participation. Employees are included in job analysis and determination of performance standards. The greater the involve- 
ment of employees in the appraisal process, the higher the acceptance level of the program, and the more confidence employees express in the system.

4. Training. Written and verbal training for both raters and employees are provided so that expectations are clarified from the onset, and acceptance is established.

5. Development. Professional development and career opportunities for the employee are identified. In addition to training, these might include such things as job rotation or special assignment.

6. Legally Defensible. An effective performance appraisal program conforms to legal standards.

The authors indicate that organizations using such programs are enthusiastic about the results. Because both supervisors and employees are involved in establishing specific performance standards, expectations are clarified. Biased and uninformed judgements are reduced. Priorities are established. Employees know where they stand. It is fairly easy to determine which objectives have been met and how well they have been achieved. Productivity is increased. The future potential of the individual may be readily assessed, and opportunities for skill enhancement identified. Career paths and goals are identified. Individual and organizational planning are facilitated. Information from the appraisal provides a basis for training and development programs. Achievement is recognized and rewarded, and problems are dealt with before they 
become serious. Vertical communication is enhanced, and cooperation increased.

The authors suggest that perhaps the greatest benefits from a behaviorally based performance appraisal program are those that involve emotions. Anxiety and misunderstandings are reduced because agreement exists between employee and supervisor on what is expected by both. Supervisors are better able to identify their management styles and adapt them if necessary. Employees indicate that they have the opportunity to initiate necessary changes, and the process advocates respect for their ideas. Employees who participate in behaviorally based appraisal programs report that managers seem more concerned about them as individuals. Workers feel less threatened when they are evaluated on the performance of their job responsibilities, rather than being judged by the way supervisors view their personality traits. Defensiveness decreases. Managers report that job satisfaction is higher, and that rates of turnover lower.

Thompson (1981) notes some interesting statistics on behaviorally based performance appraisal programs. In a five-year study of a company that changed from a trait based system to one based on work behavior, the percentage of above average appraisals decreased from $61.7 \%$ to $16.1 \%$. Yet satisfaction with the program increased. $65.8 \%$ of employees indicated that the new system was an improvement. 


\section{Performance Appraisal Methods}

The following are among the more commonly used methods of performance appraisal examined by Bernardin and Beatty (1984).

Weighted Checklists. A weighted checklist requires evaluators to check a list of statements about each employee. Although each statement has been assigned a predetermined value, the rater is unaware of its relative weight.

Summated Scales. A summated scale involves a series of statements about work behavior in which each statement is qualified in regard to the employee's performance.

Critical Incident Technique. The critical incident technique involves the collection of statements about the employee's desirable and undesirable work behaviors. These statements objectively describe the performance of important job functions. Personal judgements are not included; the statements are descriptions of observable behaviors.

BARS. When behaviorally anchored rating scales (BARS) are used, statements about employee behavior are graphed on a continuum, from least acceptable to most acceptable. The evaluator indicates which statement best describes the employee's work behavior.

Mixed Standard Scales. Mixed standards scales describe different levels of performance (low, average, high; better than, 
about the same as, worse than) on each of a number of important work behaviors.

Forced Choice Scales. A forced choice scale relies on groups of related statements from which the rater must select subsets that best describe the employee. The rater does not know the predetermined weights which have been assigned to the selections.

MBO. Management-by-objectives (MBO) involves the cooperative determination of goals and standards by the employee and manager, with subsequent evaluation based on measuring goal achievement. Appraisal is generally performed annually.

Work and planning review is similar to MBO, but with emphasis placed on frequent progress reviews.

Personal Comparison Systems. Personal comparison systems compare employees with each other. In paired comparison, each is evaluated against all others. Rank ordering lists all employees from best to worsi. Forced distribution compares employees, then distributes them at preselected points along a scale.

Unfortunately, it seems that the best methods are also the most complex and time consuming (Bernardin \& Beatty, 1984).

Whatever the method selected, a successful approach to appraisal views the process in a problem solving context, rather than as a judgmental situation. The perspective taken by organizations which approach evaluation in this way is that appraisal offers employees and managers the opportunity to identify obstacles that impede good performance and investigate creative so- 
lutions. Obstacles might include work procedures or practices, inadequate resources, lack of necessary worker skills, and misunderstandings about what is expected in terms of performance or quality (Martin, 1986).

Most organizations do not approach appraisal with such perspective. A problem solving approach requires that this attitude permeate the organization, not just pop up annually in performance review. If blame is fixed as the modus operandi, a sudden appreciation for the employee's ability to identify problems and present solutions may be viewed with suspicion. The climate of the organization is important (Sashkin, 1981).

Environmental factors of the organization which can affect the approach to performance appraisal include communication patterns, job security, the corporate culture, leadership style, and composition of the work force (Bernardin \& Beatty, 1984).

\section{Appraisal Procedures}

Whatever the approach or method, most performance appraisal can be broken down into five steps: preparation, progress review, pre-interview evaluation, the actual appraisal interview, and follow-up.

Preparation. Holley and Field (1982) advise ihat instructions given to appraisers be written. Lazer (1980) recommends that the system be standardized in instruction, administration, and forms. This will provide evidence that the organization is committed to 
eliminating bias. If standards result in adverse impact, they must be justified by rigorous validation. Thompson (1981) points out that there is no method that can absolutely validate employment tests for relating standards to job performance. However, no system can be completely safeguarded. Bernardin and Beatty point out that "a rater who. . . wishes to deliberately distort the ratings of an individual or group can do so. . . Such distortion, of course, completely defeats any purpose for which the appraisal system has been designed" (p. 96).

Some steps can be taken to enhance procedural safeguards and increase the likelihood that the appraisal process will be applied fairly. Written standards which employees help develop are more likely to be fair than standards imposed on workers. There should be an appeals process in the event that the employee does not agree with the evaluation. Multiple raters or multiple reviews of appraisal results offer additional safeguards to fairness (Waintroob, 1979).

Universal Training Systems Company (1976) suggest that the appraisal process begin with the definition of job responsibilities. Universal (1976) indicates that the definition of responsibilities should be done independently by the supervisor and subordinate. If the working relationship is good, the two meet to discuss the results, resolve any differences, and determine evaluation criteria. If tension exists in the department, it is advised that a neutral party compare the descriptions and analyze the results. 
Job analysis, like performance appraisal itself, may have many purposes. Although several methods exist, there is no one best way. Appropriateness must be determined within the context of an organization. It is recommended that more than one approach be utilized to enhance validity (Bernardin \& Beatty, 1984).

The formal job description provides a useful tool for defining job responsibilities according to Baker and Holmberg (1982) and Lazer (1980). Baker and Holmberg suggest four steps that are involved when determining objectives:

1. List the major responsibilities of the job.

2. Prioritize the key responsibilities according to those functions that are of greatest benefit in achieving goals of the organization. These will therefore contribute most to individual performance in the organization.

3. Describe specifically the objectives that are necessary to fulfill each responsibility of the job; develop standards that are specific, reasonable, and measurable to provide a means of assessing performance. Each responsibility should have one or more objective.

4. Record the responsibilities, objectives and standards clearly and concisely to the satisfaction of both worker and manager.This will prevent misunderstanding of performance expectations.

Baker and Holmberg (1982) caution that it is important to review and revise standards and objectives periodically. This en- 
courages changes in the organization and its service environment to be handled realistically, and in a timely manner.

The performance standards should not be so specific that unimportant aspects of the job are included (Miller and Steinbrecher, 1979). Unnecessarily detailed plans may become too overwhelming and encourage too much attention to insignificant details. These may be the quickest and easiest to complete, but cause the neglect of areas critical to organizational success and acceptable individual performance.

When performance standards are cooperatively determined, objectively stated, and job related, a high degree of reliability and validity are likely to result. Managers and employees are more likely to agree on responsibilities and working arrangements, including what is to be done, how it will be done, and how performance will be evaluated (Lazer, 1980).

Employees should indicate any special projects they would like to work on. Projects increase motivation by offering the opportunity for work that is personally satisfying. They encourage professional development and can contribute to flexibility in the organization.

At this time, informal progress reviews are scheduled. These periodic reviews (scheduled every one to six months) measure progress towards goals and allow for ongoing adjustments. Finally, the date for the formal review is scheduled. 
Because memory is selective and faulty, Bernardin and Beatty (1984) recommend that both employee and evaluator keep anecdotal diaries of critical performances.

Progress Review. Performance problems can be identified during progress reviews. Unrealistic goals, insufficient knowledge or skills, lack of rewards, and corfflicting motives may become apparent. These difficulties can be corrected before the problem causes serious damage. The employee will have sufficient time to make necessary changes to avoid a poor evaluation.

During the progress review, it is appropriate for the manager to emphasize the nature of appraisal as a time for mutual problem solving. This attitude can be developed by reassuring the employee that asking for help when difficulties arise is not a sign of weakness. When problems arise that require assistance, soliciting the employee's opinion before suggesting solutions may encourage novel approaches, and reconfirm trust in the employee (Gomez-Mejia \& Page, 1983).

Appraisal becomes increasingly unreliable over time, when performance is reviewed only sporadically. Sashkin (1981) and Bernardin and Beatty (1984) strongly encourage frequent progress reviews. Regular formal feedback increases employee confidence in the system, and more accurately reflects the employee's actual performance.

Pre-interview Evaluation. A couple of weeks prior to the appraisal, the manager should remind the employee of the upcoming 
review. Both need to rate performance independently, in writing. The employee should also note any concerns, personal goals, and special interest projects (Universal, 1976).

Nix (1980) suggests that supervisors identify their feelings about the upcoming meeting by answering six questions in preparation for the appraisal:

1. How do I really feel about evaluating this person? (Gut level reaction only!)

2. Why do I feel this way (either good or bad)?

3. What is the worst possible outcome of this evaluation interview? (Let your deepest fears decide this.)

4. What is the best possible outcome of this evaluation interview? (Be positive here.)

5. Indicate on the scale the likelihood of the occurrence of either number three or number four, whichever you feel is most likely.

Worst Possible No Change Best Possible

6 . Indicate on the rating scale the overall performance rating you think you will assign this person.

Unsatisfactory Average Outstanding

Figure 2. Pre-Interview Questions ( from Nix, 1980, p. 5).

When the actual time of the interview has been established, the supervisor should select the location with care. Employees may feel uncomfortable in the manager's office, so Baker and Holmberg (1982) suggest holding the review in a neutral location, such as a small conference room.

Appraisal Interview. The purpose of the appraisal is the evaluation of the employee's job performance, not the elaboration of the supervisor's opinion of performance. It is essential that the 
employee help guide the interview (Kirby, 1981). A good way to encourage this participation is to begin the review by asking the employee for a verbal self-evaluation (Baker and Holmberg, 1982; Truskie, 1982). Even if the supervisor has already received the worker's written self evaluation, the opportunity to talk about performance may make the employee more comfortable and less defensive. If future performance must be altered, change may be more likely if the problem can be verbalized to the employee's satisfaction.

The employee can be encouraged to openly discuss strengths and weaknesses by how the supervisor listens and reacts. The Labor-Management Relations Service (1974) suggests that the manager demonstrate support by active listening. This involves showing interest through eye contact, facial expressions, body posture, paraphrasing or summarizing statements, identifying the employee's feelings, personalizing good things and depersonalizing negative ones, asking questions that encourage thoughtful answers, and by demonstrating respect for the way an employee has formed opinions. Silence can also encourage dialogue. Johnson (1970) offers some techniques for getting employees to talk. Open ended questions, hypothetical cases, and suggestions ("Tell me more") can encourage elaboration.

After listening to the employee's self evaluation, Baker and Holmberg (1982) suggest talking over strengths that both have identified. Following this, the manager can enhance the positive 
atmosphere by mentioning strengths the employee may not have noted. Next to be discussed are areas of improvement that both have agreed on. This should be followed by indicating opportunities for development that the employee may not have recognized.

Universal (1976) suggests a process in the event there are major disagreements in which the employee perceives the work as satisfactory while the evaluator does not. The manager should ask the employee to explain the rating once again, without interruption, encouraging examples to clarify the worker's perspective. The manager should then restate the explanation until both are satisfied an understanding has been reached. The supervisor then presents reasons and examples for the rating. It is recommended that emotional responses, as well as cognitive reactions be elicited.

Soliciting the employee's suggestions is important (Kirby, 1981). Employees are often most aware of how the work environment could be improved and how the supervisor could contribute to greater harmony and efficiency. Many employees may be uncomfortable offering suggestions because it may seem that they are being too critical and therefore causing friction between themselves and the supervisor. The supervisor needs to stress that the role of management is not a judgmental one, but rather one of support, and that the success of the company depends upon the workers. 
To conclude the interview, the employee and supervisor need to agree on a future plan of action. Each must leave the review with a clear understanding of performance behaviors that are to be maintained or changed by either party. These new written standards must be stated specifically and objectively. As before, both participants should be involved in developing future goals. When both parties verbalize, then write goals down it indicates that maintaining performance is a joint responsibility. The summarization also indicates to the manager how well the employee understands and accepts the process and results of the evaluation (Kirby, 1981).

Follow-up. The final phase of the performance appraisal is follow-up. A summary of the session should be recorded, noting the topics and conclusions. A copy should be given to the employee for review and approval. A copy of the document should be retained by both employee and supervisor, and another placed in the worker's personnel file (Baker and Holmberg, 1982). This document offers a legal safeguard for the organization in the event of a grievance (Miller and Steinbrecher, 1979), and provides a basis for future reviews (Kirby, 1981). There should be an appeals process to ensure that one rater does not exert unfair bias against an employee. This process must provide a means of redress for employees who feel they have been dealt with unfairly (Miller and Steinbrecher, 1979). After the appraisal, continued frequent feedback 
is essential to continued acceptable performance (Bernardin \& Beatty, 1984).

Universal Training Systems (1976) summarizes the performance appraisal format:

1. Review purpose of the appraisal.

2. Discuss ratings. The employee should begin, discussing both ratings and reasons. The manager then discusses the ratings given, and the reasons.

3. Resolve significant differences.

4. Finalize ratings for records.

5. Identify any changes in job responsibilities or standards.

6. Set dates for subsequent progress reviews and performance appraisals.

Although the above procedure suggested by Universal Training Systems (1976) offers many advantages, there are a number of potential problems to consider, as these guidelines and the Performance Review Guide (n. d.) point out.

\section{Potential Problems in Appraisal}

Several problems may face the unwary manager in evaluating employee performance. Among these are the following:

1. Single Incident Some evaluators base the appraisal on one critical incident, either positive or negative. Actual overall performance is downplayed, and specific areas of performance disregarded. Undersampling results in unreliable appraisals. 
2. Training by Evaluator. When the employee is trained by the evaluator, there is a tendency to overrate performance and overestimate potential.

3. Charmers. People with exceptionally pleasing personalities often receive higher ratings than their work would indicate.

4. Halo Effect. If the supervisor perceives the employee in a positive way, all aspects of performance are viewed as positive. If overall perception of the employee is negative, so is the perception of that individual's work.

5. Irrelevant Attributes. Ability or knowledge in one area is assumed to pertain in other areas.

6. Common Ratings. High or average scores are given uniformly to all employees. Raters may be reluctant to hinder career opportunities, to give a score that will prevent an employee from receiving the maximum salary increase.

7. Easy Qut. Inflated ratings may be given to an employee to avoid a confrontation or unpleasant session. This is likely to occur when the rater and employee must continue to work together, particularly if the supervisor finds it difficult to give negative feedback. It is important to seek ways to increase rater motivation. Training, recognition, and multiple evaluators may help.

8. Lack of Understanding. Problems arise when either the employee or manager does not understand the appraisal process. Poorly defined goals or standards also contribute to misunderstandings. 
9. Unrealistic expectations. Especially when employees define their own responsibilities, they may expect unrealistic results or changes that would require organizational restructuring.

10. Time. The proposed performance appraisal process requires a substantial initial commitment of time.

11. Detailed Plans. Written goals are easier to measure, and safeguard against misunderstandings and bias. However, they may become too specific and restrictive. As a result, too much attention is given details, while objectives suffer.

12. Subjectivity. Although every attempt should be made to eliminate bias, pure objectivity is impossible. It is important to recognize this.

13. Organizational Expectations. Some organizations expect a new performance appraisal program to immediately solve long standing problems. A good appraisal system may clarify objectives and responsibilities, but it will not solve all an organization's problems.

14. Authoritative Management. Some managers who are accustomed to making decisions and establishing goals for others may have a difficult time changing their behavior to encourage participation by subordinates.

15. Validity. Adequate substantiation is impossible. Although the courts require validation, there is no method that can appropriately relate standards to job performance. 
Other researchers (Bernardin \& Beatty, 1984; Friedman \& Mann, 1981; Lazer, 1980; Rendero, 1980; Thompson, 1981) list additional problems that organizations may encounter, including: lack of follow-up, lack of commitment by managers to change, difficulty in developing performance criteria, unskilled evaluators, poor or selective memory when incidents are not recorded, hesitancy by some managers to give negative feedback, using the results of appraisals for reasons not intended, lack of support from top management, rater bias, and too many forms and documents.

Although there are a number of problems with performance appraisal, most can be overcome by awareness, development of new behaviors, and commitment to change. Training in performance appraisal enhances awareness of required knowledge and skills, allows practice of new behaviors, and demonstrates the positive effect such a system can have on individuals and organizations.

\section{Iraining}

The importance of training as an integral part of a performance appraisal program cannot be disregarded. Training should include both employees and managers. An effective training system provides the foundation for individual and organizational development. Training aids legal compliance by promoting reliability and objectivity in evaluation (Wells, 1982). Training strengthens 
communication between all levels of the organization, reduces anxiety about evaluation, and clarifies responsibilities (Kaye and Krantz, 1982).

Even so, performance appraisal is often seen as the manager's most difficult and unpleasant responsibility. The organization may provide forms and written instructions for performing the task. Yet the supervisor may do an inadequate job of appraisal due to lack of training (Nix, 1980).

Kaye and Krantz (1982) suggest that employees also need appraisal training. Evaluation is the primary cause of employee anxiety. In addition to reducing anxiety, appraisal training encourages increased autonomy and responsibility, freeing managers to atterid to higher level tasks, which contributes to organizational and individual effectiveness.

Martin (1986) suggests six aspects of performance appraisal that training should address: purpose, pre-interview preparation, the method of appraisal, problem solving techniques, goal setting, and guiding employees in career development.

Wexley and Latham (1981) identify some objectives that appraisal training may address. These include acquiring knowledge, changing attitudes and behaviors, solving problems, and developing interpersonal skills. Specific topics may include clarifying responsibilities, goal setting, performance analysis, developing employee potential, identifying rater bias, and effective listening. A combination of lecture, discussion, workbooks, case study, audio- 
visual presentation, and role-playing may be useful and appropriate methods of approaching training.

Before training, it might be beneficial to assess the level of trust that members of the organization have in the appraisal system. An approach as simple as a survey or questionnaire can provide important feedback. Bernardin and Beatty (1984) and Martin (1986) agree that trust is essential to the effectiveness of any performance appraisal program.

During the training sessions the process and purposes of appraisal are described. Workers are encouraged to participate actively in the review. The training gives both employees and supervisors an opportunity to express their concerns, and verbalize their expectations. The importance for employees of documenting their strengths and weaknesses is emphasized. Managers may not recognize all the contributions made by a worker, and the documentation calls attention to them. When weaknesses are identified, strategies can be developed to overcome them.

Defensive behaviors (such as denial, misrepresentation, aggression, submissiveness) are addressed in training. Once identified, steps can be taken to overcome these hindrances.

Some organizations have found role playing to be effective as a training tool. Managers and workers exchange roles and attempt to work out problems from the other's perspective.

The attitude that performance appraisal is a mutual opportunity to solve organizational problems can be reinforced by ob- 
serving appraisal interviews that take a problem solving approach (Sashkin, 1981).

Wexley and Latham (1981) have identified seven principles that contribute to effective training:

1. Motivation. The training must provide something of importance to the individual.

2. Knowledge of Qutcomes. Employers and raters must be made aware of the outcomes of appropriate and inappropriate behaviors.

3. Stimulus. The content must provoke interest.

4. Participation. The process must involve trainees in active learning activities and practices.

5. Modeling. Opportunity must be provided for observation and practice of desired behaviors.

6. Reward. The training outcomes must be desirable.

7. Reinforcement. The new behaviors must be encouraged.

Training cannot be viewed as a "do it once and get it over with" function of the organization. Training needs should be addressed regularly, whether in actual sessions, or as a review of previous training (Sashkin, 1981).

Training principles and methods can be incorporated into a process that involves both supervisors and employees. Based on emerging opinions and practices, a training program might include the following components: 
1. Needs Analysis. Prior to the training sessions both managers and employees should participate in a survey to identify deficiencies and concerns. These should involve both knowledge and skills. For example, knowledge might include awareness of legal expectations; skills might include interpersonal communication.

2. Training Introduction. A short lecture might provide an appropriate introduction to training processes and goals. At this time an explanation should be given of the benefits an effective performance appraisal program provides for employees, managers, and the organization. Packets of information could be used to supplement audio-visual materials. (For example, overheads outlining legal requirements could be duplicated for each participant to keep as a reference.)

3. Analysis of Performance Appraisal Problems. Films or videos might be used to demonstrate problems in evaluation. Prior to the viewing, a short summary of issues would focus participants' attention on the presentation. Each vignette should be followed by a discussion of the problem to identify appropriate methods of handling the situation.

4. Identification of Organizational Problems. Following the discussion of generic problems of employee evaluation, the session should focus on problems experienced by participants within the organization. These would include problems identified during 
the needs assessment, as well as those encountered or recalled during training.

5. Implementation of New Behaviors. Role playing (also role reversal and role rotation) can give trainees practice identifying and using appropriate behaviors. Work book exercises, such as listing job responsibilities and objectives could be done in teams. Skills training, such as active listening should be modeled and practiced.Feedback and reinforcement would be provided by other participants and trainers.

6. Development of Cognitive Skills. Case studies offer a means to increasing awareness about the cause of problems in the organization, and a method for recognizing impediments to professional and organizational development. Using studies from the trainees' organization would assure relevance and encourage transfer of training to the work environment. Identification of solutions by the group would encourage team building and carryover.

7. Goal Setting. To further expedite carry-over and to facilitate evaluation, each participant should identify personal objectives and behavior changes. These need to be documented.

8. Follow-ue. Informal groups could be organized to reinforce new behaviors and monitor progress towards goals in the work environment. Specific dates should be set for meetings. Resources (people, books, films, further training opportunities) that would provide additional assistance should be identified. 
9. Evaluation. A follow-up survey should be conducted at a specified time after training is completed. This will indicate to what extent goals have been met and behaviors changed. If desired results have not been achieved, analysis will be needed to identify the cause of the problem and identify solutions.

Effective performance appraisal enhances many other personnel functions, of the organization, such as promotion, selection, and training (Bernardin and Beatty, 1984). One area in which organizations have undermined their appraisal programs is recognizing and reinforcing managers who are effective in appraisal. Managers should be rewarded for their competence (Sashkin, 1981; Martin, 1986).

Effective performance appraisal programs not only encourage excellence but they are legally defensible. To what extent do current practices incorporate legal standards? The following chapter examines the congruence of legal standards with current appraisal practices. Following this, a model of performance appraisal for postsecondary institutions that incorporates legal standards and current appraisal practices will be introduced. 


\section{CHAPTER V}

\section{RESULTS}

The courts are being used with increasing frequency to arbitrate employment disputes. This trend is apparent in postsecondary education as well, where the courts acknowledge widespread discrimination in academia, but have not demanded the same stringent compliance with the law as they have required of non-academic institutions. The courts have demonstrated regard for academic freedom by their restraint in substituting their judgement for thaî of professional educators. This tradition of judicial restraint may be compromised if educational institutions do not take upon themselves the responsibility to eliminate employment discrimination and regulate their own behavior in accordance with established legal principles.

The goal of this study is to provide administrators of postsecondary education with guidelines for effective and legally defensible performance appraisal. These guidelines incorporate elements of a grounded legal theory of employee evaluation with components of cuirent performance appraisal practices.

1. What does statutory law mandate in performance appraisal? 
2. What issues, patterns and decisions concerning performance appraisal have been identified through the judicial process, and what degree of consistency has been shown in court decisions?

Answers to the first two research questions identified legal standards with which employers must comply.

3. What standards are suggested by performance appraisal law and practices"

The third research question will be answered by identifying elements of an emerging legal theory of performance appraisal, and analyzing them in congruence with current appraisal practices.

\section{ELEMENTS OF A GROUNDED LEGAL THEORY}

\section{OF PERFORMANCE APPRAISAL}

The Role of A Grounded Theory

Recall as discussed in Chapter I that theory explains or predicts behavior. Theory may be used to understand phenomena, to control and respond to circumstances. Theory aiso demonstrates the logical evolution of topical knowledge.

Chapter II identified attributes of good theories. Good theory works; that is, it explains relevant phenomena. Data are not forced to fit explanations. Good theory is understandable, and concepts 
are easily converted into practices. Good theories provide a basis for future research.

The following are elements of a grounded theory of performance appraisal. This theory explains the emerging acceptable standards that employers must consider in implementing a legally defensible performance appraisal system. The theory will provide administrators with an understanding of what the law expects of them regarding employee evaluation, and enable them to be responsive both to legal expectations and the needs of their organizations. This theory is based upon data drawn from actual constitutional, administrative, legislative, and judicial law, and so provides a relevant framework within which to judge compliance and develop institutional policies.

Elements of the Theory in Non-Academic Environments

Employment decisions must be free from bias because of race, color, religion, sex, national origin, age, and handicapping condition. In addition, employment decisions in the federal work force are to be made without regard for political affiliation or marital status. This protection is extended to workers, union members, and applicants.

Forbidden are acts of overt discrimination, as well as practices which result in adverse impact. Each person is to be accorded equal treatment.

Periodic pertormance appraisals are to be administered based on written, objective standards that have been developed 
from a job analysis. The evaluation must demonstrate validity, reliability, and fairness. Employment decisions are to be based on performance appraisal.

It is desirable that employees participate in the formulation of appraisal standards; however, at a minimum they must be informed of appraisal criteria. If employees are unaware of expected standards, their failure to meet them may not be used as a basis for punitive actions. Employees who demonstrate inadequate performance are to be given time and opportunity to improve.

Information regarding requirements and qualifications for advancement and other employment opportunities must be made available to all.

Administration of performance appraisals must be standardized. Evaluators must be properly trained. Employers are responsible for the discriminatory actions of supervising employees functioning in their authorized capacities.

Scoring procedures must be standardized. The relative weights of scoring criteria must be predetermined.

Two types of records must be maintained. Employers must have available written evidence of their compliance with legal requirements in employment practices. Secure records of each employee's performar:ce appraisals must be kept that account for resulting employment decisions.

Emerging legal standards continue to refine and clarify acceptable performance appraisal practices. At this point, however, 
the law is sufficiently clear in its expectations so that employers who abide by the above guidelines should be able to avoid or successfully defend challenges to their employment practices.

\section{Elements of Theory Applied to Postsecondary Institutions}

Legal standards of performance appraisal are somewhat different in academic employment than employment in general. Although the anti-discrimination language of legislative mandates applies to both academic and non-academic employees, the courts demand a much less stringent compliance by academic institutions.

Neither disparate treatment nor disparate impact are tolerated in general employment. However, customary employment procedures in postsecondary institutions encourage, or at the very least permit discrimination.

The courts have required that general employment decisions be made on the results of periodic employee evaluations that identify objective, written standards which are valid and reliable. In academia, however, the courts acknowledge that subjectivity is necessary. The courts do not require periodic evaluation in institutions of higher learning.

Unlike other employment situations, not only do the courts not require that academic employees participate in the formulation of performance standards, academic employees do not always 
need to be informed about the standards on which they will be being judged.

The courts consider academicians to be the most appropriate judges of their peers, but do not require evaluators to undergo training to address issues of competence or bias.

Unlike other situations, the criteria on which employees are evaluated do not necessarily have to be predetermined, nor does scoring have to be standardized.

Far from stating that the above practices are acceptable, the courts have again and again called for an end to discrimination in academe. Judges have strongly expressed their desire to see prejudice eliminated from postsecondary education. But by their failure to prohibit such practices, the courts in effect give approval to their ccntinuation. By the courts' refusal to intervene in academic employment disputes, the decisions rendered in education cases tolerate discriminatory practices which have been ruled unlawful in other settings. It may be true that the courts wish to see an end to prejudicial treatment of academic employees, but by the court's own definition, postsecondary institutions act with intent to discriminate.

While the courts have specified acceptable standards for performance appraisal in non-academic environments, they have few recommendations, if any, for postsecondary institutions. However, appraisal practices suggest some elements that might be useful for developing effective appraisal programs in academic 
institutions. An examination of congruence between legal guidelines and appraisal practices is in order.

\section{Congruence of Pefformance Appraisal and Legal Theories}

There do not appear to be appreciable conflicts between that which is required by law and that which is suggested by performance appraisal practice, even when applied to postsecondary education. This is because legal principles establish the minimum acceptable standards for employee evaluation. Performance appraisal practices go beyond what is essentially required by law to suggest additional practices that provide not just equal employment opportunity, but which enhance professional and organizational development.

The courts have indicated guidelines that non-academic appraisal programs should follow to comply with legal standards. Programs should be formal and behaviorally based. Objective standards that are based on job analysis must be developed to serve as appraisal criteria. These standards must be written and communicated to employees. Employees have the right to know the consequences of their performance. Evaluators are to be trained in the appraisal process to increase the likelihood of valid, unbiased evaluation. Actions may not be taken against employees whose performance is inadequate unless the worker is made aware of the inadequacy, and given the time, training, and opportunity to improve. All procedures are to be documented. Program guidelines 
must be observed when actions are taken against employees because of inadequate performance.

Performance appraisal practices suggest a number of elements that should be included in a program of employee evaluation. Assessments should be based on job analysis that defines specific, verifiable behaviors. Evaluation should be a continuous process. Employees should participate in the development of employment standards. Clear goals must be established that are challenging, but attainable. Feedback about performance, recognition of accomplishments, and opportunities for development should be provided. Training should be offered for both employees and managers.

Both appraisal practice and non-academic legal standards suggest a program based upon clearly defined, predetermined, objective behaviors that are verifiable. Employees need to know what is expected of them, the consequences of their behavior, and receive ongoing feedback. Appraisal training must be provided for raters. Opportunities for employee development should be identified as necessary.

The only difference that is suggested in applying these standards to postsecordary education is the recognized need for in academe for subjectivity in employment decisions. Specific, verifiable behaviors may be more difficult to determine when subjectivity is involved. Although postsecondary institutions are not required to implement other procedures, such as to telling employ- 
ees what is required of them or training evaluators, nothing prohibits them from doing so.

To be in legal compliance, an appraisal program must establish and define acceptable standards of behavior, except in postsecondary education. According to law, it is not mandatory, although it is recommended, that employees participate in the formulation of these standards. Appraisal theory goes beyond this, however, to suggest that employees contribute to the development of empioyment standards. Appraisal theory further encourages these standards to be challenging to the employee.

Although not required in evaluation by academic peers, in other employment situations the courts have stated that raters who evaluate performance must receive training to identify and eliminate sources of bias in appraisal. Appraisal theory strongly encourages training for the same reason, but identifies other compelling reasons for this function. Team building, enhanced motivation, improved communication, increased awareness of organizational problems and their solutions may follow as the result of appraisal training.

The courts suggest that performance be appraised periodically. Appraisal theory suggest that employee evaluation be handled as an ongoing process. While there is no disagreement between the two approaches, appraisal theory moves beyond the suggestion of intermittent review to a perspective that views evaluation as a continual function of the organization. 
To this point, legal requirement concerning performance appraisal have been identified, current appraisal practices have been discussed, and the congruence between the two addressed. Now let us return to the last of the research questions.

4. What should an appraisal program for post secondary education that synthesizes performance appraisal practices and emerging legal standards look like?

The fourth research question will be answered by presenting a model of performance appraisal for postsecondary education.

\section{ELEMENTS OF EFFECTIVE PERFORMANCE APPRAISAL}

\section{PRAC:TICE FOR POST SECONDARY EDUCATION}

The following thirteen elements of performance appraisal are based on current legal principles. They can be implemented in postsecondary institutions where inadequate programs or no programs exist. Existing appraisal practices can be compared with those recommended, and modified if these guidelines suggest means that seem more desirable for developing excellence in the organization. These principles and the practices they suggest may be applied to bott staff and professional positions; they identify a standard process without specifying appraisal content that can more appropriately be determined within each institution or department. By following these guidelines, an organization can im- 
plement an appraisal program that is both effective and legally defensible.

Thirteen elements of effective performance appraisal practice follow. The first three are practices recommended by appraisal practitioneis :

1. Identify organizational philosophy and objectives, and determine the role the department must play in accomplishing these goals.

2. Specify the objectives that must be achieved by the department to fulfill its role in meeting organizational goals.

3. Meet with departmental employees as a group to clarify organizational and departmental goals, and review the appraisal process. This information should be written, and a copy given to each employee.

If employees are familiar with the appraisal process, this presentation may be part of a staff meeting. If an appropriate appraisal program is not part of the organization, the introduction might be approached more effectively from the perspective of organizational training.

The fourth element encompasses principles that accommodate philosophical, operational, and testing standards established by the courts:

4. Request that employees prepare for individual meetings by reviewing their jot, descriptions. This review should consider how accurately the job description reflects the content and conditions 
of the job. Encourage employees to suggest ways that the job could be modified to promote personal and organizational development.

The fifth element is suggested by appraisal practice:

5. Privately review individual job descriptions to determine their appropriateness for meeting objectives.

6. Conduct individual pre-appraisal meetings to review job responsibilities, clarify and document appraisal criteria, identify personal goals, elicit suggestions for personal and departmental development, and redefine responsibilities, if necessary. Set a date for progress reviews and the formal performance appraisal.

The sixth through ninth elements accommodate legal operational and testing requirements:

7. Record meeting results and send a copy to the employee for approval.

8. A week or two before the formal appraisal, prepare an evaluation of the employee's performance, and request the employee to prepare a written self-evaluation of performance.

9. Begin the evaluation by reiterating the purpose of the performance appraisal.

Review empioyee performance, starting with the employee's self-evaluation. Discuss strengths both agree on, acknowledge contributions and assets the employee may have overlooked, examine areas that need improvement which both have identified, 
and address aspects of performance which the employee did not recognize as requiring additional attention.

Discuss the employee's career goals, and ways that attainment of these goals can be facilitated through staff development activities or redefining responsibilities. Elicit suggestions for improving the work environment and furthering organizational goals. Reevaluate and redefine job responsibilities if necessary.

The next two elements help safeguard the appraisal process from unwarranted bias and therefore address judicial concern with philosophical issues of disparate treatment and disparate impact:

10. Identify the appeal process in the event that the employee does not agree with the appraisal results.

11. Record the results of the performance appraisal, with signatures of both employee and evaluator. The employee's signature does not affirm agreement with the evaluation. The signatures serve only as an indicator that the appraisal was conducted and the topics addressed as stated. If the evaluation results are not agreed with, the employee's rebuttal should be noted on the appraisal.

Three copies of the appraisal need to be distributed: one to the employee, one to the employee's personnel file, and one to the supervisor.

The final two elements are recommended by appraisal practitioners: 
12. Circulate suggestions for departmental development to all employees, and set a date for the next staff meeting where the proposals will be discussed. If suggestions are implemented, give credit where credit is due.

13. Continue frequent feedback to monitor progress toward goals, and emphasize a problem solying approach.

Although employee evaluation is frequently one of the most stressful, ineffective practices of an organization, it need not be. These proposed guidelines for performance appraisal of employees in postsecondary education offer an effective approach to appraisal. This system provides a method for identifying goals, developing appraisal criteria, evaluating performance, and training in the appraisal process. These recommendations are based on practices that have demonstrated both effectiveness and compliance with legal standards. Therefore, their implementation will provide postsecondary administrators with appraisal programs that promote goal attainment in the organization and are legally defensible.

Performance appraisal can be highiy motivating and positive. This research suggests how effective performance appraisal practices in post secondary education can contribute to enhanced individual and organizational effectiveness. 


\section{SUMMARY AND CONCLUSIONS}

Lawmakers and judges have expressed concern with blatant employment discrimination in postsecondary education. Legislators have generated laws to eliminate discrimination. Yet judges have not required of postsecondary institutions the same strict compliance with these laws that they have demanded of other employers.

In the past, the courts have refrained from extensive involvement in the personnel concerns of professional employees in post secondary education, although this custom may be changing. Legal intervention into educational affairs has increased since the passage of the Civil Rights Act of 1964, and the Supreme Court has dealt with related issues in a comparable environment. Judges have stressed repeatedly their hesitancy to infringe on academic freedom by substiututing their judgement for that of academic peers; emphasizing, however, that they must intervene in academia if unwarranted bias in employment decisions continues.

It is desirable that the tradition of non-intervention in academic affairs should be preserved, but if discriminatory practices continue, the courts may and should overcome their reluctance to impose guidelines. The guidelines themselves may be warranted, but this still establishes the perilous precedent of judicial intrusion into academic affairs. If the courts begin to specify how tenure is granted, it would surely be a small step then to designate on what grounds it is to be awarded. 
The situation may come down to a choice between voluntarily implementing non-biased employment processes, or having court mandated programs and supervision imposed upon educational institutions that continue to discriminate. If colleges do not take upon themselves the task of implementing fair employment practices, increased regulation of academia is possible. There is also the prospect of increasingly greater proportions of resources expended on costly litigation when allegation of discrimination are made. It behooves educational administrators to review employment policies and procedures, and instigate safeguards against bias in personnel practices so that the regulation of education remains within education. Implementing a sound performance appraisal program would encourage excellence and provide such safeguard.

\section{Limitations}

This research provides postsecondary administrators with a model for effective, legally defensible performance appraisal. However, because the research upon which the model is based is inductive, conclusions cannot be proved, only suggested. The correctness of the assumptions will only be demonstrated over time.

Law changes. The law is relatively stable, but there is always the possibility that precedent will be overruled, rather than upheld. Time changes realities. Concepts of what is fair and desirable may change over time and be reflected in the actions of leg- 
islators and the judiciary. Theories of dynamic social processes must recognize this limitation. However, by viewing data about social change from the perspective of a theory grounded in the data itself, theories can develop to accommodate change.

\section{Implications for Postsecondary Education}

This research provides administrators of postsecondary education with an understanding of how law effects their employment decisions, and how they may influence law's development. This study provides a framework within which administiators can shape personnel policies.

The traditiorial restraint of judicial intrusion into academic affairs can only be justified if educational institutions take upon themselves the responsibility to eliminate discriminatory employment practices. If this does not occur, it may be that the next step for the courts will be a recognition that it is possible to intervene in appraisal decisions in postsecondary education without substituting the judgement of the judiciary for that of professional peers. If the process of appraisal is objective and fairly administered, subjective evaluation of qualifications will remain the domain of those with topical expertise.

Educators must identify and implement fair employment policies that will promote excellence. These policies will shape not only institutional behavior, but may influence developing societal expectations of fairness and equity. Organizations and their 
employees are affected by law, but they are also able to influence law. Educational administrators now have a unique opportunity to facilitate excellence in their employees and institutions, while promoting positive societal change. It is up to the academic community to govern itself.

However, there is a more compelling reason to eliminate bias in academe. There is little argument regarding the necessity to protect academic freedom from outside intervention. But although academia holds the responsibility and the privilege of regulating its own behavior, it has failed to live up to this trust.

There are two aspects to the principle of academic freedom. The first (and the traditional) concept of academic freedom is that instructors have the right to teach, within the framework of the institution, without the imposition of undue interference. But should not a second principle of academic freedom be that students have the right to learn without the imposition of biased attitudes or practices that limit their choice of study and cast doubt on their abilities to attain and utilize knowledge?

The threat to academic freedom comes not only from outside intrusions that exert undue influence: limiting free choice, free thought, and free expression. A more pernicious danger lies within, when individuals and institutions are unaware of or unconcerned with their own biases and unyielding habits of perception, thoughts, and behavior. This is particularly dangerous when those holding such attitudes are in a position to provide or deny knowl- 
edge or professional recognition. Specifically, professional educators whose responsibility it is to foster scholarship, and to sit in judgement about the rights and qualifications of other teachers to share this honored tradition must themselves be dedicated to the pursuit of truth unencumbered by persona! bias. If the right to academic freedom for teachers and institutions is considered so sacrosanct that.blatant or hidden discrimination is tolerated, what protects students' rights to an education that is free from constraints of preconceived prejudicial assumptions that question their capabilities and impede their pursuit of knowledge? If a school tolerates discriminatory treatment of its staff, can it be trusted to protect its students from discrimination?

\section{Suggestions for Further Research}

As with mos: research, although this study provides some answers, it also raises some questions that point to a need for further research.

If we tend to be unaware of our own biases and so act with unintentional discrimination, what can be done to our increase awareness of the biases we hold, and identify ways of overcoming prejudice?

What practices are followed in professional business settings, such as law, accounting, and engineering where employee are subjectively evaluated by peers? Do these practices have application for postsecondary education that would identify fair 
processes for making employment decisions? More research is needed on performance appraisal to determine what practices are most appropriate for which environments.

Research is needed to develop more specific methodologies for qualitative investigation. What disciplines, other than law, might offer useful structures for studies?

Research needs to be conducted to identify what actually happens in postsecondary employment decisions. There is a limited source of info:mation about what should happen, but little about what actually does happen.

How well prepared to make administrative decisions are college administrators? To define institutional and departmental goals and the means to achieve them? Do some problems of discrimination in postsecondary education arise from the "promotion" of scholars to administration for which they may be less well suited? Research might identify methods for providing administrators with skills to make fair and effective decisions.

Only when educational institutions eliminate prejudice in their dealings with both faculty and students can they develop an environment where knowledge can be pursued without constraints on ideas and their expression. Is not academic freedom a right so precious that it should be protected for all? 


\section{REFERENCES CITED}

Alfred, R. L., \& Ivan, S. H. A conceptual framework for institutional research in community colleges. New York: College Entrance Examination Board, 1978.

Alton, J. Ed. Legal reasoning writing and oral advocacy (3rd ed.). Portland, Oregon: Northwestern School of Law of Lewis and Clark College, 1982-83.

Arvey, R. D. Fairness in selecting employees. Reading, Massachusetts: Addison-Wesley Publishing Company, 1979.

Baker, H. K., \& Holmberg, S. R. Stepping up to supervision: conducting performance reviews. Supervisory Management, April 1982, 27, 20-27.

Beer, M. Performance appraisal: dilemmas and possibilities. Qrganizational Dynamics. 1981, 2 , 24-36.

Bergman, B. R. An affirmative look at hiring quotas. New York Iimes, January 10, 1982, p. F3.

Bernardin, H. J., \& Beatty, R. W. Performance appraisal: assessing human behavior at work. Boston: Kent Publishing Company, 1984.

Black's law dictionary (5th ed.). St. Paul: West Publishing Company, 1979.

Buckner, J. A. Help wanted: an expansive definition of constructive discharge under Title VII. University of Pennsylvania Law Review, 1988, 136, 941-969. 
Campbell, D. T., \& Stanley, J. C. Experimental and quasiexperimental designs for research. Boston: Houghton Mifflin, 1966.

Cardozo, B. N. The nature of the iudicial process. New Haven, Connecticut: Yale University Press, 1921.

Carnegie Council for the Study of Higher Education. More than survival, San Francisco: Jossey-Bass, 1975.

Carver, R. P. The case against statistical significance testing. Harvard Education Review, 1978, 48, 378-399.

Cascio, W. F., \& Bernardin, H. J. Court cases relevant to employment decisions:annotated bibliography. AFHRL Technical Report 80-40. Brooks Air Force Base, Texas: Air Force Human Resources Laboratory, Manpower and Personnel Division, Feb. 1981.

Cohen, M. L. Legal research. St Paul, Minnesota: West Publishing Co., 1978.

Congressional and Administrative News, May 1988, St. Paul: West Publishing Company.

Daniels, L. A. Prejudice on campuses is feared to be rising. New York Times, October 31, 1988, p. 7.

Derizin, N. K. The research act: a theoretical introduction to sociological methods. Chicago: Aldine, 1970.

Doyle, A. C. The celebrated cases of sherlock holmes. London: Octopus Books Ltd. 1981.

Eaton, K. Legislative leverage. Qutlook, January-February 1989, pp. 6-7.

Edwards, H. T., \& Nordin, V. D. Higher education and the law. Cambridge, Massachusetts: Institution for Educational Management, 1979. 
Edwards, H. T., \& Nordin, V. D. The american legal system. Cambridge, Massachusetts: Institution for Educational Management, 1980.

Eglit, H. C. Age discrimination (Vol. 2). Colorado Springs: Shepards/McGraw Hill, Nov. 1988.

Finkin, M. W. Regulation by agreement: the case for private higher education. Lowa Law Review, 1980, 65, 11192001.

First Interstate Bank. Performance review quide. Portland, Oregon: n.d.

Fox, D. J. The research process in education. New York: Holt, Rinehart, \& Winston, Inc. 1969.

Fox, E. H. The legal research dictionary: from advance sheets to pocket parts. Newton Highlands, Massachusetts: Legal Information Service, 1987.

Frank, J. What courts do in fact. Illinois Law Review, 1932, 26. 645-666.

Friedman, B. A., \& Mann, R. W. Employee assessment methods assessed. Personnel, Nov. 1981, 58, 69-74.

Friedman, L. M. A history of american law. New York: Simon \& Schuster, 1973.

Glaser, B. L., \& Strauss, A. L. The discovery of grounded theory: strategies for qualitative research. Chicago: Aldine Publishing Company, 1967.

Gomez-Mejia, L. R., \& Page, R. C. Integrating employee development and performance appraisal. Training and Development Journal, June 1983, 37(6), 138-145. 
Gould, S. J. The mismeasure of man. New York: W. W. Norton Company, 1981.

Gruenfeld, E. F. Performance appraisal: promise and peril. Ithaca, New York: New York State School of Industrial and Labor Relations, Cornell University, 1981.

Guba, E. G. Toward a methodolegy of naturalistic inquiry in educational evaluation. Los Angeles: CSE, UCLA, 1978.

Hamilton, A. The federalist. Middletown, Connecticut: Wesleyan University Press, 1961. (Originally published 1788).

Hammons, J. Five potholes in the road to community college excellence. Comrriunity Cóllege Review, Summer 1978, 15(1), 5-12.

Holley, W. H., \& Field, H. S. Performance appraisal and the law. Labor Law Journal, July 1975, 26, 423-430.

Holley, W. H., \& Field, H. S. Will your performance appraisal hold up in court? Personnel, Jan.-Feb. 1982, 59, 59-64.

Holmes, O. W. The common Law. Boston: Little, Brown \& Company, 1923.

Johnson, R. G. The appraisal interview guide. New York: American Management Associations, 1970.

Journal of Law and Education. 12 (3), July, 1983.

Kane, J. S. \& Freernan, K. A. MBO and performance appraisal: a mixture that's not a solution, part 1 . Personnel, December, 1986, 63(12), 26-36.

Kane, J. S. \& Freeman, K. A. MBO and performance appraisal: a mixture that's not a solution, part 2. Personnel, February, 1987, 64(2), 26-32. 
Kaye, B. L., \& Krantz, S. Preparing employees: the missing link in performance appraisal training. Personnel, MayJune 1982, 59, 23-29.

Kaye, B., \& Krantz, S. Performance appraisal: a win/win approach. Training and Development Journal, March 1983,37 (3), 32-35.

Kirby, P. G. A systematic approach to performance appraisal. Management World Dec. 1981, 10, 28-29;44.

Kleiman, L. S., \& Durham, R. L. Performance appraisal, promotion, and the courts: a critical review. Personnel Psychology, Spring 1981, 34 (1), 103-121.

Kuhn, T. S. Logic of discovery or psychology of research. In Criticism and the Growth of Knowledge, I. Lakatos \& A. Musgrave, eds. Cambridge: Cambridge University Press, 1970, 1-22.

Kuhn, T. S. The essential tension: tradition and innovation in scientific research. In C. W. Taylor, ed. The Third University of Utah Research Conference on the Identification of Scientific Talent. Salt Lake City: University of Utah Press,1959, 162-74.

Kuhn, T. S. The historical structure of scientific discovery. Science, 1962, 136, 760-764.

Labor Management Relations Service. Building a sound relationship. Labor Relations for Supervisors, Feb. 1974.

Lacayo, R. A judge's breach of confidence. Time, April 6, 1987, p. 17.

Latham, G. P., \& Wexley, K. N. Increasing productivity through performance appraisal. Reading, Massachusetts: Addison-Wesley Publishing Company, 1981. 
Latham, G. P., Cummings, L. L., Mitchell, T. R. Behavioral strategies to improve productivity. Qrganizational Dynamics, Winter 1981, 9, 5-23.

Lazer, R. I. Performance appraisal: what does the future hold? Personnel Administrator, July 1980, 25, 69-73.

Ledvinka, J. Federal regulation of personnel and human resource management. New York: Van Nostrana Reinhold Company, 1982.

Likins, J. M. Six iactors in the changing relationship between institutions of higher education and the courts. Journal of National Association of Women Deans. Administrators and Counselors, Winter 1979, 42-43, 17-23.

Llewellyn, K. N. The bramble bush. New York: Oceana Publications, Inc., 1930.

Mall, J. Most campuses get an A in sexism. Los Angeles Times, December 14, 1986, pp. 16-17.

Martin, D. C. Performance appraisal: improving the rater's effectiveness. Rersonnel, August 1986, 63(8), 28-33.

Martin, D. C., Barto! K. M., \& Levine, M. J. The legal ramifications of performance appraisal. Employee Relations Law Journal, Winter 1986-87, 12(3), 370396.

McGrath, J. E., Martin, J., \& Kulka, R. A. Judgement calls in research. Beverly Hills: Sage Publications, 1981.

Meidan, A. The appraisal of management performance. New York: American Management Associations, 1981.

Miller E. C., \& Steinbrecher, D. D. The ten commandments of 'valid' perforrnance appraisal. Personnel, Sept.-Oct. $1979, \underline{56}, 45-48$. 
Naroll, R., \& Cohen, R. (Eds.) A handbook of method in cultural anthropology. Garden City, New York: David McKay Company, Inc. 1964.

Nix, D. H. Getting ready for the appraisal interview. Supervisory Management. July 1980, 25, 2-8.

Olson, R. F. Performance appraisal: a quide to greater productivity. New York: John Wiley \& Sons, Inc. 1981.

Rendero, T. Performance appraisal practices. Personnel, Nov.-Dec. 1980, 57, 4-12.

Rienow, R. Introduction to government. New York: Alfred A. Knopf, 1967.

Romberg, R. V. Performance appraisal 1: risks and rewards. Personnel, August, 1986, 63 (8), 20-26.

Sashkin, M. Appraising appraisal: ten lessons from research for practice. Organizational Dynamics, Winter 1981, 9 , 37-50.

Schuster, S. Memorandum to branch presidents. American Association of University Women Legal Advocacy Fund, August 1988.

Strunk, W., Jr., \& White, E. B. The elements of style (3rd ed.). New York: M.acMillan, 1979.

Survey provides piece of the productivity puzzle. Training and Development Journal. Oct. 1980, 34(10), 7.

Thompson, D. Performance appraisal and the civil service reform act. Public Personnel Management Journal, Nov. $1981,10,281-288$.

Truskie, S. D. Getting better results from performance reviews. Wall Street Journal, Oct. 4, 1982, p.28. 
United States Department of Commerce, Bureau of Census. Statistical Abstract of the United States 1988, (108 ed.). Washington, D. C.: Author, 1987.

Universal Training Systems Company. How to review and evaluate employee performance. Chicago: Dartnell Corporation, 1976.

Vile, M. J. C. Constitutionalism and the separation of powers. Oxfcrd: Clarendon Press, 1967.

Waintroob, A. R. The developing law of equal employment opportunity at the white collar and professional level. William and Mary Law Review, 1979, 21 , 45-85.

Wasserstrom, R. A. Racism, sexism, and preferential treatment: an approach to the topics. UCLA Law Review, 1977, 24, 581-603.

Wells, R. G. Guiaelines for effective and defensible performance appraisal systems. Personnel Journal, October 1982, 776-782.

Wexley, K. N., \& Latham, G. P. Developing and training human resources in organizations. Glenview, Illinois: Scott, Foresman \& Company, 1981. 


\section{LEGAL REFERENCES CITED}

Age Discrimination in Employment Act of 1967 - Public Law 90202; 81 Stat. 602.

Albemarle Paper Company v. Moody 422 U. S. 405 (1975)

Board of Regents of State Colleges v. Roth 408 U. S. 564 (1972).

Brito v. Zia Company 478 F. 2d 1200 (1973).

Brown v. Board of Education 347 U. S. 483 (1954).

Civil Rights Act of 1964 - Public Law 88-352; 78 Stat. 241.

Civil Rights restoration Act of 1987 - Public Law 100-259; Stat 28.

Civil Service reform Act of 1978 - Public Law 95-454; S. 2640.

Consolidated Rail Corporation v. Darrone 104 S. Ct. 1248 (1984).

Equal Employment Opportunity Act of 1972 - Public Law 92-261; 86 Stat. 103.

Equal Employment Opportunity Commission v. Sandia Corporation 639 F. 2d 600 (1980).

Equal Employment Opportunity Commission/White v. Tufts $421 \mathrm{~F}$. Supp. 152 (1975).

Executive Order Number 11246; September 28, 1965.

Executive Order Number 11347; October 13, 1967.

Executive Order Number 11478; August 12, 1969. 
Faro v. New York University 502 F. 2d 1229, 1974.

Flowers v. Crouch-Walker Corporation 552 F. 2d 1277 (9177).

Furnco Construction Corporation v. Water 438 U. S. 567 (1978).

Greenspan v. Automobile Club of Michigan 495 F. Supp. 1021 (1980).

Griggs v. Duke Power Company 401 U. S. 424 (19700.

Grove City College et. al. v. Terrel H. Bell, Secretary of Education et. al., 104 S. Ct. 1211 (1984).

Hishon v. King \& Spaulding 467 U. S. 69 (1984).

International Brotherhood of Teamsters $v$. the United States, et. al. 431 U. S. 324 (1976).

Johnson v. Transportation Agency 94 L. Ed. 2d. 615, (1987).

Johnson v. University of Pittsburgh 435 F. Supp. 1328 (1977).

Marbury v. Madison 2. U. S. (5 Cranch) 137 (1803).

McDonnell Douglas Corporation v. Green 411 U. S. 792 (1973).

Mount Healthy School District Board of Education v. Doyle $429 \mathrm{U}$. S. 274 (1977).

Namenwirth v. Board of Regents of the University of Wisconsin System 769 F. 2d 1235 (1985), certiorari denied, 474 U. S. 1061 (1986).

Parson v. Kaiser f.luminum and Chemical Corporation 497 F. Supp. 339 (1980).

Penk v. Oregon Slate Board of Higher Education 816 F. 2d 458, certiorari denied 108 S. Ct. 158 (1987). 
Perry v. Sindermar.n 408 U. S. 593 (1972).

Powell v. Syracuse University 580 F.2d 1150 (1978) certiorari denied 493 U. S. 984 (1979).

Rehabilitation Act of 1973 - Public Law 93-112; 87 Stat. 355.

Rogers v. International Paper Company 613 SW 2d. $84 \hat{4}$ (1976).

Rowe v. General Motors Corporation 457 F. $2 d 348$ (1972).

Stastny v. Southern Bell Telephone and Telegraph Company $628 \mathrm{~F}$. 2d 267 (1.980).

Tidwell v. Americail Oil Company 332 F. Supp. 424 (1971).

Uniform Guidelines on Employee Selection Procedures of 1978.

Federal Register 43 (166) 251-264.

United States Constitution. Amendment I.

United States Constitution. Amendment V.

United States Constitution. Amendment $X$.

United States Constitution. Amendment XIV.

United States v. N. L. Industries, Inc. 479 F. $2 d 354$ (1973).

Wade v. Mississipji Cooperative Extension Service 528 F. $2 d 508$ (1976).

Washington, Mayol of Washington, D. C. et al v. Davis 426 U. S. 229 (1976). 


\section{APPENDIX \\ THE UNITED STATES LEGAL SYSTEM}

\section{INTRODUCTION}

The operations of organizations and the behavior of people in them are shaped in part by laws to which they must conform. Employment practices are regulated by laws that stem from the United States Constitution, the government administration and its agencies, congress, and the courts. But although law influences entities, it can also be influenced by them. Members of congress often propose legislation based on suggestions from their constituents. Court decisions may be predicated on a compelling argument that suggests a solution for dealing with employment practices which have been legally challenged. Administrators must understand both how the legal system impacts their organizations, and how they may be able to impact the law. To do so, it is essential to understand how the legal system works.

The United States Constitution is the cornerstone of the American legal system. The form and function of national government are determined by its provisions. The constitution established a federal administration; that is, a union of 
independent states that acknowledges the authority of a central government (Edwards \& Nordin, 1980).

Authority not specifically assigned the federal government, nor denied the states, is delegated to the states (U. S. Const. amend. X). This stipulation restrains the federal government's undue use of power, and allows the states a great deal of self-determination. But by encouraging the independence of state governments, this provision furthers a pluralistic legal system. Laws are made, enforced, and arbitrated differently in various jurisdictions. This philosophy of specific jurisdiction is important for administrators to understand. Federal law establishes the minimum acceptable standards that govern behavior. The states are free to require more; they cannot accept less.

In addition to prescribing a dual organization of government, the constitution created and empowered three branches of government; legislative, executive, and judicial. Each branch is autonomous, and limited to specific functions. Law may originate in any of these three branches. Laws of all three branches require compliance. 


\section{THE BRANCHES OF GOVERNMENT}

At both the state and national level, government is divided into three separate branches: legislative, executive, and judicial. All departments are considered equal, although the judicial branch is authorized to review the constitutionality of the executive and legislative divisions (Edwards \& Nordin, 1980). This right of review does not indicate supremacy of the judiciary. It signifies, rather, that the evaluation of government acts should be uninfluenced by control of the nation's resources (legislative) or strength (executive). With neither the power of the purse nor the power of the military, the judicial branch is the weakest, and therefore the safest, guardian of political rights (Hamilton, 1788/1961).

To ensure that no one department of government commands too much power, the United States operates under the system of checks and balances. As explained by John Adams, only by balancing the power of government branches can tyranny be checked (Vile, 1967).

Initially the legislative branch enjoyed greater freedom from scrutiny than either the courts or the administration. Based on their experience with European monarchies and judicial systems that favored the elite, the Revolutionary citizens were suspicious of strong eentral authority and wary of the justice dealt by the courts. The legislature, comprised of local citizens, was considered to be the division most likely to protect individual 
rights and uphold the constitution. Within a matter of years, as legislatures became weighed in favor of landowners and the wealthy, confidence in this body declined. In 1803, a mere sixteen years after the constitution was ratified, in Marbury v. Madison, the Supreme Court declared an act of congress unconstitutional (Friedman, 1973). As time passed and other interactions took place, the role of each branch became more clearly defined.

\section{The Legislative Branch}

Legislative Function. As decreed by article I, section 1 of the U. S. Constitution, the legislative branch is composed of a Senate and a House of Representatives. The Constitution delegates to the legislature many responsibilities. Rienow (1967) suggests that five of these responsibilities have particular legal significance: constitutional amendment, legislative review, electorate, resource allocation, and lawmaking. Although details of all these functions make fascinating reading, you will have to peruse the first four on your own. Only the responsibility of lawmaking has immediacy for this research.

Perhaps the most obvious role of the legislature, and the one most relevant to the development of employment regulation, is that of a lawmaking body. The mores and values of society are formed by congress into laws and policy. The law reflects existing values of society, and also defines desirable societal goals. 
Congress both mirrors and molds public opinion; what it is and what it ought to be (Rienow, 1967).

Actual legislative structure varies from state to state, yet all perform the same functions as congress. Likewise, the process by which a law is enacted differs somewhat from state to state, but substantially follows the federal procedure (Edwards \& Nordin, 1980).

Enactment of Laws. Legislative enactment begins with the introduction of a proposal. Although a member of Congress must make the formal presentation, the idea for the legislation may come from an unlimited number of sources. In addition to congressional members themselves, suggestions come from constituents (individuals or groups), or from the executive branch. Executive communication generally comes from the president, a cabinet member, or an agency director in the form of a draft of the desired bill. Executive communication often follows shortly after the president's State of the Union message.

Once a propusal has been introduced, the entire Congress must have the opportunity for consideration and debate. The bill is generally considered first in a committee of the chamber in which the proposal was introduced. The proposal then passes to the full Senate or House for approval. Once approved by the originating body, the proposed legislation is called an act, and is sent to the other chamber. If the bill is passed in its original form, it is sent to the President. If amended, the act returns to the chamber of 
origin and the differences are worked out (sometimes). After both Senate and House agree, the bill is sent to the President for final approval (Edwards \& Nordin, 1980).

\section{The Executive Branch}

Executive Siructure. Article II, section 1 of the U. S. Constitution designates the president as chief executive of the country. Section 2 of the same article gives the president authorization to select public officials. Officials of major importance such as ambassadors and Supreme Court justices require congressional approval. The president, at the discretion of congress, has sole authority over the appointment of lesser officials.

The executive branch is structured and functions as a bureaucracy. A bureaucratic government serves the purpose of ensuring skilled continuity of services, relatively free from politics. Legislators cannot possibly be informed adequately on every issue, nor can they thoroughly understand the operation of every government agency. Therefore, most government functions, including the development of administrative law, are carried out by non-elected individuals. In the executive chain of command, these civil servants are directly or indirectly accountable to the president (Rienow, 1967).

The agencies of the federal government form a pyramid-type structure, with the: line of direct or indirect authority leading ultimately to the president. Although this bureaucratic form of ex- 
ecutive structure is unwieldy and sometimes results in conflicting and cumbersome legislation, it is necessary for enduring administrative function.

Executive Function. The principle function of the executive branch is to administer the conversion of law from legislative decree to practical, enforceable regulations that reflect the intent of congress. The interpretation and application of law is the crux of government, but it poses a crucial problem in the delicate balance of power. It is necessary for the legislature to maintain some authority over the executive branch. Without this oversight, it would be easy for the administration to place itself above the law. Yet for the sake of national security and efficiency, the administration needs a certain degree of autonomy. Hence, the administration is also empowered with regulatory authority (Rienow, 1967).

A second function of the executive branch, therefore, is legislative in nature. Congress is not always clear in its intent, and laws are not always well written. Oiten the weakness of law becomes apparent only in its application. By virtue of their expertise, the administration and its agencies are able to advise the legislature. However, it would be cumbersome and ineffective for the operation of government to limit the regulatory power of the administration to advisement alone. Recognizing this, congress delegates regulatory power to agencies that may be better able to anticipate problems with enforcement. Therefore, executive power 
also includes the authority to create regulations appropriate for implementing the directives of the legislature, and adjudicate disputes.

Each agency develops a separate body of law over time. Rienow (1967) notes that this requires a third function of the executive branch: coordination. The administration holds the responsibility for managing the functions of the separate divisions of government so that all work smoothly together. This management oversight is required to reduce departmental overlap and conflicting regulations. Sometimes it works.

Conflict and overlap are impossible to eliminate in a large and multi-leveled administration. The executive branch is a bureaucracy both in its reliance upon conformity to massive regulation, as well as its classic bureaucratic structure.

The effort at streamlining the executive branch and making its agencies more responsive is ongoing. There is continual reorganization, dismantling, and creation of agencies. New law is constantly developed to facilitate the work of agencies or to meet emerging societal requirements. Entrenched bureaucrats with conflicting interests contribute to the glut of constantly changing regulations (Rienow, 1967). Not surprisingly, the judiciary is increasingly called upon to arbitrate disputes over regulations and examine the appropriateness of the government's use of power (Edwards \& Nordin, 1980). This dynamic nature of regulation underscores the need of administrators to understand the legal sys- 
tem, recognize how it can be influenced, and develop a sense of how the law is likely to evolve.

\section{The Judicial Branch}

Structure of the courts. The Constitution specifies that the judicial power of the United States be vested in one supreme court. Congress is also allowed to establish lesser courts as deemed appropriate (U. S. Constitution, Article IH, sec. 1). A complex judiciary with overlapping jurisdictions, rendering inconsistent decisions has developed over time. How does the court system actually work? (Or, perhaps you are wondering, how can the court system actually work?)

Alton (1982-83) explains that each state has a separate judicial system, established by the authority of its state government (generally the state constitution). Although structure and procedure vary in different states, all adhere to the same fundamental principles of justice. At the lowest level are the myriad trial courts where most cases are heard. Called by different names according to locale, these include municipal, city, or circuit courts, and encompass special tribunals such as juvenile and probate courts. The losing party in lower court usually has the right of at least one appeal to a court not involved in the original hearing.

The highest court in the state (often called the state supreme court, court of appeals, supreme judicial court, or some 
other name) rarely retries the case on its merits. The appeals court merely reviews procedure and statutory law connected to the lower court case to determine if both were properly applied.

Because of an increasingly large number of appeals in our litigious society, some states have established appellate courts between the lower courts and the state supreme court. In other states, the intermediate appellate courts are departmentalized in an attempt to hancle the volume of cases. Each department generally rules on cases independently; occasionally the whole court as a body hears a case to settle a dispute concerning a point of law .

The state supreme court is usually the court of last resort. Once the state court reaches a decision, the case can be appealed further only in certain circumstances. If a case involves a dispute between two jurisdictions (two states, for example, or parties from two states), an issue of federal interest, or a question concerning the $U$. S. Constitution, then an appeal may be made to the United States Supreme Court (Alton, 1982-83).

Most cases heard in the U.S. Supreme Court originate not in the state system, but within the federal system. The Federal (or United States) Court System has three levels: the district courts, the circuit courts of appeal, and the U. S. Supreme Court. As authorized by the Constitution, the federal courts have jurisdiction over cases: (1) in which the United States government is a party, (2) where state courts may display bias, as in the instance of a suit between the citizens of two states, (3) which concern ambas- 
sadors or public officials, (4) that involve a foreign government or its citizens, (5) which question the $U$. S. Constitution, maritime law, treaties, or federal legislation (Edwards \& Nordin, 1980).

There are ninety-one district courts. Each state has at least one; the District of Columbia and Puerto Rico have one each. A single judge usually presides in trial courts. If the case is appealed to a higher court, a panel of three judges will hear the case in the intermediate appellate court.

Cases appealed from district court are heard in one of eleven circuit courts of appeal. Three judges preside over each trial. In the extremely rare situation where a case presents an exceptionally difficult or significant problem, all thirty-three judges may deliberate (Alton, 1982-83). Cases judged in the circuit court may be appealed to the United States Supreme Court.

An appeal to the U. S. Supreme Court, the highest court in the land, does not guarantee a hearing. The court receives about 5000 appeals annually. After studying the cases, those considered to be of significant national importance and properly within the jurisdiction of the high court are selected for review. About 225 cases are heard each year (Edwards \& Nordin, 1980). Four of the nine members of the court must agree to hear the case. The denial of a hearing does not riecessarily mean a proper decision was reached in the lower court. Even though the justices may not agree with a holding, the case may not be argued in the high court if it does not 
meet the requirements of national significance and jurisdiction (Alton, 1982-83).

The judiciary holds the responsibility of interpreting the law. But as Llewellyn (1930) points out, the rules of the law are not as important as the prevention and settlement of disputes. We are affected more by interpretation of law than by its legislation. To be able to predict how the law will affect lives, it is necessary to understand how the courts handle disputes. Comprehension of the principles behind the system of justice is needed before the function of law can be fully appreciated, and its decisions applied to policy development in organizations.

Judicial Principles. Statutory law is often weak. Legislation is frequently drawn with a general idea of how society ought to act. The resulting regulation may be poorly written, ambiguous, parochial, abstract, or subject to multiple possible meanings. Occasionally a law is introduced with too specific a situation in mind, making it unrealistic as a guideline for behavior (Llewellyn, 1930). Case law, the law of the courts, offers the means to improve legislation.

The purpose of the courts is to fill the gaps in legislation, to clear up ambiguities, to prevent and resolve conflicts, and to ensure that an individual's rights are not compromised by statutes. Though it is reasonable to assume that lawmakers try to make good laws, often the weaknesses of legislation become apparent only in practice. It then becomes the task of the courts to deter- 
mine the legislators' probable intent, and to apply this meaning to the situation immediately before the court. How would the authors of the law ariswer questions now that they obviously did not think of while writing the law? Statutes do not cover all circumstances for which they were intended, and case law refines the scope of regulation (Cardozo, 1921).

Intrinsic to case law is the concept of corrimon law. Common law is the spirit of the law. It goes beyond statutes, legal precedent, and judicial history, although it may include them. It encompasses the principles upon which judgements were made, the implied doctrines of legal decisions, cultural mores, customs, and usage. As collective decisions develop into patterns, the common law evolves. This evolution reflects the changing values of society (Alton, 1982-83).

Society's standards change, and therefore so do ideas of justice. Contrary to what is commonly believed, law is not immutable. There is no such thing as "the law", written in stone, not to be changed. Law develops, changes, becomes clarified over time (Llewellyn, 1930).

Law not only changes over time, it also varies with locale. The law is piecemeal. Various courts decide cases differently. One court may decide a case one way. Another court (or judge) may reach a different decision in a case with essentially the same circumstances. The problem may never arise in a third jurisdiction. There will be inconsistencies and contradictions. Despite vari- 
ances in interpretation, however, the common law tradition has brought about uniform techniques, reasonings, and approaches to seeking justice. This tradition of accommodating principles of social justice while ensuring uniformity of practice allows trends to emerge. Trends, Llewellyn (1930) reminds us, permit prediction.

To understand the impact of law on societies, and particularly on organizations, it is important to realize how the courts will require them to act. That is, legal advisors need to be able to predict the judgements of the courts. Of course, as prediction is never certain, it helps to know how the actions of the court are directed and influenced. Legal principles are as important as legal precepts (Llewellyn, 1930).

Legal principles develop in three ways: by evolution, by tradition, and by social change. Evolutionary principles are those that have emerged through a historical process. Traditional principles are those that reflect established customs. Sociological principles indicate emerging values and expectations of the community (Cardozo, 1921).

Trial by jury is an example of a principle that evolved through history. The purpose of a jury is to insure an impartial trial by allowing peers to pass judgement. Originally, neighbors comprised the jury. Neighbors knew the personalities and lives of those involved in the dispute. It was assumed that this knowledge would allow the jurors to determine what actually happened and 
thus pass fair judgement. Although the purpose of a trial by jury has remained the same over centuries, the makeup of the jury has changed. Neighbors no longer judge. Juries now are made up of unknown peers who are expected to reach a decision free from bias and unencumbereo by the pressure of a personal relationship with those on trial (Llewellyn, 1930).

Rules governing air travel often demonstrate how legal principles are determined by tradition. The customary way of doing things became the required way when flying progressed to the point that demanded regulation. For example, the increasing volume of international air travel indicated the appropriateness of a common language used by pilots and controllers. Because air travel had been developed and used primarily by English-speaking people, English became the mandatory language of the air.

School desegregation exemplifies the sociological development of a legal principle. In the 1954 Supreme Court case Brown v. the Board of Education, the court ruled that segregating students on the basis of race was discriminatory. The court stated that the traditional doctrine of "separate but equal" was intolerable because separate facilities were inherently unequal. This decision was contrary to historical precedent and customary practice. Rather, the holding signified that changing societal values no longer found bigotry acceptable.

Formal legar principles, those with clearly articulated theories, are fairly easy to analyze. Formal law is logical and deals 
with recognized certainties that facilitate prediction. But the actual practice of law does not always conform to the formal theories often taught in law schools and presented in legal reviews. Actual law is slippery. Legal theory is important as a framework for basic legal analysis. Deduction alone, however, does not yield just, desirable, predictable solutions. The courts also work by hunches, work within contexts (Frank, 1932). As Justice Oliver Wendell Holmes (1923) so famously expressed, "The life of the law has not been logic: it has been experience" (p. 1).

The underpinnings of case law, according to Llewellyn (1930), are grounded in four directives:

(1) The court must cecide the dispute that is before it.

(2) The court can decide only the particular dispute that is before it.

(3) The couri can decide a particular dispute only according to a general rule which covers a whole class of similar disputes.

(4) Everything, everything, everything, big or small a judge may say in an opinion, is to be read with primary reference to the particular dispute, the particular question before him (p. 40).

To say the courts must decide a case does not mean that an individual always has the right to review under any circumstances. The court may not arbitrate a dispute that is not within its jurisdiction. No: is the court obligated to hear insignificant complaints. Llewellyn (1930) describes this exemption thus, 
"Peter, I will not listen to you when you whine" (p. 23). However, the court may not refuse to hear a case because it is difficult or controversial. One major purpose of case law is to resolve difficulties and controversies.

The court may refer to similar cases or situations, considering them in its decision and opinion. It must, however, rule only on the particular case before it. Only then do the pronouncements become law. Commenting on other issues may clarify reasoning or intent, continues Llewellyn (1930), but comments must be considered suggestion, not law .

By requiring disputes to be arbitrated within a general framework, judges are prevented from rendering too narrow a decision, or one influenced by personal sentiment or bias. Disputes must be resolved within the context of other similar cases. Decisions must be based on the precedent established by a group of similar cases. No single case has significance by itself.

A judge's holding must be analyzed as it applies to that one specific case. This safeguard prevents the abstraction of a specific ruling from a case and its transformation into a vague directive. A judge must resolve the case from within the framework of generalities, but may render only specific decisions.

Llewellyn (1930), emphasizes that legal solutions are rarely found in a single case. The context of similar incidents is needed to understand the theme of common law running through the cases. This frame of references clarifies nuances in terminology, draws 
attention to common significant facts, and identifies the substantiality of the opinion.

Llewellyn (1930) compares case law to a bead necklace: the kind, perhaps, that doting grandparents give their darling granddaughters. Pearls are added one by one as significant events occur. Over time the pearls, each pretty enough by itself, become a truly beautiful necklace. Each differs in some small way, perhaps in tone or size. The ninute differences add to the excellence of the necklace. Of course, a pearl that clearly does not belong would flaw the desirability of the necklace, and must be assigned to another purpose. Individually the pearls have some worth, yet it is when they are strung together that their real value becomes apparent.

So it is with case law. Imagine that the position taken is like the string. As supporting precedents are added, the case before the court becomes stronger. The more numerous the precedents, and the greater the supporting evidence, the more value there is for influence and prediction.

Mastery of judicial principles alone does not guarantee that one will be able to predict the development of the law. It is also necessary to understand how the courts function to predict their actions.

Judicial function. Prior to the trial, the lawyer for the plaintiff (the plaintiff being the party that initiated the suit) must provide the zourt with the facts (complaint), and the relief 
sought. Once the case is before the court, the plaintiff's lawyer explains what the prosecution intends to do. Evidence, such as documents, objects, witnesses, is presented. The plaintiff attorney first examines the witnesses, who are then cross-examined by the defense (the defendant's lawyer). The defense lawyer presents the defendant's case, after which the plaintiff's lawyer may cross-examine. Next the plaintiff's lawyer refutes the opposing evidence. Then it is the turn of the defense to present the defendant's side of the case, and rebut the prosecution. The lawyers address the jury; first the plaintiff, then the defense, after which the plaintiff's attorney rebuffs the presentation of the defense. During this final persuasion, each counsel analyzes and summarizes the case. In a jury trial, the judge instructs the jurors, who retire to deliberate the evidence and present a verdict. In the situation of a trial without a jury, the judge returns a decision (Llewellyn, 1930).

It seems simple enough, but as Llewellyn (1930) points out, "This does not look so bad. But it is much worse than it looks" ( $p$. 40).

To begin at the beginning, with the prosecutions presentation of facts, it can be seen that things are already looking murky. Facts are really assumptions about what probably happened weeks, months, even years ago. Some "facts" are biased, inaccurate; some are pure deceit. Some critical incidents might be omitted entirely if they would weaken the client's case. At times, legal technical- 
ities prevent the introduction of important evidence. Courts actually review not facts, but conflicting evidence about what may have happened (Frank, 1932).

Then there are witnesses. There are witnesses who are fallible, witnesses whose memories are faulty. There are witnesses who hold biases, and witnesses who lie. There are witnesses who are occasionally mistaken, and witnesses who are afraid to tell the truth.

What about the lawyers? Do they always seek truth? Impartial justice? Could winning acclaim and and a percentage of huge settlements conceivably be the only goal of some? Is it possible there are some lawyers with a flair for the dramatic, who might try to sway a jury, with their theatrics; who might use entertainment to distract from justice and extort a favorable verdict? How about the skillful lawyer who might slip in an emotive word or two, or purposely misdirect the jury by deliberate choice of wording? We may all agree on the fact that Little Bo Peep has indeed lost her sheep. But was she forgetful? unlucky? negligent? swindled? Or consider for a moment this Mary who had a little lamb. Are we talking about a pet or a dinner?

The judge presents still another variable element. Like all other humans involved in the case, the judge is imperfect. The judge may enter the case with a decision already in mind, ruling on evidence and procedure in such a way that personal bias is supported. The judge at times may act with prejudice towards one of 
the parties or counsel. The instructions to the jury may be unintelligible. Frank (1932) reports that some judges admit to wishing they could render a decision without having to hear the case, already having determined the ruling. Testimony can be confusing and muddle issues that seem so clear at the onset. And to further add to our inability to adequately assess the credibility and skill of the judge is the fact that most cases heard without a jury require no written opinion. The decision stands, unencumbered by reasoning, precedent, or clarification of oblique points of law. And what of the jury? Twelve people, assumed to be unbiased, theoretically unaware of the particulars of the case, are called to determine the "facts". It is possible that after hearing hours or months of testimony, jurors might become bored, inattentive. They might think one of the lawyers is really cute. With lack of legal training, jurors might not recognize critical facts or evidence. They might disregard the judge's instructions. They might let personal bias or prior knowledge affect their verdict. Llewellyn (1930) concedes that the verdict sometimes depends upon how appealirg a witness or client is.

There is a further element of weakness in court. Llewellyn (1930) reminds us that the use of words can distort perceptions and be misleading. Some terms may have multiple meanings; others may be poorly defined, or overly technical. You might assume that Little Bo Peep cannot remember what meadow she left those 
critters in when Little Boy Blue gave her the come-hither. I might guess that she stayed too long at the blackjack table.

And yet another danger threatens. A decision may be improper, but appear to be acceptable because it is well written. On the other hand, a good decision might be devalued because of a poorly worded opirion (Frank, 1932).

Once the facts have been agreed upon, and a verdict is returned, the mayhem may be only beginning. The losing party may file an appeal to a higher court. Appeals are costly, but not necessarily to the lower court loser, particularly if the action of appeal is unwarranted. Appeals buy time, not necessarily justice (Llewellyn, 1930). If the power of justice can be misused through the appeals process, why is it allowed?

The appeals court serves multiple purposes. One role of the court is the revien' of cases to ensure that the lower court decision rendered was appropriate. The appeals process also reduces conflicting opinion, and seeks uniformity of decision. The appeals court does not retry a case on its merits. Review is always sought on the notion that the lower court erred. The error is assumed to have occurred not on facts, but on a point of law. Thus the case is not heard by a jury, but by one or more judges who are considered learned in the law, and in a position to determine its fair application. It may be argued that the lower coust was not the proper tribunal for the hearing; a federal question should not be tried in a state court, for example. An objection may be raised that proce- 
dure was not properly observed. Lawyers are obligated to follow certain court rules, which are presided over by the judge. If a lawyer states an objection and is overruled, this action may form the basis ior an appeal (Llewellyn, 1930).

The appeals court may decide the case in a number of ways. Most commonly, the lower court case is affirmed, reversed, or overruled. The appellate court may affirm the ruling of the lower court, upholding the original decision. The court may reverse the decision. A reversal indicates the earlier decision was improper and the judgement is no longer effective, thereby awarding the victory to the other party. If the case is overruled, it means the law set down in the earlier case is no longer acceptable and cannot be considered precedent. The original decision is still considered the appropriate solution of the case for the parties involved, however (Alton, 1982-83).

Although in theory the appeals court does not retry the facts of the case, it may interpret them differently than did the lower court. (And remember these facts are really assumptions, and have been further weakened by their selective recording.) The reinterpretation may be accidental or purposeful. Judges differ in attitudes. Some seek justice through social change. Some seek to preserve the status quo (Llewellyn, 1930). (Some seek reelection.) Hoimes (1933) suggests that most appellate courts do in fact uphold or revise laws to facilitate the public good. Although one aim of judicial review is to assure the rationality of administrative 
and legislative regulation, law reflects both administrative policy and societal values.

Administrative policy obviously affects society, particularly institutions. The courts refine the law, and ultimately determine what it is. The intent of law and policy, and its impact on organizations may therefore be best understood through the analysis of judges' opinions (Edwards \& Nordin, 1980).

Contrary to popular belief, judges do not always hear the case and then make a decision. Often the decision and the underlying opinion--the opinion is the rationale for the decision-- are determined by a judge, or by the consultation of several judges. Then the case is heard, and if nothing unanticipated surfaces during the hearing, the decision is accepted. Sometimes the case is heard, decided, and one judge is chosen to write the opinion. Other times the decision stands without opinion. At times the resolution is based on what the law is. Other times, the decision is based on what the court thinks the law ought to be. The opinion is what makes the case, and therefore the law (Llewellyn, 1930). Understanding this, it becomes evident that through the examination of collected opinions regarding a particular issue, it is possible to grasp the intent of the law and predict developments that may occur.

The same factors that influence personal decisions impact judicial decisions. Although judges strive for objectivity, they are 
affected consciously and unconsciously by their training, instincts, beliefs, values, and concepts of justice (Cardozo, 1921).

At times a judge's ideas of right and wrong differ from the community. In that case, which values should be reflected in the decision? It depends upon the situation. Sometimes a judge feels the responsibility to set standards that are contrary to the community's accepted customs. For example, overturning the separate but equal doctrine in public schools was inconsistent with standard practice. In other circumstances, it would be inappropriate to impose personal standards of morality on others. If the judge considers dancing sinful, this does not justify outlawing Mademoiselle Twinkletoe's Ballet Studio. The tricky part of this, of course, is for the judge to recognize when it is appropriate to choose personal interpretation of the law over social mores. Cardozo (1921) cautions that this knowledge comes only with experience, study, and contemplation.

Often judges will determine principles of justice at issue in the case, then study the law to uncover the rationale and support for the decision. Unfortunately, the record usually does not indicate the judge's questions, thoughts, assumptions, and conflicts as the opinions were developed. What is recorded becomes fact, official; little of the controversy is exposed (Frank, 1932).

It seems that in the judicial process the only certainties are variance and change. Cardozo (1921) expresses it this way; "Hardly 
a rule of today but may be matched by its opposite of yesterday" (p. 26). Why does the law appear so inconsistent?

In court reports, particularly in appeals, significant facts that iead to opinions may not be included. Judges differ in their preparation, knowledge, skill, attitudes, and ability to manipulate the law to desired conclusions (Llewellyn, 1930). Even when a case is heard by a panel of judges who reach a unanimous decision, there may be some disagreements. All of the judges may agree on both the facts and the rules. Or they may agree on facts, and not on rules. Or on rules, but not facts. Or disagree on both rules and facts, but still agree on the decision. Then, of course, there is the situation where the decision is not unanimous, and the possibilities of variance become even greater (Frank, 1932). Each variable represents a challenge to the law's consistency.

The law, however, is surprisingly stable. The common law policy of precedeni requires consistency in decisions that concern the same facts. It is precedent that reveals judicial concepts and reasonings, and gerierates confidence in the judicial system (Cardozo, 1921).

Precedent has some limitations. Precedent holds only in the same jurisdiction. The precedents of the Oregon court may be of some interest to Washington, but they have no legal authority there. Even the decisions of the United States Supreme Court establish precedent unly to the extent that they concern federal statutes or the United States Constitution. Precedent is binding 
only in cases involving the same material facts. Obviously, this is a matter of judgement, as no two situations will be identical (Alton, 1982-83).

Although precedents established in other jurisdictions are not binding, they are orten carefully considered, and frequentily influence decisions. When these considerations are incorporated into an opinion, they are known as dicta. Dictum is influential, non-binding author:ty. It is useful because it may demonstrate the reasoning used to reach a decision, and may suggest the disposition of the judiciary toward related questions. It is also an efficient method of dealing with a tricky problem. If Oregon has already solved the problem, and the resolution seems just and appropriate, why should Washington resolve the same problem?

A holding, as opposed to dictum, is an authoritative, binding ruling. Theoretically, a holding must be followed as precedent until overruled (Alton, 1982-83).

Precedent forces conformity to social values, reduces contradiction, prevents insidious change, offer the wisdom of past experience, and saves the time and effort of settling the same dispute over and over.

There is danger in precedent, though. Early decisions may represent bias or ignorance. Conditions change. Society changes. Poor wording may cause subsequent disputes. It is more difficult to change precedent than to uphold it, but precedent can be overruled (Llewellyn, 1930). 
When a judge downplays precedent, the legal tenet that only the case currently before the bench can be decided is called upon. The judge determines that the scope of the earlier case is too narrow to apply to the present one. "This rule only holds of redheaded Walpoles in pale magenta Buick cars" (Llewellyn, 1930, p. 73). Although this does not in itself overrule the precedent, it may undermine its authority to the extent that the law may change. It requires great competence on the part of the judge to weaken or overrule precedent, and that is desirable. It is unlikely that a poor judge will be able to modify the law. A skilled judge may be able to bring about needed change.

The law is very stable, yet it is in constant flux. Where does that leave us as individuals, and as members of organizations? To use the law as our ally we need to understand three things: how the law works, what it requires of us, and how we may be able to predict the actions of the court.

According to Llewellyn (1930) prediction is as much an art as a science. It is easy to be mislead. An error may be made in deductive reasoning, inappropriately extracting specific issues from preceding decisions. The error might be inductive, committed in the process of building theory from cases. Both logic and theory may be appropriate, but the attitude of the judge or jury may negate the most carefully developed rationales.

By analyzing the way a specific court or judge has handled cases, it is possible to predict future outcomes. Attention must be 
given the particular facts the court chose to stress, the extent of interest demonstrated in specific issues, and the interpretation of points of law. Most important is the analysis of opinions, particularly dissenting opinions. Dissent, says Llewellyn (1930), may be the best clue to the future change in the court's attitude. Dissenting opinions may offer another perspective on facts, issues, law, or reasoning. Rather than indicating possible future change, a dissent may even strengthen the authority of the case because it indicates careful consideration was given the decision.

It may be reassuring to remember that although the law is inconstant, precedent holds authority. And although precedent may be overruled, it is a difficult task that requires great skill.

With the trend toward increased regulation and litigation in society, it is to our advantage to understand the law's impact on our lives and institutions. Llewellyn (1930) suggests that to understand this impact we first must determine what the courts might be expected to do, then plan strategy. It might not hurt to plan alternate strategies as well, as it has been noted that judges and juries sometimes return unanticipated verdicts. As noted by the Carnegie Council for the Study of Higher Education (1975), "It takes a dash of bravado to make a projection; but a touch of madness to believe too much in its invincibility" (p. 49). 